CLEBER ROBERTO GUIRELLI

\title{
PREVISÃO DA CARGA DE CURTO PRAZO DE ÁREAS ELÉTRICAS ATRAVÉS DE TÉCNICAS DE INTELIGÊNCIA ARTIFICIAL
}

Tese apresentada à Escola

Politécnica da Universidade de São

Paulo para a obtenção do Título de

Doutor em Engenharia.

São Paulo 


\section{PREVISÃO DA CARGA DE CURTO PRAZO DE ÁREAS ELÉTRICAS ATRAVÉS DE TÉCNICAS DE INTELIGÊNCIA ARTIFICIAL}

Tese apresentada à Escola

Politécnica da Universidade de São

Paulo para a obtenção do Título de

Doutor em Engenharia.

Área de concentração:

Sistema de Potência

Orientador:

Prof. Dr. José Antonio Jardini

São Paulo 
AUTORIZO A REPRODUÇÃO E DIVULGAÇÃO TOTAL OU PARCIAL DESTE TRABALHO, POR QUALQUER MEIO CONVENCIONAL OU ELETRÔNICO, PARA FINS DE ESTUDO E PESQUISA, DESDE QUE CITADA A FONTE.

Este exemplar foi revisado e alterado em relação à versão original, sob responsabilidade única do autor e com a anuência de seu orientador.

São Paulo, 20 de dezembro de 2006

Assinatura do autor

Assinatura do orientador

FICHA CATALOGRÁFICA

Guirelli, Cleber Roberto

Previsão da Carga de Curto Prazo de Áreas Elétricas através de Técnicas de Inteligência Artificial./ Cleber Roberto Guirelli - ed. rev. - São Paulo, 2006.

$127 \mathrm{p}$.

Tese (Doutorado) - Escola Politécnica da Universidade de São Paulo. Departamento de Engenharia de Energia e Automação Elétricas.

1.Previsão de carga. 2. Redes neurais. I.Universidade de São Paulo. Escola Politécnica. Departamento de Engenharia de Energia e Automação Elétricas. 


\section{AGRADECIMENTOS}

Ao Prof. Dr. José Antonio Jardini pela valorosa e competente orientação e paciência ao longo do desenvolvimento deste trabalho.

Aos membros do grupo de pesquisa GAGTD do Departamento de Engenharia de Energia e Automação Elétricas, em especial ao Prof. Dr. Luis Carlos Magrini e ao engenheiro Jorge Yasuoka.

A CTEEP Transmissão Paulista e ANEEL financiadoras do projeto de P\&D que viabilizou essa tese e aos engenheiros Antonio Carlos Campos e Mário Bastos.

À minha esposa Simone Frazão Botelho pelo apoio e incentivo constantes.

A todos que, direta ou indiretamente, contribuíram para que esse trabalho se realizasse. 


\section{RESUMO}

\section{GUIRELli, C. R. Previsão da Carga de Curto Prazo de Áreas Elétricas através}

de Técnicas de Inteligência Artificial. 2006. 127p. Tese (doutorado) - Escola

Politécnica, Universidade de São Paulo, São Paulo, 2005.

Hoje em dia, com a privatização e aumento da competitividade no mercado elétrico, as empresas precisam encontrar formas de melhorar a qualidade do serviço e garantir lucratividade. A previsão de carga de curto prazo é uma atividade indispensável à operação que pode melhorar a segurança e diminuir custos de geração. A fim de realizar a previsão da carga, é necessária a identificação de padrões de comportamento de consumo e da sua relação com variáveis exógenas ao sistema tais como condições climáticas.

Originalmente o problema foi resolvido de forma matemática e estatística através de técnicas tais como as séries numéricas, que fornecem bons resultados, mas utilizam processos complexos e de difícil modelamento.

O surgimento das técnicas de inteligência artificial forneceu uma nova ferramenta capaz de lidar com a grande massa de dados das cargas e inferir por si mesmo a relação entre as variáveis do sistema. Notadamente, as redes neurais e a lógica fuzzy se destacaram como as técnicas mais adequadas, sendo que já vem sendo estudadas e utilizadas para a previsão de carga a mais de 20 anos.

Este trabalho apresenta uma metodologia para a previsão da curva de carga diária de áreas elétricas através do uso de técnicas de inteligência artificial, mais especificamente as redes neurais.

Inicialmente são apresentadas as principais técnicas de previsão sendo dado maior detalhamento as redes neurais e a lógica fuzzy. É feita a análise dos dados necessários à previsão e seu tratamento. Em seguida, o processo do uso de redes neurais e lógica fuzzy na previsão é descrito e é apresentado o desenvolvimento e resultados obtidos com o desenvolvimento e implementação de um sistema de previsão com redes neurais na concessionária CTEEP Transmissão Paulista.

Como contribuição dessa tese, a transformada Wavelet é analisada como ferramenta para a filtragem e compactação de dados na previsão com redes neurais. 


\begin{abstract}
GUIRELLI, C. R. Short Term Load Forecasting in Electrical Areas Using
\end{abstract}

Artificial Intelligence. 2006. 127p. Thesis (Doctor Degree) - Escola Politécnica, Universidade de São Paulo, São Paulo, 2005.

Nowadays, with privatization of utility companies and increase in competition in the energy market, companies must increase their service quality and ensure profits. Short term load forecasting is essential for operation of power systems and can increases security and reduces generation costs. Forecasting the load demands the identification of load patterns and its relations with exogenous variables such as weather.

Originally, the problem was solved using mathematics and statistics with techniques such as time series, which produces good results but are complex and have a difficult modeling.

With the advent of artificial intelligence techniques, new tools capable of dealing with large amounts of data and learn by themselves system variables relations were available. Artificial neural networks and fuzzy logic came up as the most suitable for load forecasting that have been tested and used for load forecasting for the last 20 years.

This work presents a methodology for daily load forecasting of electrical areas using artificial intelligence techniques, specifically neural networks.

At first, forecasting techniques are presented with emphasis on neural networks and fuzzy logic. Acquisition and treatment of data are analyzed. The load forecasting using neural networks and fuzzy logic is described and the results of the development and tests of a load forecasting system at CTEEP Transmissão Paulista presented.

As contribution of this thesis, Wavelet transform is analyzed as a tool for denoising and data compression for neural network load forecasting. 


\section{SUMÁRIO}

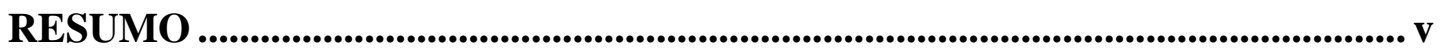

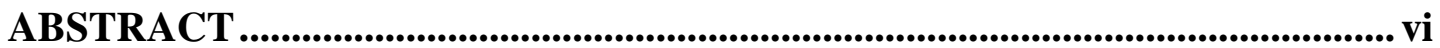

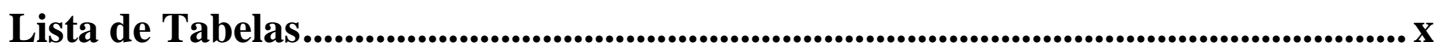

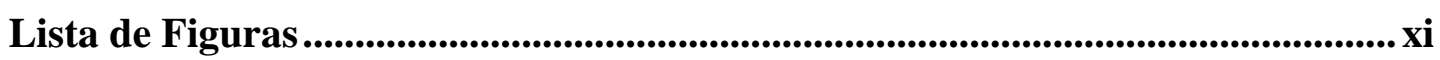

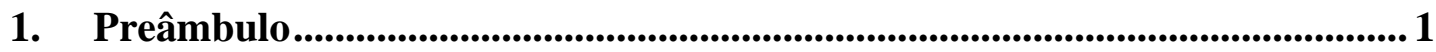

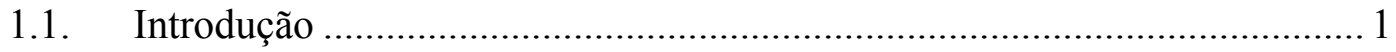

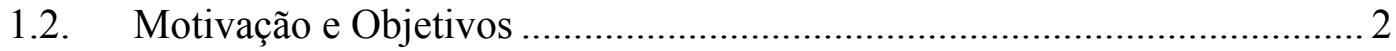

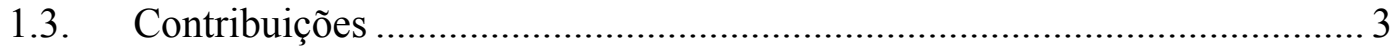

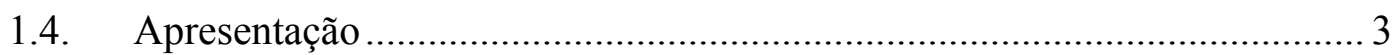

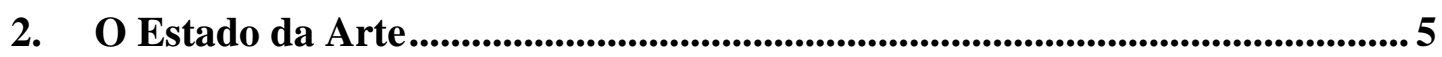

2.1. Métodos Estatísticos de Previsão ……......................................................... 5

2.1.1. Regressão Linear Múltipla ….......................................................... 6

2.1.2. Séries Temporais Estocásticas …................................................... 7

2.1.2.1. Processo auto-regressivo …..................................................... 7

2.1.2.2. Processo da média móvel .......................................................... 8

2.1.2.3. Processo da média móvel auto-regressiva................................... 9

2.1.2.4. Processo da média móvel integrada auto-regressiva (ARIMA)... 9

2.1.3. Alisamento Exponencial ............................................................ 10

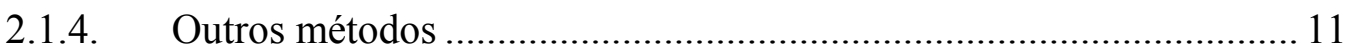

2.2. Métodos de Inteligência Artificial ........................................................... 11

2.2.1. Sistemas Especialistas ................................................................... 12

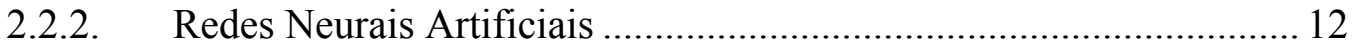

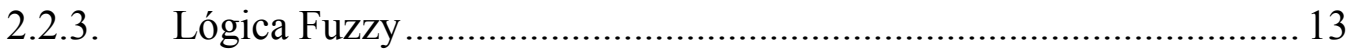

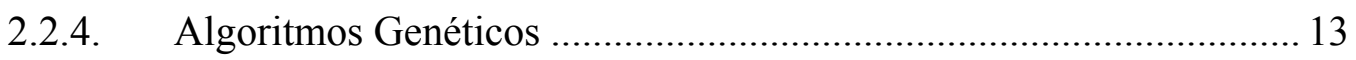

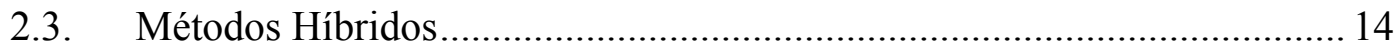

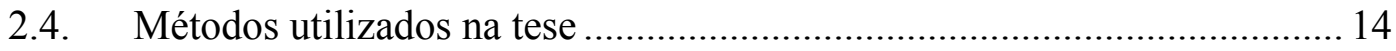

3. Obtenção e Tratamento de Dados .......................................................................... 15

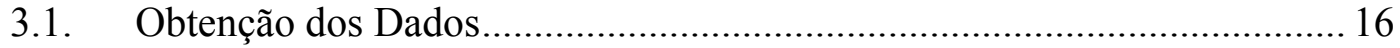

3.2. Filtragem e Compactação dos Dados........................................................ 17

3.2.1. Filtragem por Identificação de Dados Corrompidos.......................... 18 
3.2.2. Filtragem por Transformada de Fourier.......................................... 23

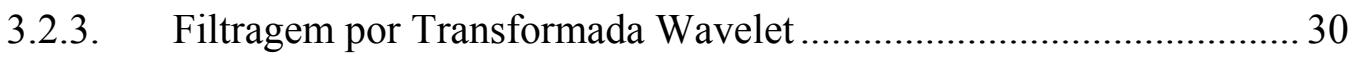

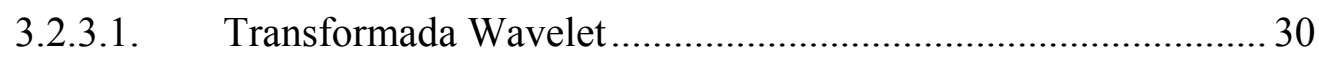

3.2.3.2. Filtragem de Sinais com Wavelets......................................... 32

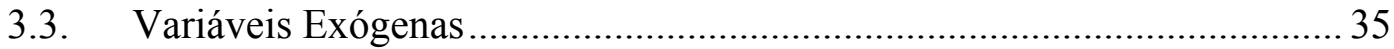

3.3.1. Medições de Temperatura Ambiente ................................................. 35

3.3.2. Outras Variáveis Exógenas ............................................................. 38

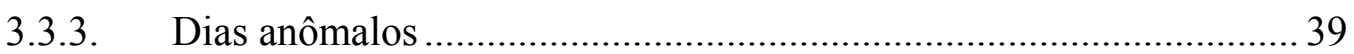

3.4. Análise de Padrões nos Dados de Carga ................................................. 40

4. Previsão da Carga através de Inteligência Artificial ..................................... 44

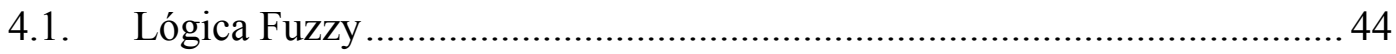

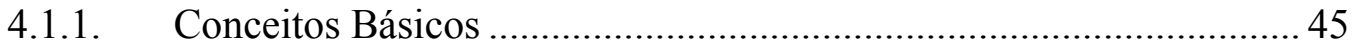

4.1.2. Sistema de inferência fuzzy ............................................................ 47

4.1.3. Previsão de Carga Através de Lógica Fuzzy ..................................... 50

4.1.4. Aplicação prática da previsão de carga através de lógica fuzzy ........51

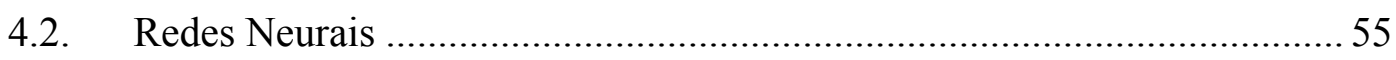

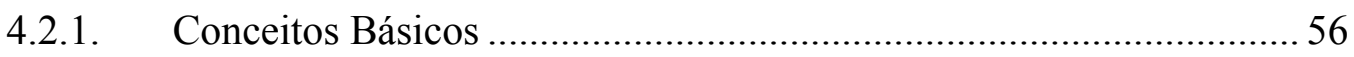

4.2.2. Previsão de Carga através de Redes Neurais ..................................... 58

4.2.3. Aplicação prática da previsão de carga através de redes neurais.......59

4.2.4. Previsão de carga através de redes neurais e Wavelets...................... 64

5. Integração em sistema corporativos ..................................................................... 69

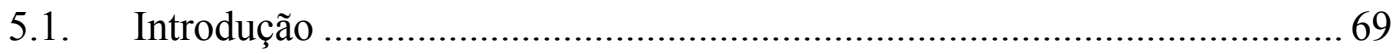

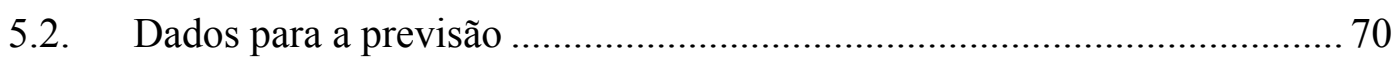

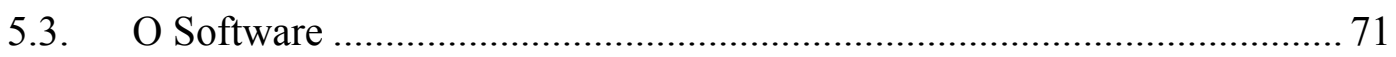

5.3.1. Aquisição de dados ......................................................................... 73

5.3.1.1. Aquisição de dados de carga ..................................................... 73

5.3.1.2. Aquisição de dados de temperatura........................................... 73

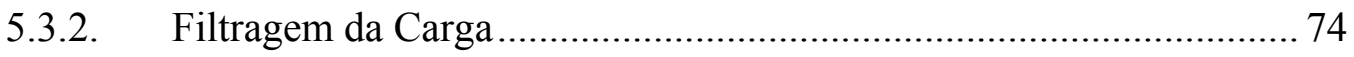

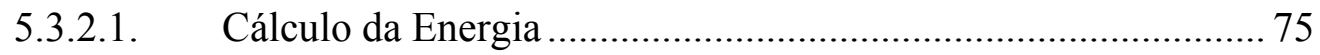

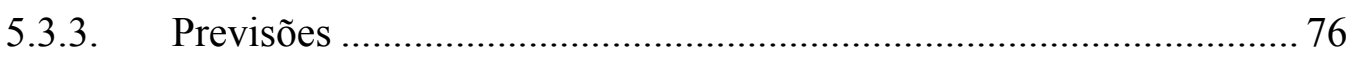

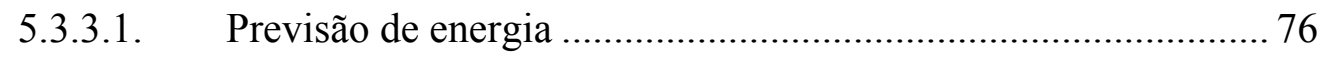

5.3.3.2. Previsão da Carga.................................................................... 80 


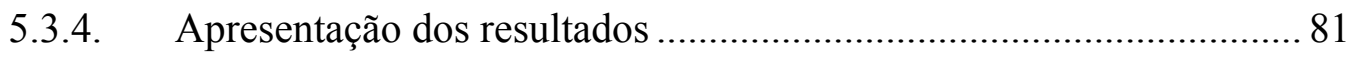

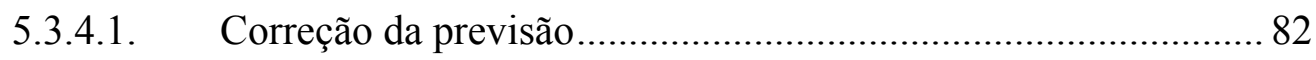

5.3.5. Treinamento de Redes Neurais ........................................................ 84

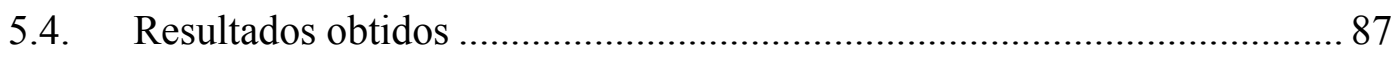

5.5. Resultados obtidos em trabalhos semelhantes ......................................... 90

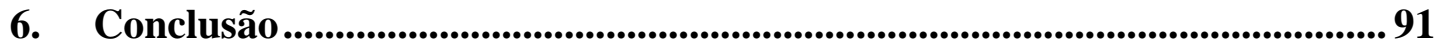

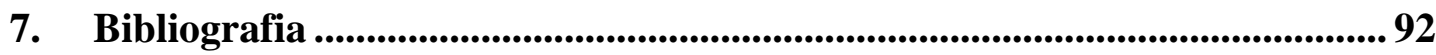

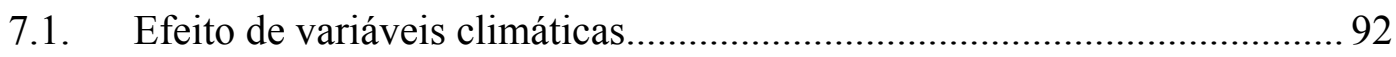

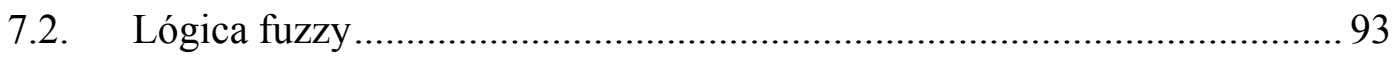

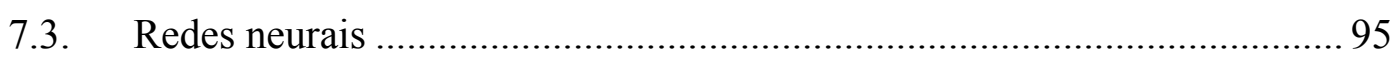

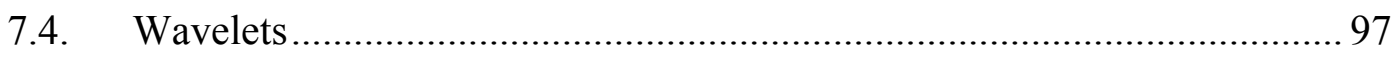

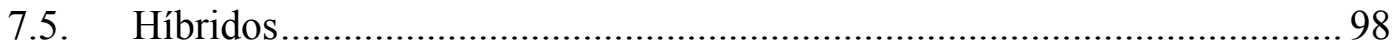

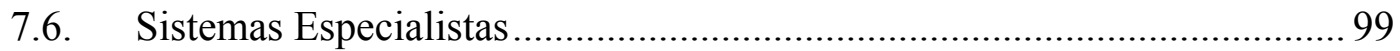

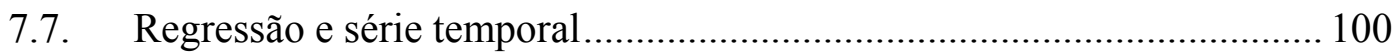

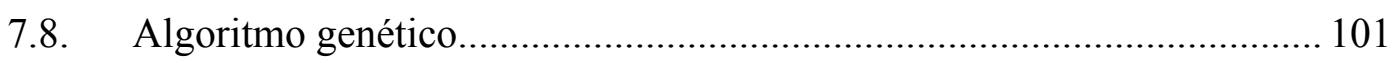

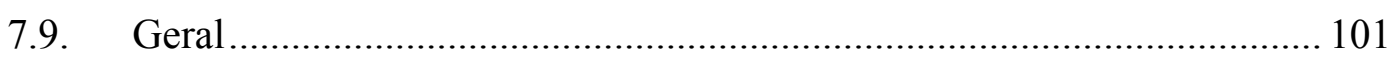

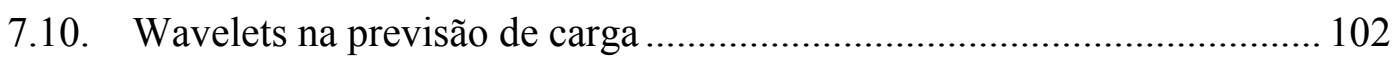

ANEXO A - Erro Percentual das Previsões ........................................................ 104

ANEXO B - Determinação automática de modelos fuzzy ................................. 105 


\section{Lista de Tabelas}

Tabela 3-1 - Dados para exemplo de cálculo do resíduo ............................................................... 19

Tabela 3-2 - Identificação de erros por estimação e resíduo (J) ................................................... 20

Tabela 3-3 - Compactação de curvas via FFT ........................................................................... 25

Tabela 3-4 - Descrição de algumas famílias de Wavelets................................................................. 31

Tabela 4-1 - Resultados da previsão da carga 15 minutos a frente, com sistema Fuzzy ............... 52

Tabela 4-2 - Resultados da previsão de carga 1 hora a frente, com sistema fuzzy ........................ 53

Tabela 4-3 - Previsão de carga 1 hora a frente através de lógica fuzzy com uso de temperatura

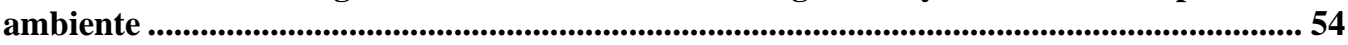

Tabela 4-4 - Melhores RNAs para previsão de carga nas Segundas-feiras ................................... 60

Tabela 4-5 - Erros médios da previsão de energia para cada dia da semana............................... 63

Tabela 4-6 - Testes para RNAs de previsão com Wavelets............................................................ 67

Tabela 5-1 - Inserção de dados de carga filtrados ........................................................................ 75

Tabela 5-2 - Erros médios das RNAs de previsão de energia ....................................................... 77

Tabela 5-3 - Melhores configurações de RNA para a previsão da carga ....................................... 80

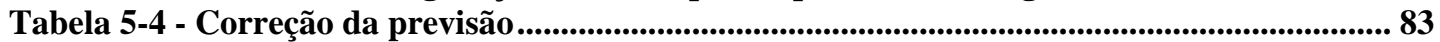

Tabela 5-5 - Desempenho das redes neurais de previsão de energia............................................. 87

Tabela 5-6 - Desempenho das redes neurais de previsão de carga................................................ 87

Tabela 5-7 - Desempenho das redes neurais de previsão de carga da CPFL ................................ 88

Tabela 5-8 - Desempenho das redes neurais de previsão de carga da CESP ................................ 88

Tabela 5-9 - Desempenho das redes neurais de previsão de carga da ELETROPAULO ............. 88

Tabela 7-1 - Dados para desenvolvimento de sistema de inferência fuzzy .................................. 105

Tabela 7-2 - Potenciais dos dados de entrada ........................................................................ 107

Tabela 7-3 - Novos potenciais dos dados de entrada ....................................................................... 108

Tabela 7-4 - Centros dos clusters obtidos................................................................................. 108

Tabela 7-5 - Fuzzyficação na regra 1 ......................................................................................................... 110

Tabela 7-6 - Fuzzyficação na regra 2............................................................................................... 110

Tabela 7-7 - Parâmetro $\beta$ para os dados de entrada ................................................................ 112

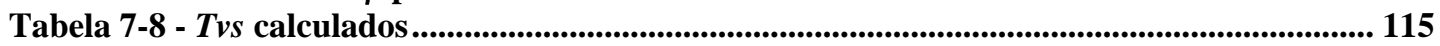

Tabela 7-9 - Conseqüências calculadas ................................................................................ 115 


\section{Lista de Figuras}

Figura 2-1 - Modelo de Série Temporal Estocástica.................................................................. 7

Figura 3-1 - Medições com erros para cálculo do resíduo............................................................... 19

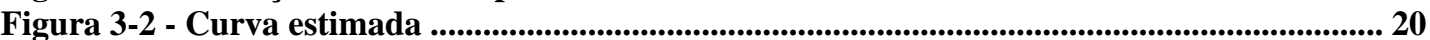

Figura 3-3 - Curva de Carga do Estado de São Paulo .............................................................. 21

Figura 3-4 - Curva de carga original e filtrada........................................................................ 21

Figura 3-5 - Curva de carga com e sem filtragem ................................................................... 22

Figura 3-6 - Carga do estado de São Paulo de 16 a 22 de julho de 2001....................................... 24

Figura 3-7 - Espectro da curva de carga do dia 18 de julho ....................................................... 24

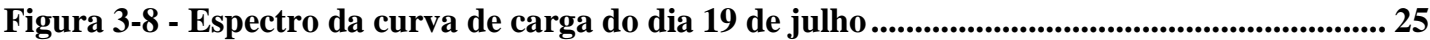

Figura 3-9 - Filtragem FFT mantidas 10 harmônicas...................................................................... 26

Figura 3-10 - Filtragem FFT mantidas 30 harmônicas..................................................................... 26

Figura 3-11 - Filtragem FFT mantidas 50 harmônicas............................................................. 27

Figura 3-12 - Filtragem FFT mantidas 100 harmônicas................................................................... 27

Figura 3-13 - Comparação entre processos de filtragem através de FFT ...................................... 28

Figura 3-14 - Comparação entre processos de filtragem através de FFT ................................... 28

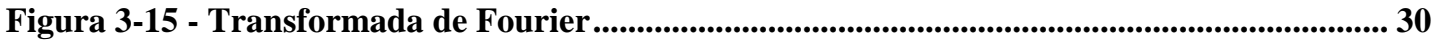

Figura 3-16 - Transformada Wavelet ........................................................................................ 30

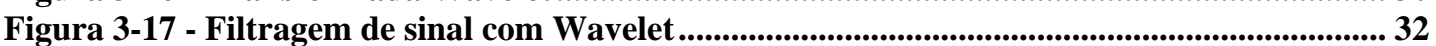

Figura 3-18 - Filtragem com Wavelets através do MATLAB ......................................................... 33

Figura 3-19 - Comparação com filtragem Wavelet e com filtro de dados corrompidos ............... 34

Figura 3-20 - Relação entre Energia Diária e Temperatura Ambiente - 2001 .............................. 36

Figura 3-21 - Relação entre Energia Diária e Temperatura Ambiente - 2002................................ 36

Figura 3-22 - Relação entre Energia Diária e Temperatura Ambiente - 2003.............................. 37

Figura 3-23 - Relação entre Energia Diária e Temperatura Ambiente - 2004 ................................ 37

Figura 3-24 - Efeito de feriado na curva de carga ........................................................................ 39

Figura 3-25 - Curva de carga durante jogo da copa do mundo ..................................................... 40

Figura 3-26 - Curva de carga de São Paulo para 2003................................................................. 41

Figura 3-27 - Curva de carga de São Paulo em Abril de 2003 .................................................... 41

Figura 3-28 - Curva de carga de segundas-feiras de 2003 ........................................................... 42

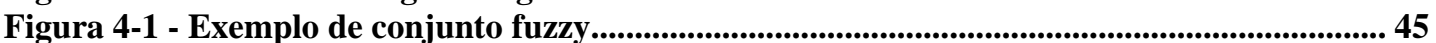

Figura 4-2 - Função de pertinência Gausiana............................................................................... 46

Figura 4-3 - Função de pertinência Trapezoidal ............................................................................. 46

Figura 4-4 - Função de pertinência Triangular .......................................................................46

Figura 4-5 - Sistema de Inferência Fuzzy .................................................................................. 48

Figura 4-6 - Exemplo de sistema de inferência Fuzzy para cálculo de gorjeta ............................. 49

Figura 4-7 - Tela do software de determinação automática de modelos Fuzzy............................ 51

Figura 4-8 - Sistema de Inferência Fuzzy para previsão da carga ................................................ 52

Figura 4-9 - Distribuição dos erros da previsão fuzzy para $t+1$..................................................... 53

Figura 4-10 - Distribuição dos erros da previsão fuzzy para $t+4$................................................ 54

Figura 4-11 - Neurônio Artificial .................................................................................................................... 56

Figura 4-12 - Rede Neural tipo MLP......................................................................................5 57

Figura 4-13 - Software para treinamento de Redes Neurais ......................................................... 59

Figura 4-14 - Distribuição dos erros da previsão dos pontos de carga ......................................... 61

Figura 4-15 - Energia diária das quintas-feiras, indicados os feriados............................................ 62

Figura 4-16 - Energia diária das terças-feiras, indicados os feriados ........................................ 62

Figura 4-17 - Distribuição dos erros da previsão de energia diária................................................ 63

Figura 4-18 - Rede Neural Wavelet ............................................................................................6 64

Figura 4-19 - Curva de carga decomposta por Wavelet db4 ............................................................. 65

Figura 4-20 - Recomposição de curva de carga por anti-transformada Wavelet ........................... 66

Figura 4-21 - Comparação entre curvas reais e prevista por previsão Wavelet ............................ 67

Figura 4-22 - Distribuição dos erros da previsão Wavelet.............................................................. 68

Figura 5-1 - Configuração do sistema na rede TCP/IP ..................................................................... 72

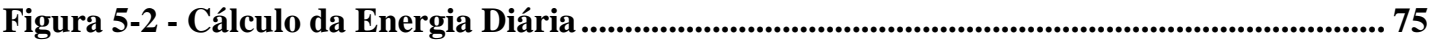

Figura 5-3 - Distribuição dos erros de previsão de energia da CTEEP ........................................... 77

Figura 5-4 - Distribuição dos erros de previsão de energia da CPFL .......................................... 78 
Figura 5-5 - Distribuição dos erros de previsão de energia da ELETROPAULO.......................... 78

Figura 5-6 - Distribuição dos erros de previsão de energia da CESP .................................................. 78

Figura 5-7 - Tela de visualização da curva real (vermelha) e prevista (verde) ................................ 81

Figura 5-8 - Correção da Previsão ................................................................................................. 83

Figura 5-9 - Geração de arquivos de treinamento para redes neurais ............................................... 84

Figura 5-10 - Tela de treinamento das redes neurais ............................................................................... 85

Figura 5-11 - Configuração de redes neurais/concessionária................................................................. 86

Figura 5-12 - Distribuição de erros da previsão de carga da CTEEP .............................................. 87

Figura 5-13 - Distribuição dos erros para previsões da ELETROPAULO ...................................... 89

Figura 5-14 - Distribuição dos erros para previsões da CESP ............................................................. 89

Figura 5-15 - Distribuição dos erros para previsões da CPFL .............................................................. 89

Figura 7-1 - 'Fuzzyficação' de variável ......................................................................................... 105

Figura 7-2 - Funções de pertinência obtidas ............................................................................................ 109

Figura 7-3 - Fuzzyficação do conjunto de dados 2 ................................................................................. 110

Figura 7-4 - Cálculo das pertinências no exemplo de sistema de inferência fuzzy ........................ 114 


\section{Preâmbulo}

\subsection{Introdução}

A previsão de carga de curto prazo, que pode variar de minutos a dias, vem se tornando mais importante desde a criação de mercados competitivos de energia. Muitos países desregulamentaram seus sistemas elétricos e a energia elétrica se tornou uma commodity vendida a preço de mercado. Como a previsão da carga tem uma participação importante na composição do preço, ela se tornou de vital importância para a indústria.

Se o erro da previsão for pequeno, pode-se melhorar a segurança do sistema e diminuir os custos de geração, postergando-se investimentos nesta área.

Mas a carga de um sistema elétrico está sujeita a diversos fatores externos ao sistema e não-lineares de difícil modelamento tais como estações do ano, temperatura, hábitos de consumo, dias da semana, etc., também chamados de variáveis exógenas, o que torna a sua previsão uma tarefa difícil.

A fim de realizar a previsão da carga com exatidão, uma série de métodos vêem sendo desenvolvidos e aprimorados ao longo dos anos. Inicialmente temos uma série de métodos matemáticos aplicados a previsão que podem ser divididos em métodos de séries temporais, nos quais a carga é modelada como uma função dos valores passados e modelos causais onde a carga é modelada como uma função de fatores externos tais como clima e variáveis sociais. Entre os métodos de séries numéricas temos os modelos autoregressivos, filtro de Kalman, etc. Entre os causais temos o modelo de BoxJenkins, ARMAX, etc.

Todos esses métodos têm conseguido, com maior ou menor grau de exatidão, executar a previsão da carga.

Já nos últimos anos, foram desenvolvidas as técnicas de inteligência artificial e elas passaram a ser aplicadas a previsão da carga. Entre as técnicas temos as redes neurais, a lógica Fuzzy, sistemas especialistas, etc. 
Esses métodos têm como vantagem uma melhor resposta a não-linearidades grandes e rápidas que podem aparecer nas cargas além de não dependerem de complexos modelos matemáticos.

Além desses métodos, foram desenvolvidos uma série de métodos combinando dois ou mais métodos, sendo chamados de híbridos.

Apesar de todos os métodos citados serem capaz de prever a carga, eles continuam sendo aperfeiçoados e novos métodos continuam a ser desenvolvidos com a finalidade de se melhorar a exatidão da previsão, sua confiabilidade e o tratamento de situações anômalas como feriados e variações climáticas abruptas.

\subsection{Motivação e Objetivos}

O trabalho pretende:

- Apresentar uma visão geral sobre o problema da previsão de carga em sistemas elétricos;

- Descrever e comparar as principais técnicas de previsão;

- Detalhar o uso de inteligência artificial na previsão da carga, mais especificamente as redes neurais e a lógica Fuzzy;

- Detalhar o tratamento de dados e uso de variáveis exógenas na previsão;

- Apresentar uma aplicação prática desenvolvida para a previsão da curva de carga diária do sistema de transmissão da CTEEP Transmissão Paulista com uma antecedência de até dois dias. 


\subsection{Contribuições}

As seguintes contribuições podem ser destacadas com o trabalho desenvolvido:

- Uma análise profunda da carga do estado de São Paulo, levando ao melhor entendimento de seu comportamento;

- Desenvolvimento de uma metodologia e programas para previsão de carga, que foram instalados no centro de operação da CTEEP Transmissão Paulista em Bom Jardim;

- Uma avaliação comparativa conceitual dos vários métodos, desde séries temporais até o uso de técnicas de IA;

- Avaliação do efeito de variáveis exógenas na carga e determinação de padrões sazonais no consumo.

- Avaliação do uso de transformadas wavelet como ferramenta de filtragem de dados e previsão de carga em conjunto com redes neurais.

\subsection{Apresentação}

No capítulo 1, "Preâmbulo", foi apresentada uma introdução, os objetivos, as contribuições e esta apresentação.

No capítulo 2, "O Estado da Arte", apresenta-se o estado da arte, analisando as principais técnicas de previsão de carga.

No capítulo 3, "Medições", são analisados o tratamento dos dados de carga e as variáveis exógenas;

No capítulo 4, "Previsão", são analisadas detalhadamente as técnicas de previsão através de Redes Neurais e Lógica Fuzzy;

No capítulo 5, "Integração em Sistemas Corporativos", é analisado o desenvolvimento e implementação de um sistema de previsão de carga na CTEEP Transmissão Paulista. 
No capítulo 6, "Conclusão", são analisados os resultados obtidos com o sistema de previsão e a eficiência das técnicas de IA, avaliando suas vantagens e problemas de utilização. 


\section{O Estado da Arte}

Desde a década de 80, uma série de métodos vêem sendo aplicados para a previsão da carga. Pode-se dividir os métodos entre estatísticos e baseados em inteligência artificial.

Entre alguns dos métodos clássicos tem-se:

- Regressão Linear Múltipla;

- ARIMA;

- Alisamento exponencial;

- Análise espectral;

Entre os métodos baseados em inteligência artificial tem-se:

- Sistemas especialistas;

- $\quad$ Redes neurais;

- Lógica Fuzzy;

- Algoritmo Genético;

Também vêem sendo desenvolvidos uma série de métodos chamados híbridos, que combinam dois ou mais métodos de previsão de carga.

A seguir, apresenta-se um levantamento das principais técnicas disponíveis para a previsão da carga e uma breve análise.

\subsection{Métodos Estatísticos de Previsão}

Os métodos estatísticos podem ser agrupados em métodos regressivos e métodos baseados em séries temporais. Os modelos regressivos consideram a carga como uma combinação linear de funções tais como senóides, exponenciais, etc. Entre alguns dos métodos regressivos temos a regressão linear, alisamento exponencial e decomposição espectral.

Os modelos baseados em séries temporais incorporam na previsão os efeitos de fatores tais como temperatura ambiente, histórico do comportamento da 
carga e efeitos aleatórios. Entre os métodos temos a Média Móvel Autoregressiva (ARMA), espaço de estados, etc.

Os métodos estatísticos têm a vantagem de serem técnicas matemáticas já bem desenvolvidas e estudadas, mas, dependem de um modelamento matemático complexo do problema além de terem dificuldade de lidar com variações rápidas de fatores como clima, feriados, etc.

Esses métodos ainda hoje são usados e estudados mas estão sendo gradativamente substituídos pelas técnicas de inteligência artificial ou utilizados em combinação com as mesmas [94],[97],[98],[99].

\subsubsection{Regressão Linear Múltipla}

A carga pode ser modelada como uma função linear de múltiplas variáveis do tipo:

$$
y(t)=a_{0}+a_{1} x_{1}(t)+\cdots+a_{n} x_{n}(t)+a(t)
$$

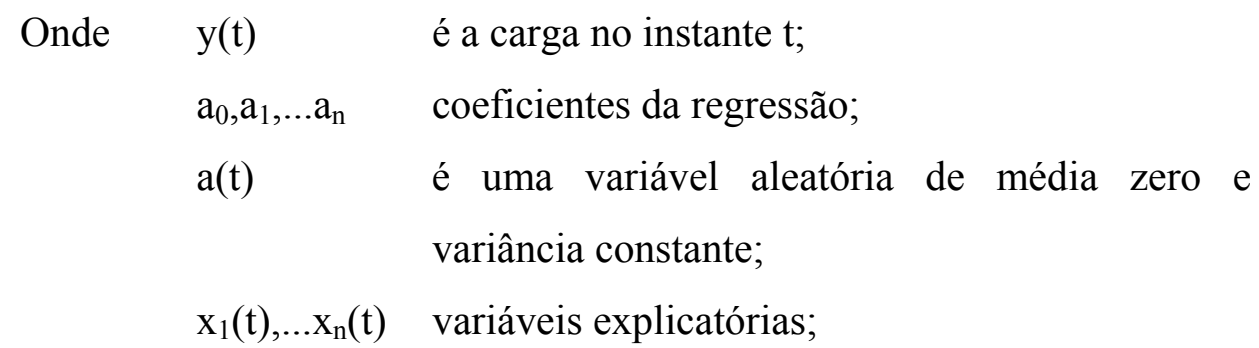

As variáveis explicatórias são fatores que influenciam a carga do sistema tais como, por exemplo, a temperatura ambiente.

Os coeficientes de regressão podem ser encontrados pelo método dos mínimos quadrados e análises estatísticas podem determinar a significância de cada variável explicatória para previsão da carga

Encontram-se poucas aplicações desse método, pois comparações mostram que ele apresenta erros maiores que outros métodos [106] . 


\subsubsection{Séries Temporais Estocásticas}

Um método muito utilizado para a previsão da carga consiste em modelá-la como uma série temporal estocástica.

A carga em cada instante t é definida como a resposta de um filtro linear a um sinal de ruído branco com média zero e variância constante. O modelamento do filtro fornece o modelo de previsão.

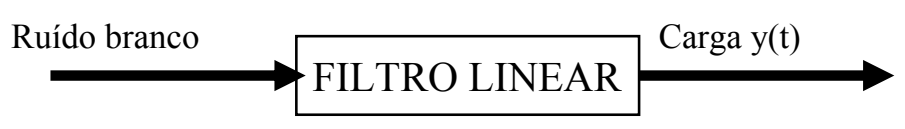

Figura 2-1 - Modelo de Série Temporal Estocástica

O filtro pode ser modelado através de uma série de modelos descritos a seguir.

\subsubsection{Processo auto-regressivo}

$\mathrm{O}$ processo AR (autoregressive), onde o valor da carga $\mathrm{y}(\mathrm{t})$ é uma função linear das cargas nos momentos anteriores, $\mathrm{y}(\mathrm{t}-\mathrm{n})$, mais um ruído aleatório a(t). Assim tem-se:

$$
y(t)=\phi_{1} y(t-1)+\phi_{2} y(t-2)+\cdots+\phi_{p} y(t-p)+a(t)
$$

Onde $\quad \phi_{p} \quad$ são as constantes da função auto-regressiva

$$
p \quad \begin{aligned}
& \text { número de instantes anteriores usados na } \\
& \text { regressão }
\end{aligned}
$$

A carga no instante $t$ depende das cargas passadas até o instante $t-p$. Assim, o processo auto-regressivo é dito de ordem $\mathrm{p}$.

Definindo-se o operador backward shift B tal que: 


$$
y(t-1)=B y(t)
$$

e conseqüentemente:

$$
y(t-m)=B^{m} y(t)
$$

a equação da carga pode ser dada por:

$$
\phi(B) y(t)=a(t)
$$

Onde:

$$
\phi(B)=1-\phi_{1} B-\phi_{2} B^{2}-\cdots-\phi_{p} B^{p}
$$

\subsubsection{Processo da média móvel}

No processo da média móvel (MA - moving-average), o valor da carga é uma função linear dos valores atuais e passados de uma série de ruído branco $\mathrm{a}(\mathrm{t})$, a(t-1),.., definido pelos erros de previsão ou resíduos das observações disponíveis. Assim, tem-se:

$$
y(t)=a(t)-\theta_{1} a(t-1)-\theta_{2} a(t-2)-\cdots-\theta_{q} a(t-q)
$$

E, similar ao método auto-regressivo pelo operador B, tem-se:

$$
y(t)=\theta(B) a(t)
$$

Onde:

$$
\theta(B)=1-\theta_{1} B-\theta_{2} B^{2}-\cdots-\theta_{q} B^{q}
$$

Sendo $q$ a ordem do processo. 


\subsubsection{Processo da média móvel auto-regressiva}

O processo da média móvel auto-regressiva ou ARMA (autoregressive moving-average) é um processo muito utilizado onde o valor da carga é uma função linear dos valores da carga nos instantes anteriores e dos valores atuais e passados de uma série de ruído branco. Assim tem-se:

$y(t)=\phi_{1} y(t-1)+\cdots \phi_{p} y(t-p)-a(t)-\theta_{1} a(t-1)-\theta_{2} a(t-2)-\cdots-\theta_{q} a(t-q)$

E pode-se escrever:

$$
\phi(B) y(t)=\theta(B) a(t)
$$

A ordem do processo é dada pelo valor de carga mais antigo e pelo ruído branco mais antigo. Assim, o processo acima tem ordem $p, q$.

\subsubsection{Processo da média móvel integrada auto-regressiva (ARIMA)}

A teoria para séries temporais lida com processos estacionários, que são séries temporais onde não há uma mudança sistemática na sua média (sem tendências), não há mudança sistemática na sua variância e sem variações periódicas. Para tratar um processo não-estacionário, deve-se remover suas tendências e sazonalidades de modo a torná-lo estacionário. Para isso, diferencia-se a série temporal através de um operador $\nabla$ tal que:

$$
\nabla y(t)=y(t)-y(t-1)=(1-B) y(t)
$$

$\mathrm{e}$

$$
\nabla^{d} y(t)=(1-B)^{d} y(t)
$$


Que fornece o modelo:

$$
\phi(B) \nabla^{d} y(t)=\theta(B) a(t)
$$

Onde: $y(t)=\phi_{1} y(t-1)+\cdots \phi_{p} y(t-p)+a(t)-\theta_{1} a(t-1)-\cdots-\theta_{q} a(t-q)$

O processo acima é dito de ordem $(p, d, q)$.

\subsubsection{Alisamento Exponencial}

No alisamento exponencial considera-se que cada elemento de uma série temporal consiste de uma constante mais uma componente de erro:

$$
x_{t}=b+\varepsilon_{t}
$$

$\begin{array}{lll}\text { Onde } & b & \text { componente constante } \\ \varepsilon & \text { componente de erro }\end{array}$

Como a parte b é constante ao longo de cada segmento da série mas pode variar ao longo do tempo, pode-se definir que uma medição atual é função das anteriores sendo que as mais antigas possuem um peso exponencialmente menor :

$$
s_{t}=\alpha x_{t}+(1-\alpha) s_{t-1}
$$

Onde $\quad s \quad$ são os valores previstos das medições

$x \quad$ são as medições

$\alpha \quad$ é a constante de alisamento

$t \quad$ instante em que calcula a série temporal 


\subsubsection{Outros métodos}

Além dos métodos descritos brevemente acima, existe ainda uma série de métodos para previsão, entre eles :

- Método de Holt-Winters;

- Método de Box-Jenkins;

- Previsão Bayesiana;

- Filtro de Kalman;

- Decomposição espectral;

Apesar de seu uso estar diminuindo, ainda encontramos aperfeiçoamentos e novos métodos estatísticos sendo aplicados. Recentemente o uso de séries temporais caóticas vem sendo analisado para a previsão de carga.

\subsection{Métodos de Inteligência Artificial}

O desenvolvimento dos métodos de inteligência artificial (IA) forneceu aos pesquisadores formas de codificar conhecimento humano em um programa computacional (sistemas especialistas) e determinar o comportamento de um sistema baseado apenas no seu histórico (treinamento), ou seja, passou-se a dispor de métodos de interpolação de sistemas que não dependiam de um modelamento matemático complexo ou conhecimento profundo do sistema (redes neurais e lógica fuzzy).

Mas ainda assim, os métodos de IA apresentam problemas próprios. É complexa a codificação de conhecimento humano, difícil determinar quais dados e variáveis são importantes para o sistema de previsão, a determinação dos processos de treinamento é complexa e ainda não é bem conhecida.

Ainda assim, os métodos de IA tem sido amplamente utilizados com resultados na maioria das vezes melhor que as técnicas matemáticas tradicionais.

Entre os principais métodos de IA temos os Sistemas Especialistas, Redes Neurais e Lógica Fuzzy. 
A seguir, temos uma breve descrição de alguns dos métodos.

\subsubsection{Sistemas Especialistas}

Um sistema especialista pode ser definido como: "Um programa que possui uma grande base de dados sobre um domínio especifico e usa um complexo raciocínio por inferência para realizar tarefas que podem ser feitas por um especialista humano".

Uma dificuldade de seu uso é que necessitamos de um especialista capaz de prever a carga para podermos converter seu conhecimento em regras matemáticas, processo que pode ser extremamente difícil, o que torna a aplicação apenas de sistemas especialistas para a previsão da carga não muito disseminada. Na maioria das vezes eles estão associados a outras técnicas como a Lógica Fuzzy e as Redes Neurais gerando resultados melhores que essas técnicas separadamente.

\subsubsection{Redes Neurais Artificiais}

As Redes Neurais Artificiais (RNAs) são uma técnica de processamento baseada em sistemas nervosos biológicos tais como o cérebro humano. São compostas de um grande número de unidades interconectadas denominadas neurônios. Elas utilizam uma técnica semelhante ao aprendizado humano através de exemplos para resolver problemas. As RNAs são configuradas para problemas específicos através de um processo denominado aprendizado. Elas já vêm sendo utilizadas na previsão da carga desde 1990 com sucesso.

Seu uso na previsão de carga consiste em se treinar a rede fornecendo um conjunto de dados de entrada e saída. A saída é a carga que se deseja prever e as entradas são as cargas anteriores.

Essa rede treinada é capaz de prever valores futuros com base nas informações de carga já ocorridas. Variáveis podem ser facilmente incluídas 
na rede neural sem que seu relacionamento matemático com a carga seja conhecido.

Há uma série de técnicas para RNAs onde variamos a estrutura da rede e o método de treinamento.

\subsubsection{Lógica Fuzzy}

A Lógica Fuzzy ou Nebulosa, diferente da lógica convencional, não utiliza apenas valores absolutos de sim e não ou 0 e 1. Uma variável Fuzzy pode assumir qualquer valor entre 0 e 1 de modo a incorporar imprecisões e imperfeições do mundo real.

Desenvolvida originalmente por Zadeh em 1965, sua aplicação inicial foi para sistemas de controle mas rapidamente passou a ser aplicada em outras áreas, havendo paralelamente $\mathrm{o}$ desenvolvimento de toda a teoria matemática da lógica Fuzzy.

A sua aplicação à previsão de carga se deve ao fato de ser capaz de aproximar qualquer função não-linear com uma exatidão arbitrária e de encontrar padrões em grandes conjuntos de dados

\subsubsection{Algoritmos Genéticos}

Os algoritmos genéticos (Genetic Algorithms - GAs) são uma ferramenta poderosa para problemas de otimização combinatória de larga escala. São baseados no conceito de que a evolução natural é capaz de fornecer soluções eficientes e complexas utilizando-se de mecanismos relativamente simples baseados na sobrevivência do individuo mais adequado, na passagem de características vantajosas aos descendentes e em mutações.

Os GAs não são usados diretamente na previsão da carga mas como uma ferramenta para auxilio de outros métodos como por exemplo otimização da estrutura de uma rede neural. 


\subsection{Métodos Híbridos}

Os métodos Híbridos procuram combinar diversas técnicas a fim de compensar os problemas e dificuldades de cada uma e atingir uma maior exatidão na previsão.

Entre os métodos híbridos mais estudados temos os Fuzzy-Neural, NeuroFuzzy, Neural-genético, etc.

A combinação de Lógica Fuzzy, Redes Neurais e GA procura resolver o problema de determinar a melhor estrutura de rede neural ou funções de pertinência da lógica fuzzy.

\subsection{Métodos utilizados na tese}

Embora existam dos diversos métodos de previsão disponíveis, esta tese trata apenas o uso de técnicas de inteligência artificial, especificamente as redes neurais artificiais e a lógica fuzzy.

Os princípios das redes neurais do tipo multi-layer perceptron, métodos de treinamento e aplicação a previsão de curvas de carga são discutidos no capítulo 4.2 e sua aplicação prática em um ferramenta computacional desenvolvida no capítulo 5 .

Os fundamentos da lógica fuzzy, seu uso em sistemas de inferência e sua aplicação na previsão da carga em instantes específicos estão detalhados no capítulo 4.1 e no anexo B. 


\section{Obtenção e Tratamento de Dados}

A qualidade da previsão de carga através de métodos de IA depende da escolha das variáveis mais significativas para a previsão e da disponibilidade de um histórico dessas variáveis, a fim de que o comportamento do sistema possa ser aprendido através de um processo de treinamento.

Assim, precisamos determinar quais grandezas, além da própria carga do sistema, tem efeito de forma significativa e se há um histórico com uma quantidade de dados suficiente para garantir um treinamento adequado do sistema de IA. Ainda será necessária uma análise qualitativa dos dados e, caso seja necessário, determinar um processo de tratamento destes.

O comportamento do consumo em um sistema elétrico depende diretamente dos hábitos dos diversos tipos de consumidores. Assim, qualquer fator que afete as indústrias, residências, etc., terá efeito sobre a curva de carga. Esses fatores são denominados variáveis exógenas e entre eles têm-se fatores sociais, econômicos e climáticos.

Para a previsão de carga de curto prazo, a temperatura ambiente é reconhecidamente um dos fatores com maior efeito sobre a curva de carga. Sazonalidades como dia da semana e estações do ano também afetam as curvas.

Alguns fatores aleatórios ou raros são especialmente problemáticos para a previsão pois afetam a carga de maneira totalmente fora dos padrões. O melhor exemplo são os feriados e outros dias especiais além de alguns eventos que afetam pontualmente o consumo tais como jogos da copa do mundo, finais de novelas, etc. 


\subsection{Obtenção dos Dados}

A obtenção das curvas de carga é tarefa relativamente simples pois atualmente a maioria das concessionárias dispõe de algum sistema computacional com o histórico das grandezas do sistema elétrico.

A obtenção de um histórico das variáreis exógenas do sistema pode ser um problema já que a concessionária passa a depender da existência de fontes externas.

No caso de grandezas climáticas, há uma grande quantidade de entidades que realizam medições e dispõe de históricos detalhados e de muitos anos.

Além de serem necessárias medições e histórico de variáveis exógenas, normalmente é necessário fazer uso de previsões dessas grandezas para o dia em que desejamos prever a carga. Isso pode ser um problema já que os fatores econômicos e sociais muitas vezes são difíceis de serem previstos.

Grandezas climáticas podem ser previstas, mas devido a sua complexidade, é mais adequada à obtenção de dados de serviços especializados.

Serviços de pesquisa meteorológica como o CPTEC (Centro de Previsão de Tempo e Estudos Climáticos) fornecem previsões climáticas confiáveis com 3 dias de antecedência. Além desse período, a confiança na previsão climática diminui e com isso a qualidade de uma previsão da carga. 


\subsection{Filtragem e Compactação dos Dados}

A medição de qualquer grandeza, além do erro inerente ao medidor, está sujeita a ruídos não-estacionários e não-gausianos para os quais não existe modelamento e problemas como possíveis falhas dos medidores, da telemetria, etc.

O excesso de problemas nas medições pode contaminar o padrão de dados do sistema de modo a prejudicar o aprendizado de um sistema de previsão baseado em IA. Assim, se faz necessária uma filtragem das medições, ou seja, é necessária a utilização de um processo capaz de identificar e corrigir o maior número possível de medições problemáticas.

Os sistemas de aquisição de dados de um sistema elétrico normalmente aquisitam dados a intervalos de tempo pequenos, normalmente menores que 1 minuto. Essa é uma amostragem excessiva para uma curva de carga. Trabalhando com uma curva de carga de um dia amostrada a cada minuto, tem-se 1440 medições por dia e mais de quinhentas mil medições em um ano. É uma resolução muito grande e uma quantidade de dados em excesso que precisará ser processada e armazenada.

Uma amostragem em torno de 15 minutos mostrou-se adequada para acomodar as necessidades de previsão do sistema elétrico e de processamento e armazenamento em um sistema computacional.

Desse modo, dado um histórico de dados, além de ser necessária uma filtragem, precisa-se reduzir o número de medições.

A seguir temos o exemplo de três métodos para filtragem: a identificação de dados corrompidos, a filtragem por transformada de Fourier e por transformada Wavelet. 


\subsubsection{Filtragem por Identificação de Dados Corrompidos}

Uma técnica para a identificação de dados corrompidos (bad data detection) [124] é utilizada no método dos Mínimos Quadrados Ponderados em estimadores de estado e pode ser aplicada como filtro nas medições de carga.

Dado um intervalo de tempo e um conjunto de medições, pode-se ajustar uma curva (modelamento) que permita estimar a medição em qualquer instante do intervalo.

Supondo que o modelo adotado represente adequadamente o comportamento do conjunto de medições, qualquer medição que se afaste muito da curva estimada tem uma boa chance de estar com problemas.

$\mathrm{O}$ ajuste da curva do modelamento às medições pode ser avaliado pelo resíduo da medição $\boldsymbol{J}$, sendo definido para cada medição como:

$$
J_{i}=\frac{\left(x_{\text {imedido }}-x_{\text {iestimado }}\right)^{2}}{\sigma^{2}}
$$

onde $J_{i} \quad$ resíduo da medição no instante $i$

$\sigma \quad$ desvio padrão do conjunto de medições :

$$
\sigma=\sqrt{\frac{1}{n} \sum_{i=1}^{n}\left(x_{i}-\bar{x}\right)^{2}}
$$

$n$ número de medições

$\bar{x}$ média das medições

$x_{\text {imedido }} \quad$ medição do instante $i$

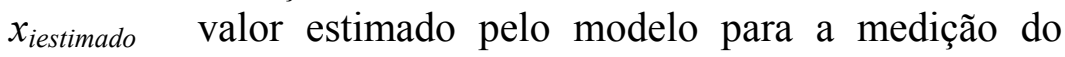
instante $i$

Para $J_{i}$ abaixo de um valor limite, verificamos que a medição se ajusta bem ao modelo e se estiver acima do limite, a medição deve estar com problemas. O problema consiste em determinar o limite para o qual o $J_{i}$ identifica uma medição como aceitável ou com problemas. 
Os erros de medição são números aleatórios de modo que $J_{i}$ também o é. A função densidade de probabilidade de $J$ corresponde a uma distribuição chiquadrada $\left(\chi^{2}\right)$.

Se o resíduo total do sistema $J=\sum J_{i}$ estiver acima de um limite definido na distribuição, temos a probabilidade escolhida de termos uma medição com problemas no conjunto. A melhor candidata é a medição com o maior resíduo $J_{i}$.

O processo pode ser facilmente entendido com os dados fornecidos na Tabela 3-1 e visualizados na Figura 3-1.

Tabela 3-1 - Dados para exemplo de cálculo do resíduo

\begin{tabular}{|c|c|}
\hline $\mathbf{x}$ & $\mathbf{y}$ \\
\hline 1 & 10,4 \\
\hline 2 & 18,0 \\
\hline 3 & 26,7 \\
\hline 4 & 29,4 \\
\hline 5 & 53,2 \\
\hline 6 & 37,0 \\
\hline 7 & 46,8 \\
\hline 8 & 45,8 \\
\hline 9 & 48,7 \\
\hline 10 & 56,8 \\
\hline
\end{tabular}

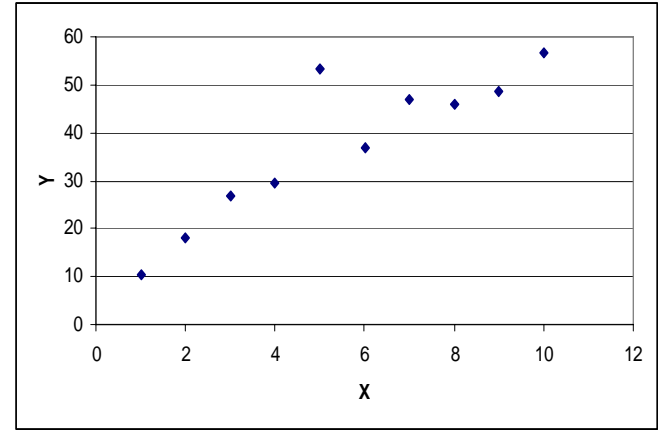

Figura 3-1 - Medições com erros para cálculo do resíduo

No conjunto de dados, com modelagem linear, foram introduzidos erros aleatórios em todos os valores ma propositadamente alto na medição 5. 
Podemos comprovar o resultado encontrando a curva que melhor se ajusta aos pontos por regressão linear (Figura 3-2) e calcular o resíduo de cada ponto, conforme a Tabela 3-2.

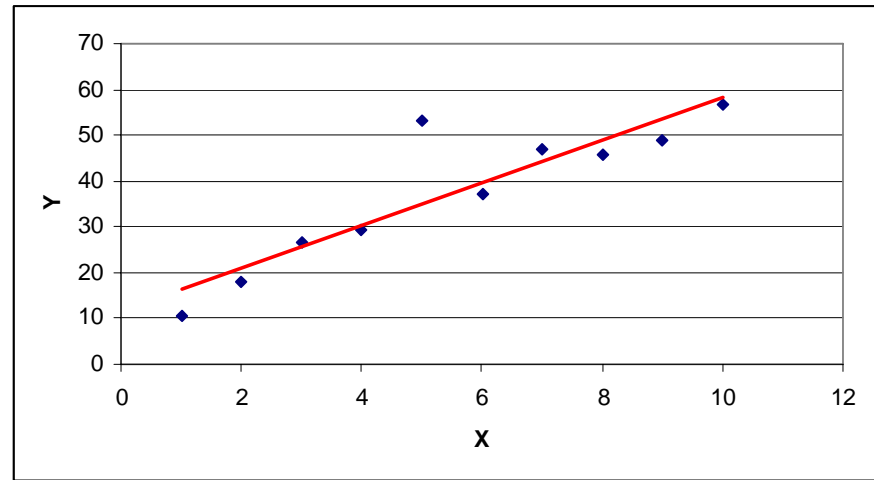

Figura 3-2 - Curva estimada

Tabela 3-2 - Identificação de erros por estimação e resíduo (J)

\begin{tabular}{|c|c|c|c|}
\hline $\mathbf{x}$ & $\mathbf{y}$ & $\mathbf{y}$ estimado & $\boldsymbol{J}$ (resíduo) \\
\hline 1 & 10,4 & 16,4 & 0,19 \\
\hline 2 & 18,0 & 21,1 & 0,05 \\
\hline 3 & 26,7 & 25,7 & 0,00 \\
\hline 4 & 29,4 & 30,3 & 0,00 \\
\hline 5 & 53,2 & 35,0 & $\mathbf{1 , 7 0}$ \\
\hline 6 & 37,0 & 39,6 & 0,03 \\
\hline 7 & 46,8 & 44,2 & 0,03 \\
\hline 8 & 45,8 & 48,9 & 0,05 \\
\hline 9 & 48,7 & 53,5 & 0,12 \\
\hline 10 & 56,8 & 58,1 & 0,01 \\
\hline
\end{tabular}

A aplicação do mesmo processo a uma curva de carga é possível, mas é mais complexa, pois não termos uma curva que se adapte a carga. A solução é analisar a curva de carga em intervalos de tempo pequenos. Na Figura 3-3 pode-se observar uma curva de carga típica para o estado de São Paulo. 


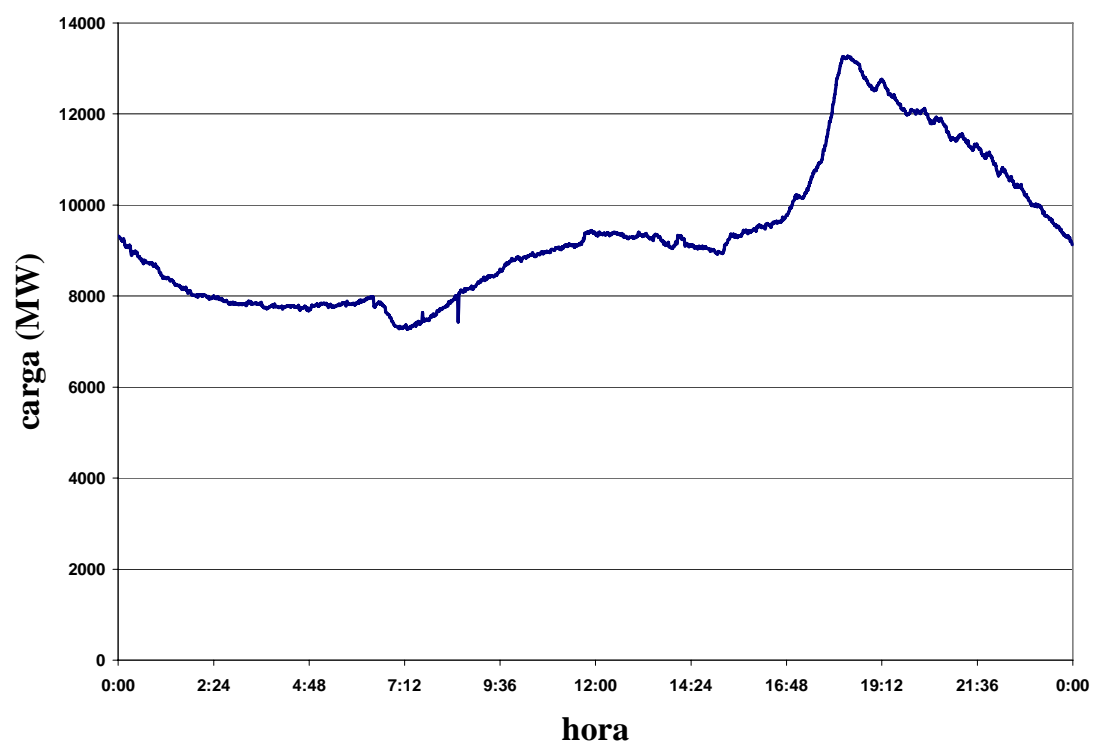

Figura 3-3 - Curva de Carga do Estado de São Paulo

A curva de carga na Figura 3-3 possui medições amostradas a cada minuto. Testes com o processo de filtragem mostraram que aplicá-lo na curva em janelas de intervalo de 15 minutos produz um bom resultado. A Figura 3-4 mostra exemplos de curvas de carga com e sem filtragem por identificação de dados corrompidos.

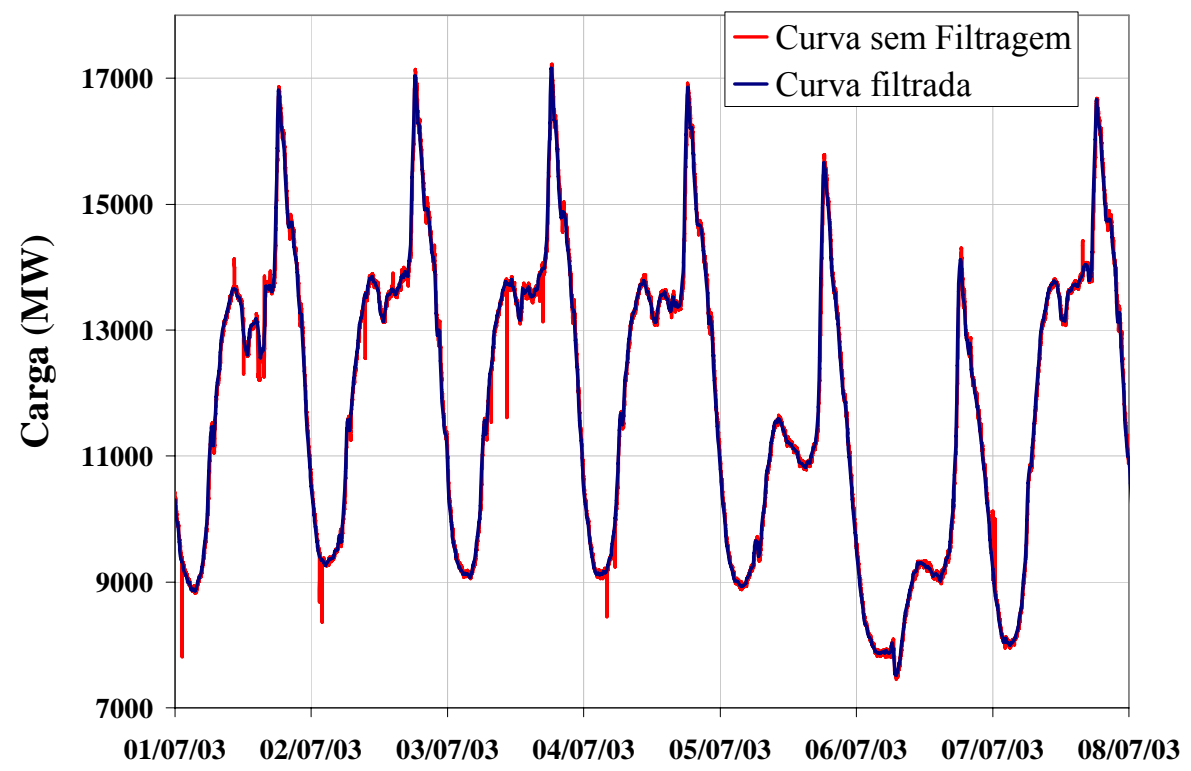

Figura 3-4 - Curva de carga original e filtrada 
A implementação computacional do processo e testes com dados reais de carga se mostrou eficiente e rápida fornecendo bons resultados. Em casos onde se tem muitas medições erradas próximas e com valores bem distantes do real, o filtro apresenta alguma dificuldade em recompor adequadamente a curva de carga, conforme a Figura 3-5 .

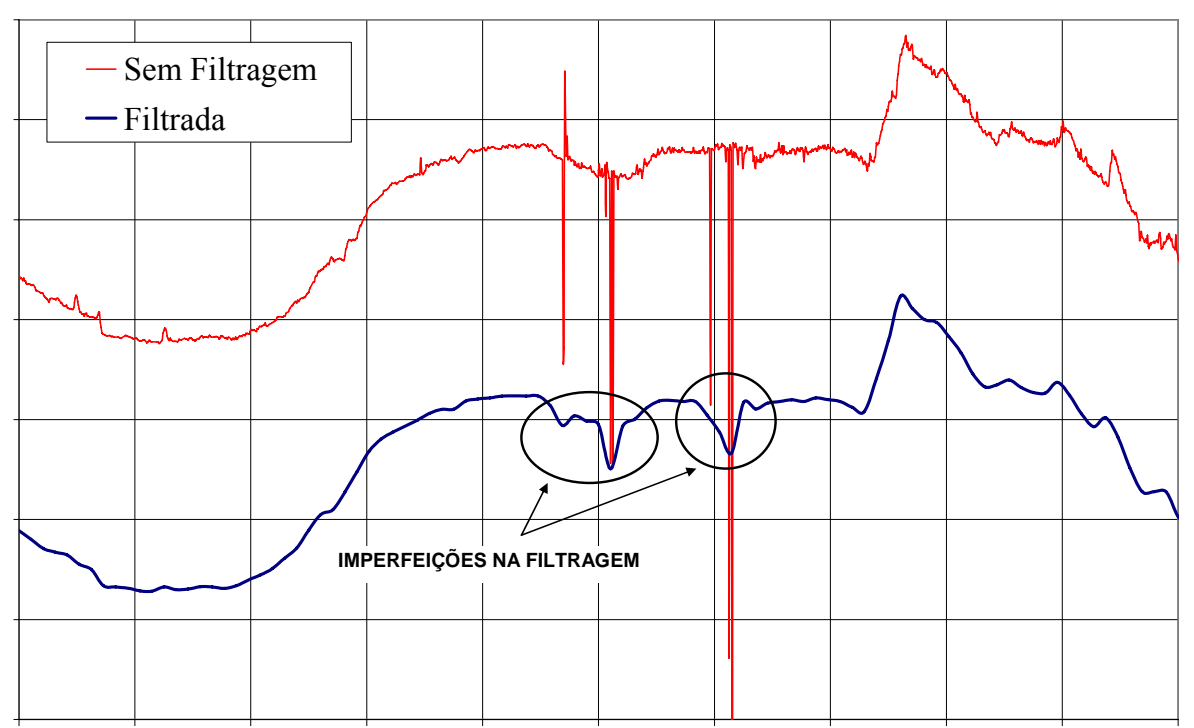

Figura 3-5 - Curva de carga com e sem filtragem

Em curvas com intervalo de amostragem pequeno, tem-se um grande número de medições por dia, o que gera uma grande massa de dados a ser manipulada. O processo de filtragem descrito pode ser utilizado para reduzir a freqüência de amostragem das curvas.

Após a filtragem das medições, pode-se substituir os pontos de um intervalo por seu valor médio, o que vai preservar a informação da energia da curva e reduzir o número de pontos das curvas de carga.

Para as curvas apresentadas, com amostragem de 1 minuto tem-se 1440 pontos e reduzindo a amostragem a 15 minutos, tem-se apenas 96 pontos. Uma redução de cerca de $93 \%$ na quantidade de informação a ser armazenada e tratada sem perda da informação importante fornecida pelas curvas. 


\subsubsection{Filtragem por Transformada de Fourier}

A transformada de Fourier é uma técnica amplamente utilizada para a análise e filtragem de sinais. Ela permite a decomposição de quase qualquer tipo de função em uma soma de senóides de amplitude e freqüência diferentes. As componentes de mais alta freqüência são normalmente associadas a ruídos e ao eliminá-las estamos executando uma filtragem.

A transformada discreta de Fourier (TDF) de um sinal $\mathrm{x}(\mathrm{n})$ composto de $\mathrm{N}$ pontos, é definida como:

$$
F(k)=\sum_{n=0}^{N-1}\left[f(n) e^{-\frac{j k 2 \pi n}{N}}\right]
$$

E a sua inversa como:

$$
f(n)=\frac{1}{N} \sum_{k=0}^{N-1}\left[F(k) e^{\frac{j k 2 \pi n}{N}}\right]
$$

Onde $\quad k \quad$ é o número da componente

$N \quad$ é o número de amostras do sinal $f(n)$

$F(k) \quad$ é a k-ésima componente de Fourier

$f(n) \quad$ é o sinal discreto

j $\quad \sqrt{-1}$

O módulo de $F(k)$ indica a intensidade de cada componente $\mathrm{k}$ também denominada de harmônica. O conjunto das intensidades das harmônicas é denominado de espectro.

Vamos verificar a aplicação da TDF em curvas de carga do estado de São Paulo como as observadas na Figura 3-6. 


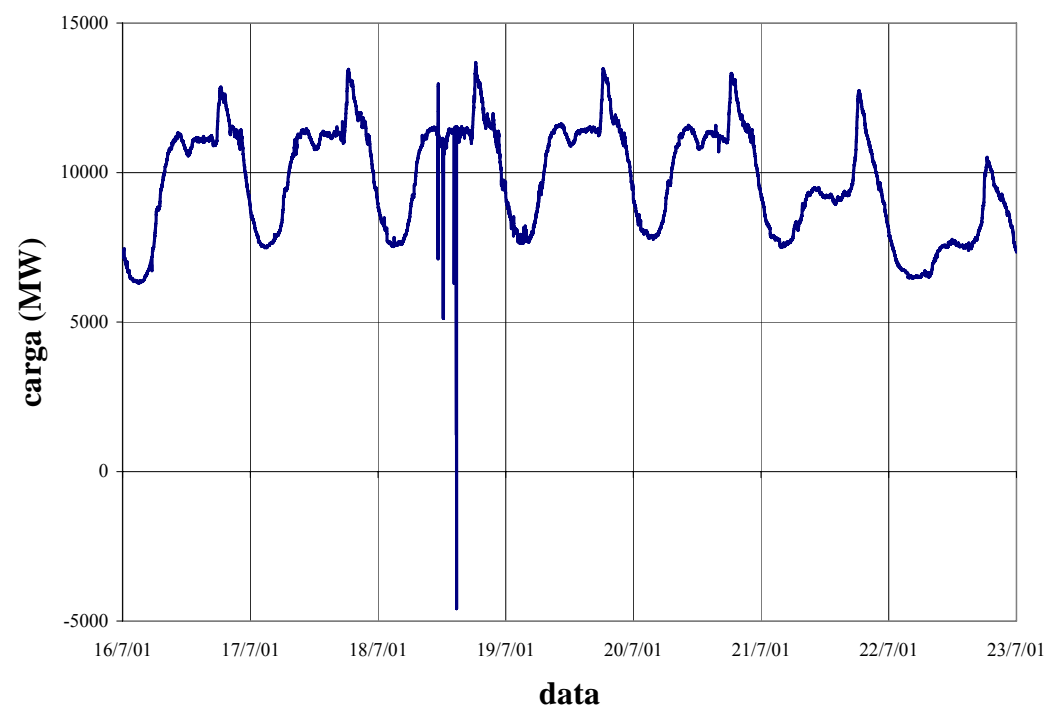

Figura 3-6 - Carga do estado de São Paulo de 16 a 22 de julho de 2001

A curva de carga observada possui uma amostragem de 1 minuto.

Pode-se verificar que apenas a curva do dia 18 possui medições visivelmente com problemas. Os demais possuem apenas um ruído de pequena amplitude.

Ao aplicar a TDF às curvas de carga dos dias 18 e 19 têm-se os espectros observados na Figura 3-7 e Figura 3-8.

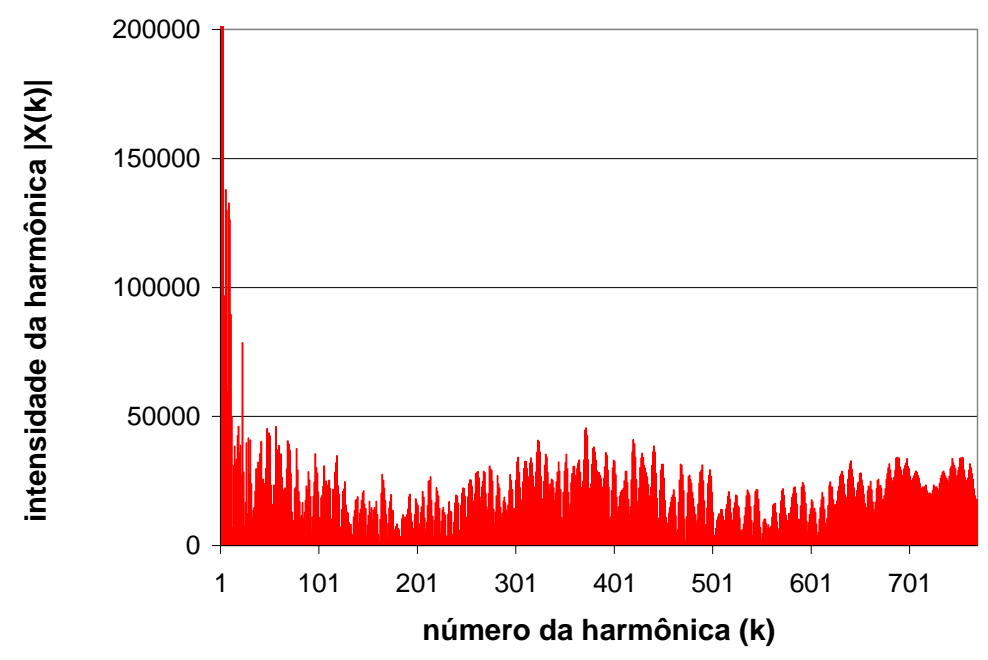

Figura 3-7 - Espectro da curva de carga do dia 18 de julho 


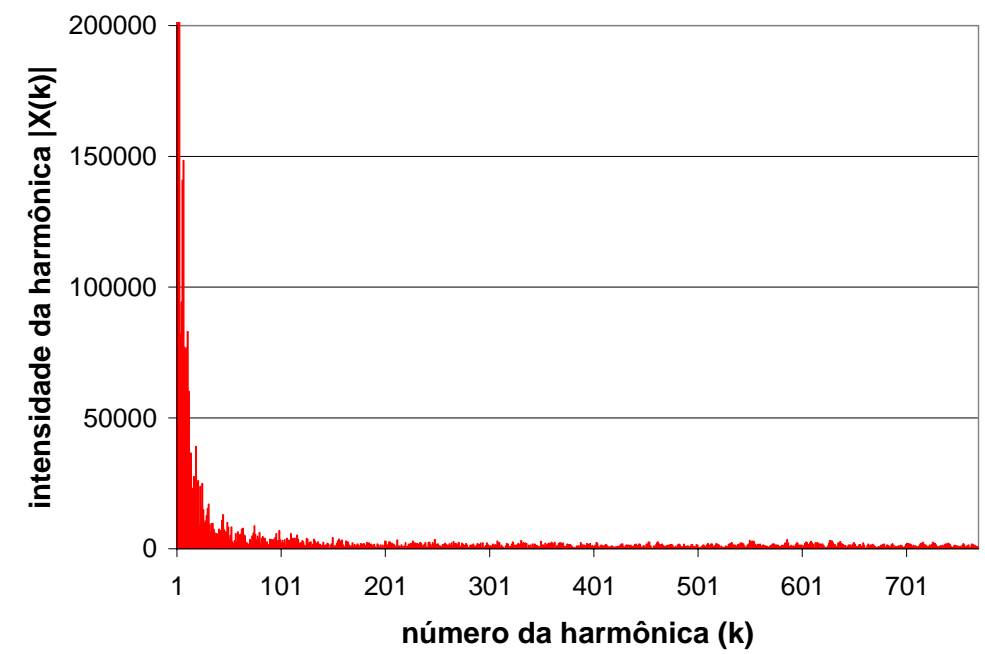

Figura 3-8 - Espectro da curva de carga do dia 19 de julho

Para executar a filtragem do sinal deve-se eliminar parte das harmônicas ou reduzir a sua intensidade. O problema consiste em determinar quais harmônicas eliminar ou reduzir de modo a filtrar o sinal evitando a perda de informação na curva. Ao eliminar harmônicas, reduz-se a quantidade de informação que precisa ser armazenada em cada curva permitindo assim a compactação da informação.

As curvas de carga diárias sendo analisadas possuem 1440 pontos (amostragem de 1 minuto). Ao executar a TDF, passa-se a ter 1440 valores complexos (componentes de Fourier). Além da componente 0, temos que o restante do espectro é simétrico de modo que só precisa-se armazenar 770 números complexos ou 1440 valores. Ao eliminar harmônicas, reduz-se o número de valores necessários para representar a curva conforme visto na Tabela 3-3.

Tabela 3-3 - Compactação de curvas via FFT

\begin{tabular}{|c|c|}
\hline Harmônicas mantidas & Pontos armazenados \\
\hline 10 & 21 \\
\hline 30 & 61 \\
\hline 50 & 101 \\
\hline 100 & 201 \\
\hline 200 & 401 \\
\hline
\end{tabular}


A fim de se determinar o número de harmônicas a ser mantido, executou-se uma série de filtragens variando o número de harmônicas mantido. Nas Figura 3-9, Figura 3-10, Figura 3-11 e Figura 3-12 vê-se alguns dos resultados obtidos.

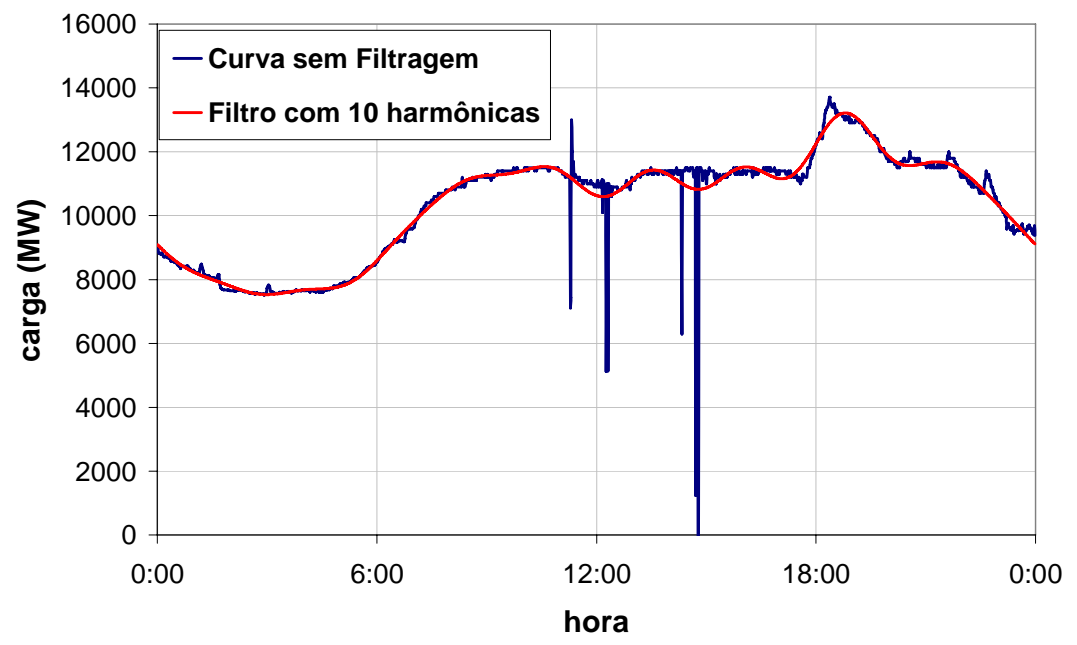

Figura 3-9 - Filtragem FFT mantidas 10 harmônicas

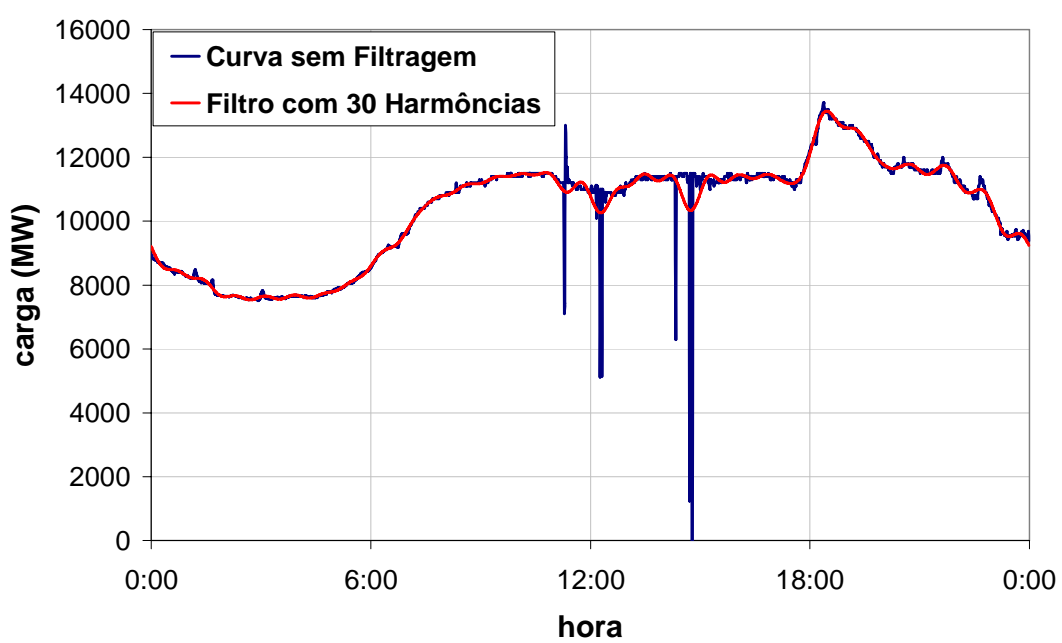

Figura 3-10 - Filtragem FFT mantidas 30 harmônicas 


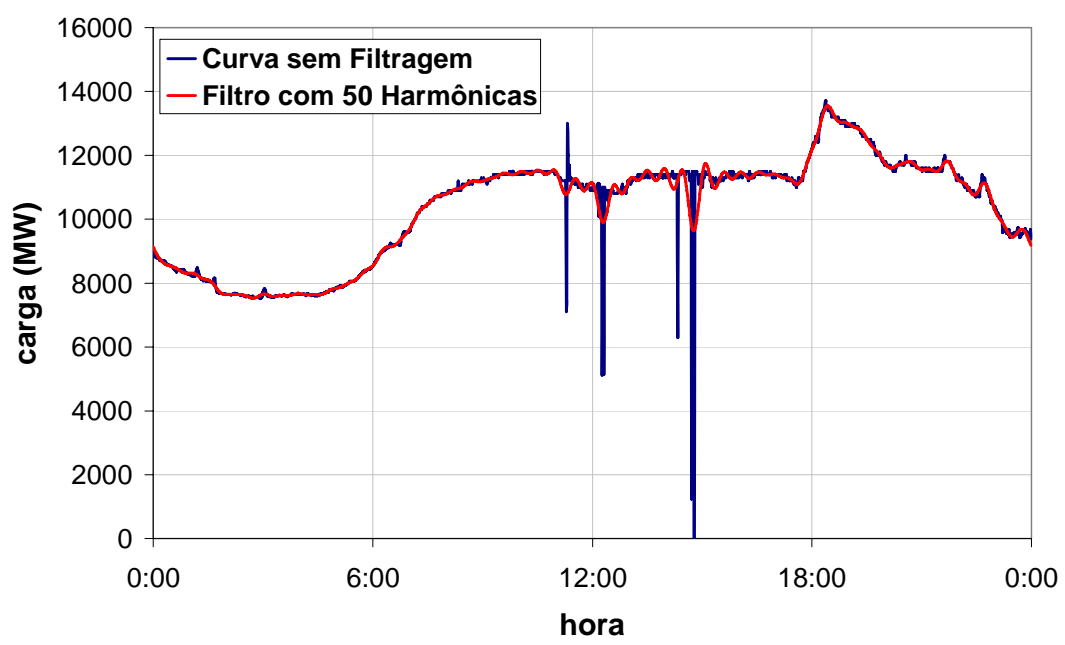

Figura 3-11 - Filtragem FFT mantidas 50 harmônicas

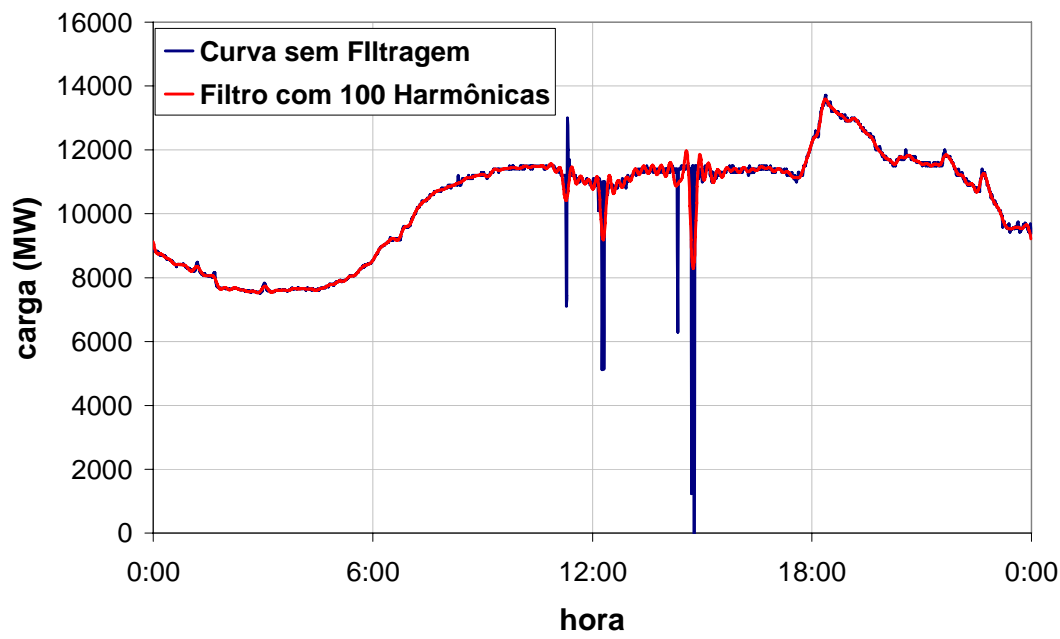

Figura 3-12 - Filtragem FFT mantidas 100 harmônicas

Pode-se observar que a aplicação da filtragem por FFT elimina a maior parte dos problemas de medição de pequena intensidade, mas acaba gerando deformações nas curvas nas proximidades de grandes erros.

Como o processo de filtragem de dados corrompidos nos permite reduzir os pontos da curva de carga diária para 96 valores sem deformação ou perda de informação significativa na grande maioria das curvas, para que o processo por TDF seja mais vantajoso, devem-se reduzir a curva no máximo a 96 valores ou 47 harmônicas. 
Na Figura 3-13 pode-se observar a comparação entre diversas filtragens de uma curva de carga.

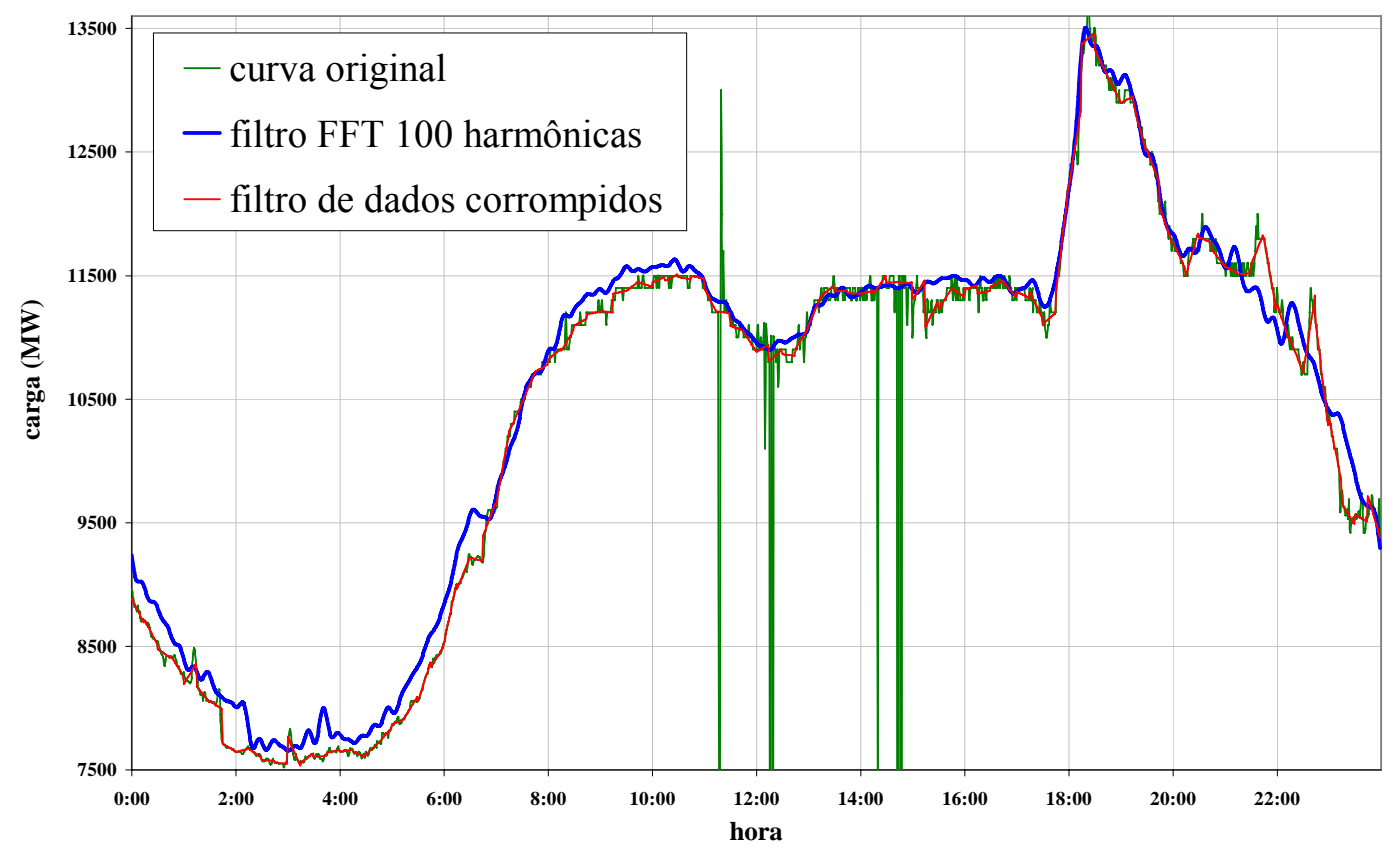

Figura 3-13 - Comparação entre processos de filtragem através de FFT

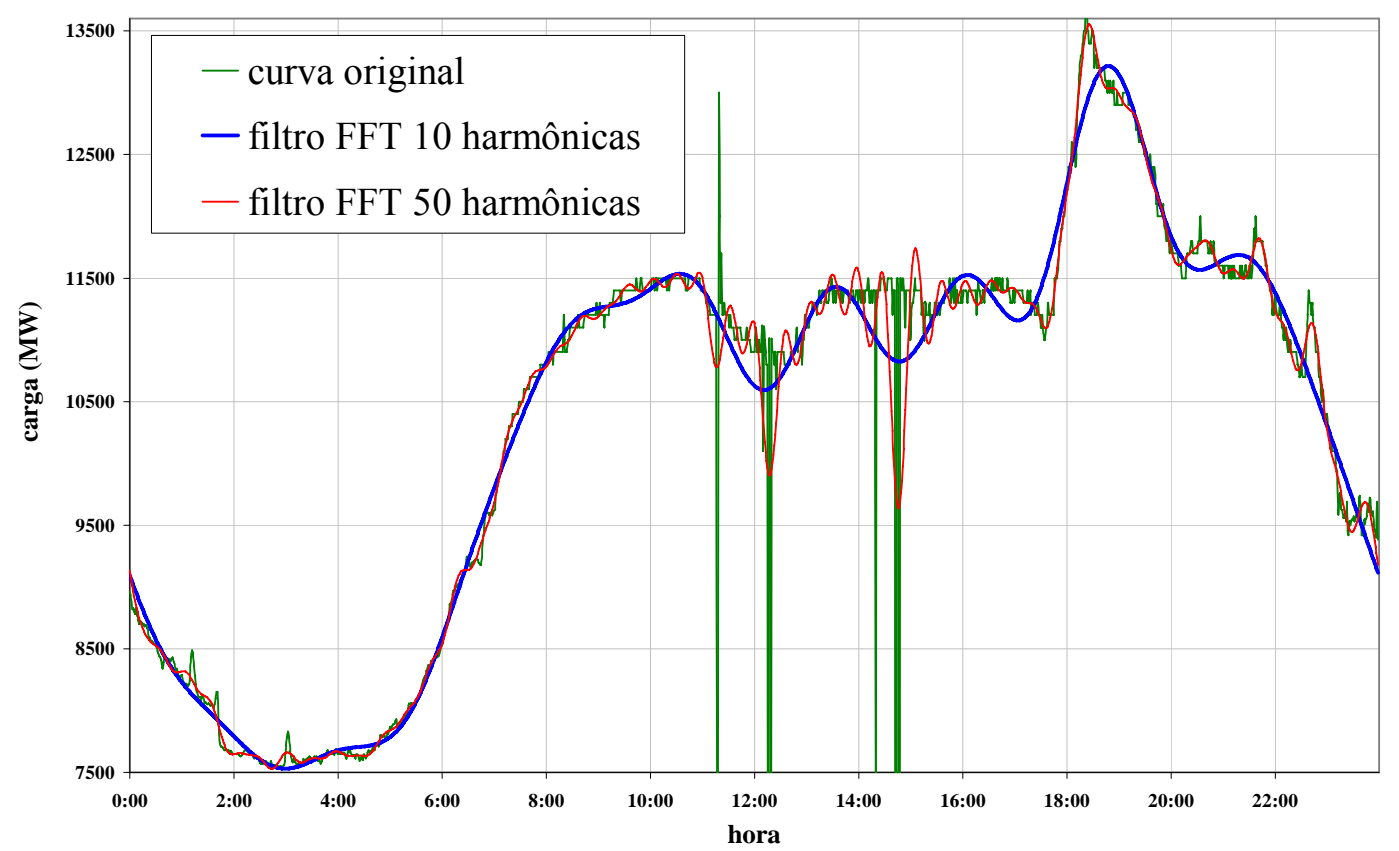

Figura 3-14 - Comparação entre processos de filtragem através de FFT 
Tem-se que o uso da TDF a ponto de reduzir satisfatoriamente o número de pontos da curva ( $<50$ harmônicas), a deforma consideravelmente.

Assim temos que o processo de filtragem com a TDF além de matematicamente e computacionalmente mais complexo, não fornece resultados tão bons quanto à eliminação de dados corrompidos nos casos em estudo. 


\subsubsection{Filtragem por Transformada Wavelet}

\subsubsection{Transformada Wavelet}

As Wavelets foram mencionadas pela primeira vez em 1909 por A. Haar, mas apenas após 1930, diversos grupos de pesquisa, trabalhando independentemente, desenvolveram plenamente suas bases matemáticas.

Enquanto a análise de Fourier se utiliza de funções senoidais para representar um sinal, as Wavelets decompõe um sinal em componentes de freqüência e escalas diferentes utilizando-se de funções variadas e não apenas senóides.

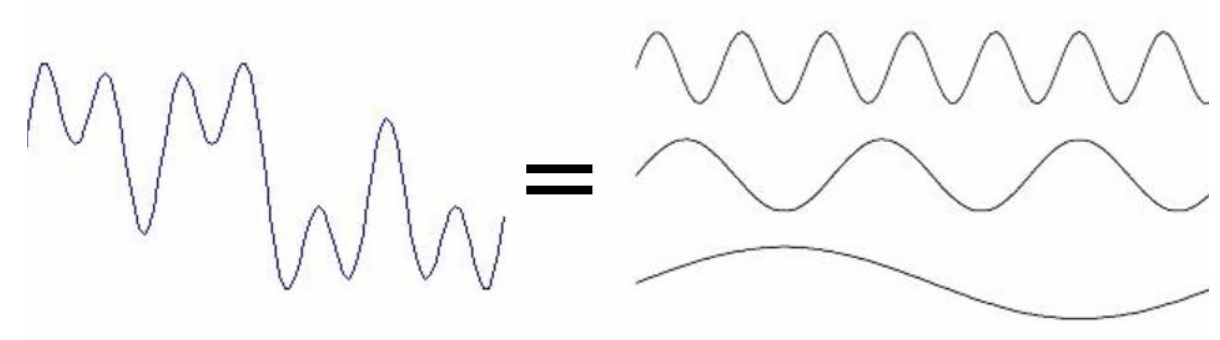

Figura 3-15 - Transformada de Fourier

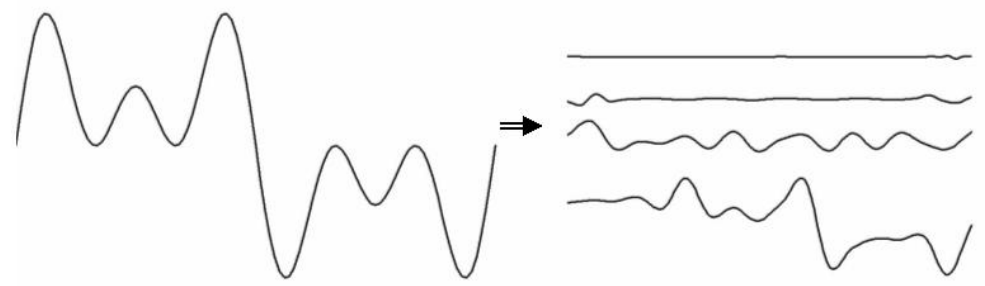

Figura 3-16 - Transformada Wavelet 
As funções de decomposição são chamadas de Wavelet, Wavelet Mãe ou Wavelet analisadora. As funções Wavelet são agrupadas em famílias, algumas das quais podemos observar na Tabela 3-4.

Tabela 3-4 - Descrição de algumas famílias de Wavelets

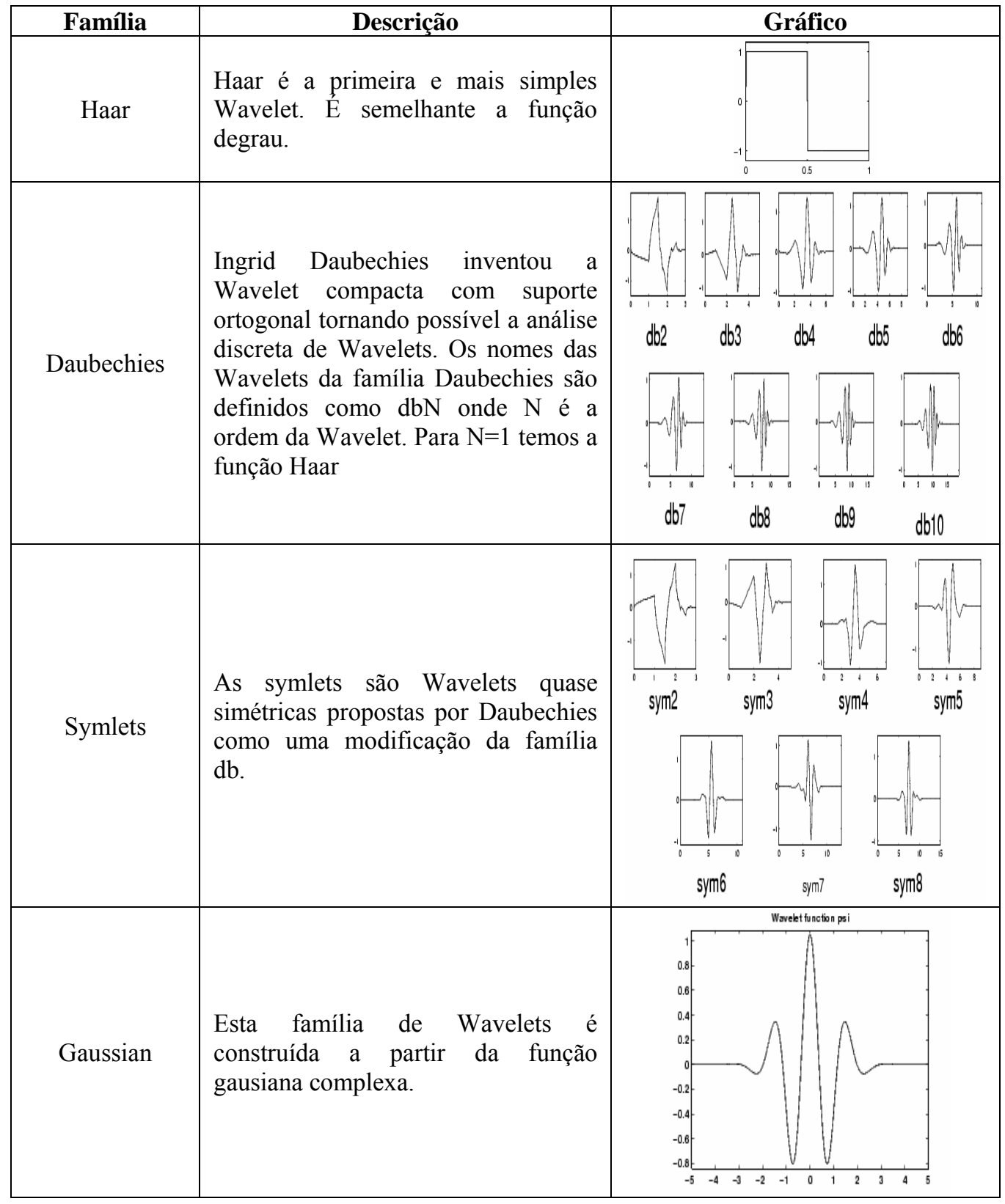


As aplicações da transformada Wavelet são das mais variadas como, por exemplo, visão computacional, compressão de dados, filtragem de ruídos, identificação de padrões, etc.

O uso da transformada Wavelet para filtragem de dados para previsão de carga foi apresentado por Swee [82] em 1999 identificando o processo como de grande potencial.

\subsubsection{Filtragem de Sinais com Wavelets}

Em 1988, Mallat desenvolveu um algoritmo de transformada discreta Wavelet - DWT (Discrete Wavelet Transform ) que permite decompor e recompor um sinal em duas componentes. Uma das componentes corresponde as altas freqüências do sinal ou aos detalhes em menor escala do sinal e o outro as baixas freqüências ou o sinal sem os detalhes. Aplicando-se o processo sucessivamente, pode-se filtrar cada vez mais o sinal.

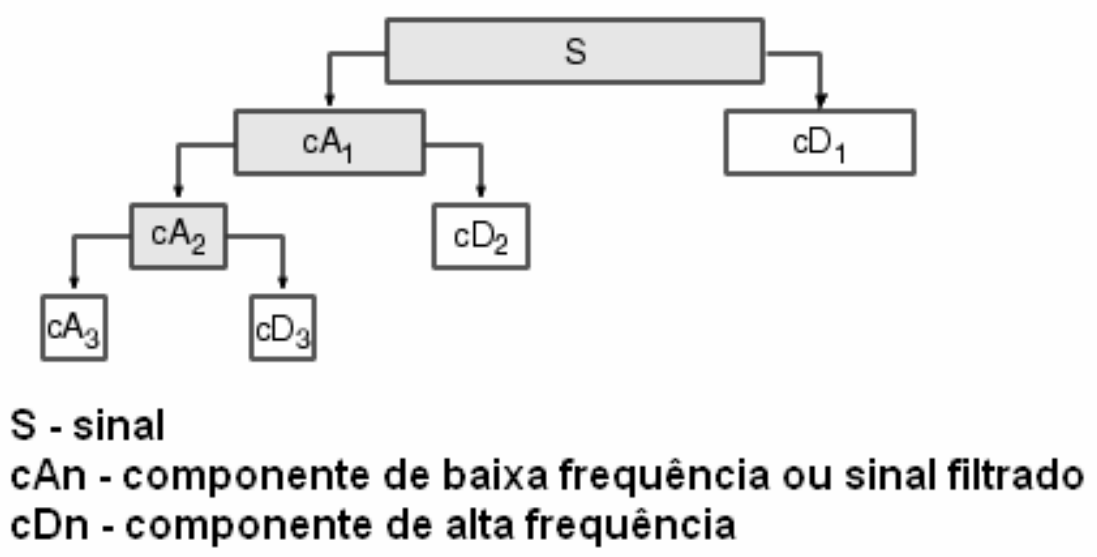

Figura 3-17 - Filtragem de sinal com Wavelet

A filtragem do sinal pode ser repetida até $\log _{2} N$ vezes, onde $\mathrm{N}$ é o número de amostras do sinal sendo filtrado. Cada filtragem gera um 
conjunto de coeficientes, similares aos coeficientes de Fourier, e a cada filtragem o número de coeficientes diminui.

$\mathrm{Na}$ Figura 3-18 nota-se o sinal original $S$, o sinal após cinco decomposições $\left(a_{5}\right)$ e as varias etapas de decomposição $\left(d_{1}, d_{2}, d_{3}, d_{4}\right.$, $d_{5}$ ). O sinal pode ser reconstituído com os valores de $a_{5}$ e $d_{i}$. Eliminando valores de $d_{i}$ ao reconstituir o sinal constitui uma filtragem.

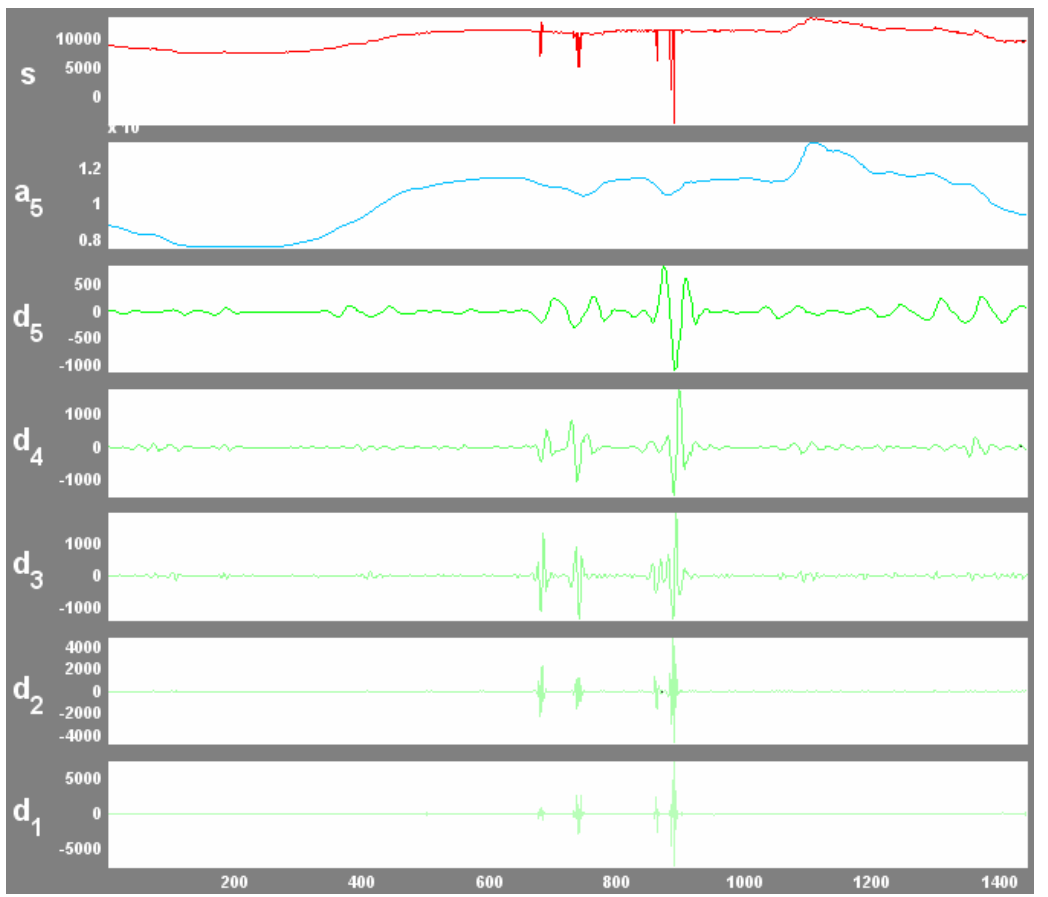

Figura 3-18 - Filtragem com Wavelets através do MATLAB

Na Figura 3-19 tem-se o exemplo da filtragem através da técnica convencional e com a transformada Wavelet utilizando o $d b 4$ com 6 níveis de filtragem, onde as componentes $d_{1, . .} d_{5}$ foram completamente eliminadas. 


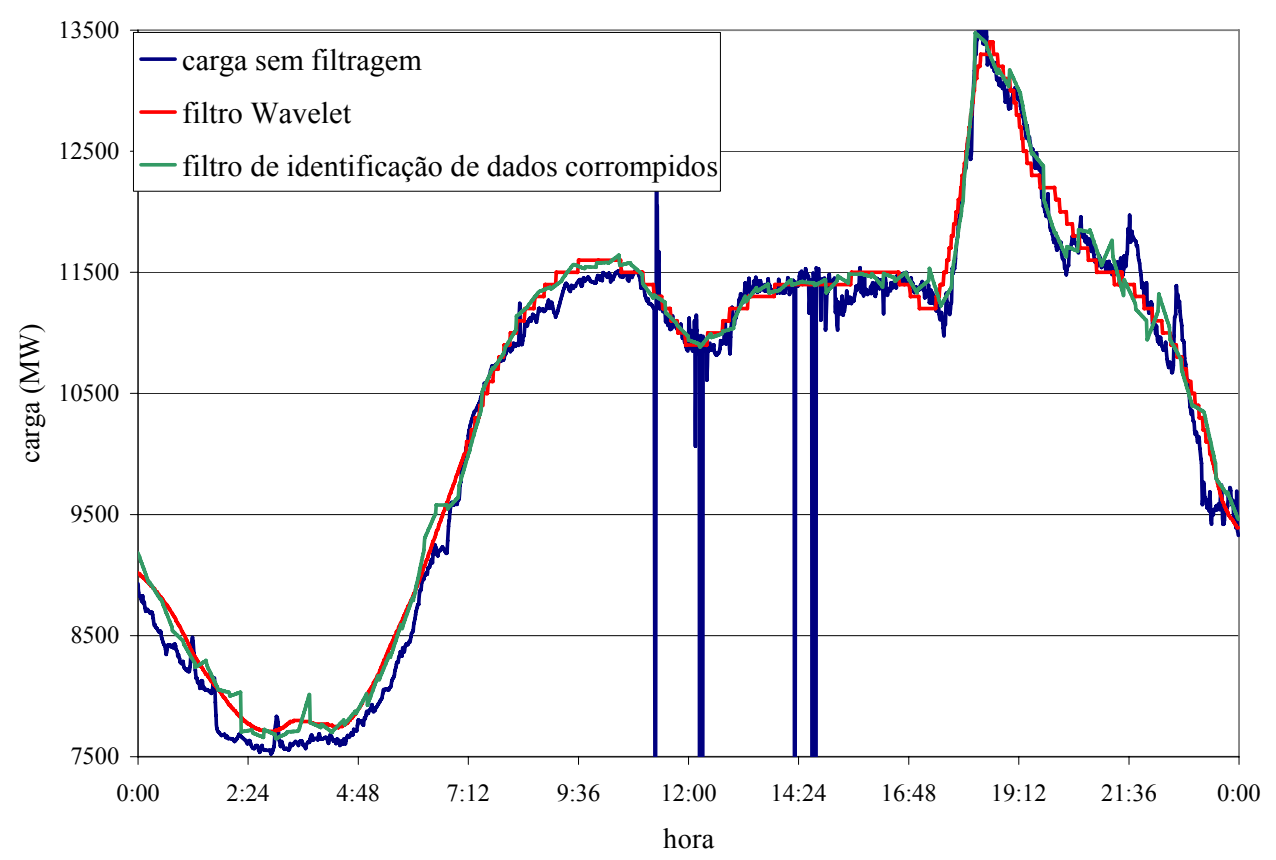

Figura 3-19 - Comparação com filtragem Wavelet e com filtro de dados corrompidos

Como na transformada de Fourier, ao invés de se armazenar a curva filtrada, pode-se armazenar os coeficientes da transformada Wavelet. No exemplo utilizado, uma curva com 1440 pontos, filtrada com $d b 4$, eliminando-se as componentes $d_{1}$ a $d_{5}$, se reduz a 29 coeficientes. Assim tem-se que a transformada Wavelet além de permitir a filtragem dos dados, permite a sua compactação. 


\subsection{Variáveis Exógenas}

Uma série de efeitos externos ao sistema elétrico tais como fatores climáticos, econômicos e sociais afetam diretamente o padrão de consumo causando alterações nas curvas de carga. Com a finalidade de se realizar uma previsão de carga mais precisa, esses fatores devem ser identificados e a sua relevância analisada.

A análise bibliográfica identifica os fatores climáticos, e especialmente a temperatura ambiente, como os mais influentes na previsão da carga.

Em 1998, Wen [1] já indicava a necessidade da temperatura ambiente como variável em um modelo estocástico para a previsão da carga.

Em 1992 a necessidade do uso de variáveis climáticas em redes neurais estava identificada por Peng [2] e Ho [3].

Chow [7] e Feng [9] mostram que sistemas de previsão com variáveis climáticas possuem menor erro de previsão.

\subsubsection{Medições de Temperatura Ambiente}

Sendo reconhecidamente um dos fatores externos com maior influência sobre a carga, é preciso analisar o efeito da temperatura ambiente em um sistema de previsão de curvas de carga.

A obtenção de um histórico de medições e de previsões de temperatura é simples, pois hoje em dia uma série de empresas de meteorologia dispõe de históricos de vários anos e para todo o país. Os serviços de previsão podem fornecer a previsão confiável da temperatura ambiente com uma antecedência de até três dias.

Como os históricos de temperatura compreendem curvas diárias que podem ter amostragens que vão de minutos a horas, dispõe-se de uma grande quantidade de informação. Ao se realizar testes de previsão de carga por métodos de IA, vemos que ao invés de utilizar toda a curva de temperaturas 
de um dia, pode-se obter resultados muito bons utilizando apenas a temperatura máxima, mínima e/ou média.

A relação da temperatura com o consumo não é totalmente linear, mas pode ser identificada analisando-se a energia diária em função da temperatura. A análise dos dados mostrou que uma relação quadrática fornece o melhor ajuste das curvas, conforme observado nas Figura 3-20, Figura 3-21, Figura 3-22 e Figura 3-23. As covariâncias $\left(R^{2}\right)$ de cada curva estão indicadas.

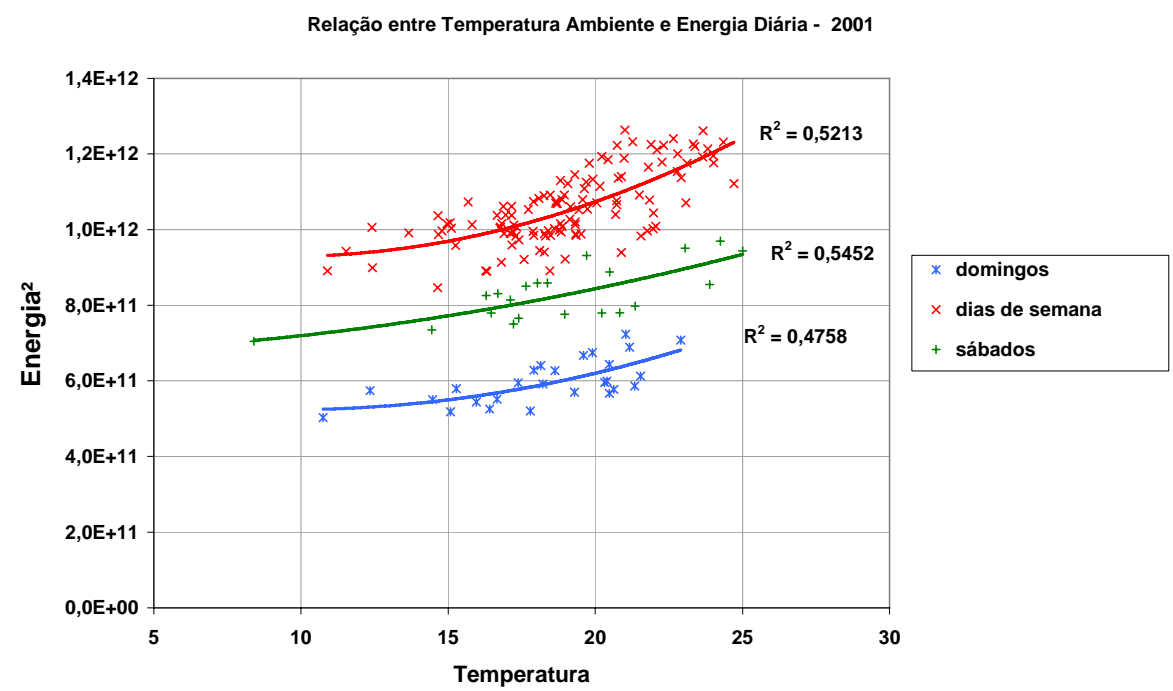

Figura 3-20 - Relação entre Energia Diária e Temperatura Ambiente - 2001

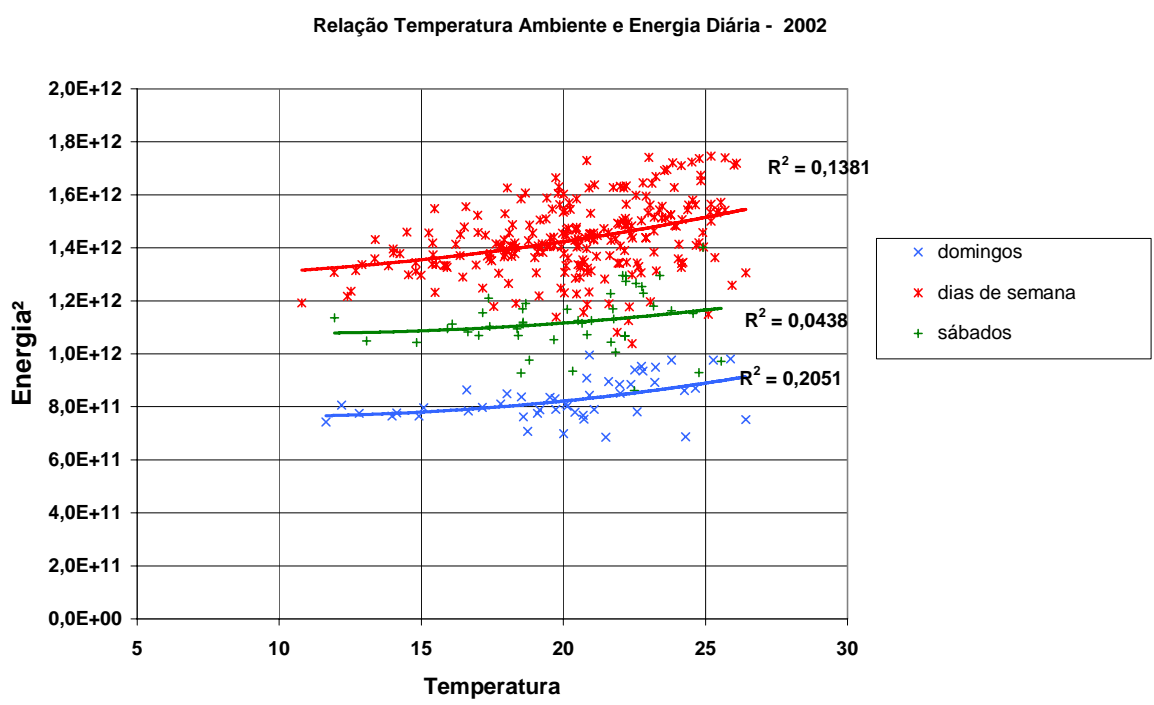

Figura 3-21 - Relação entre Energia Diária e Temperatura Ambiente - 2002 
Relação Temperatura Ambiente e Energia Diária - 2003

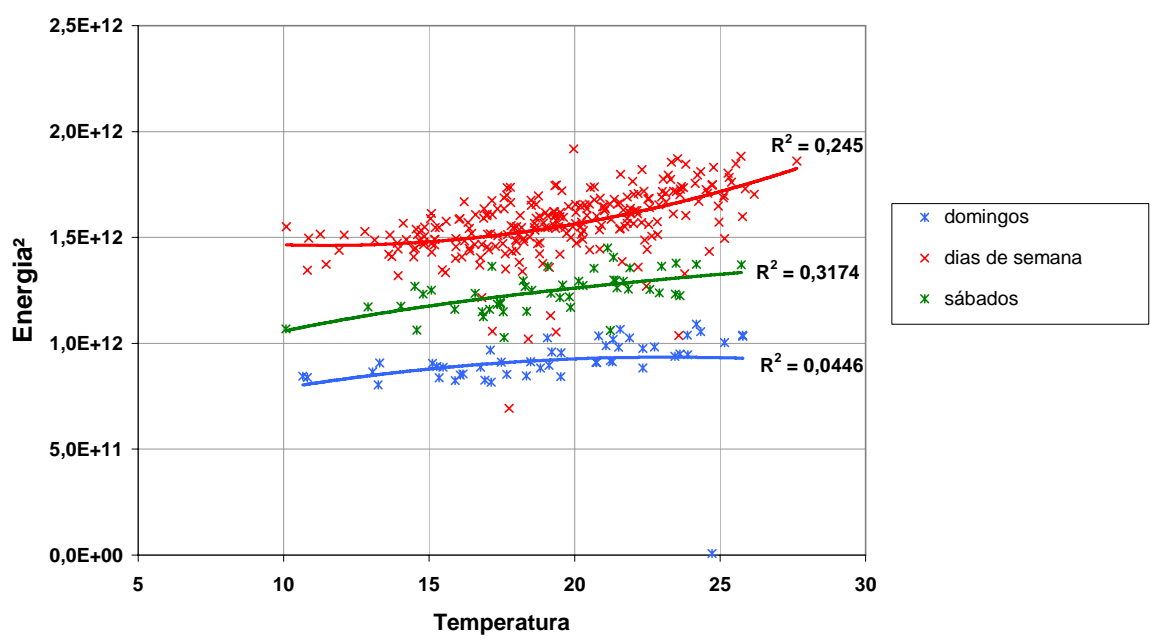

Figura 3-22 - Relação entre Energia Diária e Temperatura Ambiente - 2003

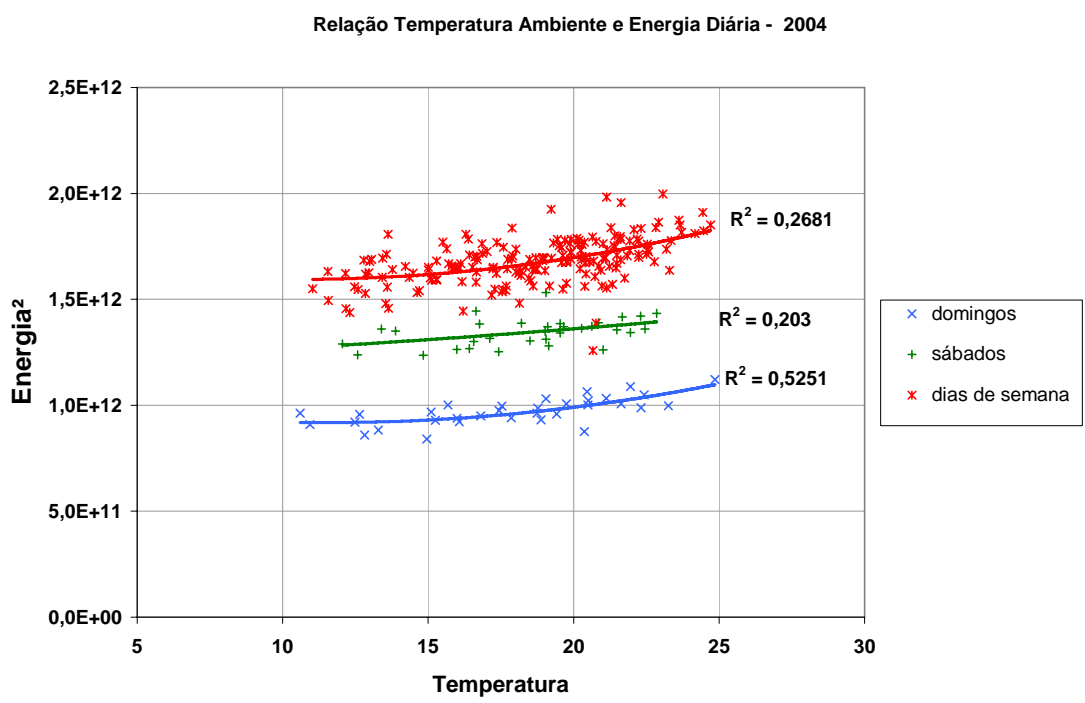

Figura 3-23 - Relação entre Energia Diária e Temperatura Ambiente - 2004 


\subsubsection{Outras Variáveis Exógenas}

Diversas outras grandezas exógenas têm efeito sobre o consumo de energia elétrica. Entre elas temos:

- Insolação (número de horas de brilho solar direto);

- Pluviosidade (presença ou ausência de chuvas no período);

- Nebulosidade (dias nublados e parcialmente nublados);

- Hora do pôr-do-sol;

- $\quad$ PIB (previsão de longo prazo);

- Etc.

A quantidade de trabalhos utilizando variáveis além da temperatura ambiente não é grande para a previsão de curto prazo.

Chow [7] apresenta uma rede neural que utiliza além da temperatura ambiente, a umidade relativa, chuva e nebulosidade. Taylor [11] utiliza além da temperatura, iluminação e efeito do vento. Lima [17] se utiliza de temperatura ambiente máxima, insolação, nebulosidade e hora do pôr-dosol. 


\subsubsection{Dias anômalos}

Fatores sociais como feriados e 'pontes' afetam significativamente a curva de carga e precisam ser levados em conta nos modelos de previsão. O efeito de um feriado pode ser observado na Figura 3-24, onde a curva indicada em vermelho, o feriado, apresenta uma padrão diferente do esperado.

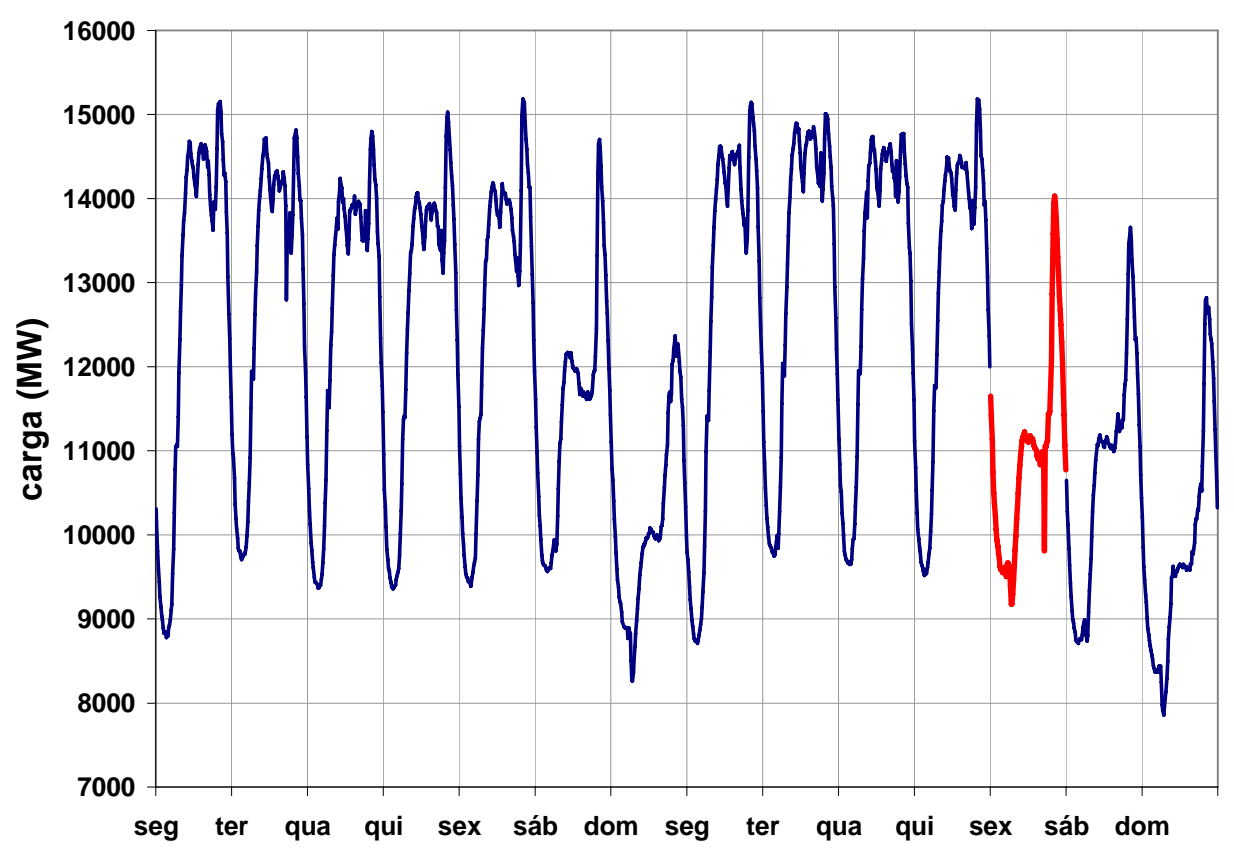

Figura 3-24 - Efeito de feriado na curva de carga

Alguns eventos específicos como jogos de copa do mundo e finais novelas também possuem efeitos restritos a algumas horas mas significativos na carga do sistema. Na Figura 3-25 observa-se a curva de carga dos dias 19/6, $26 / 6$ e $3 / 7$ de 2002 . No dia 26 houve a semi-final da copa do mundo as $8 \mathrm{~h} 30$ com jogo do Brasil. O efeito na curva de carga é localizado mas significativo. 


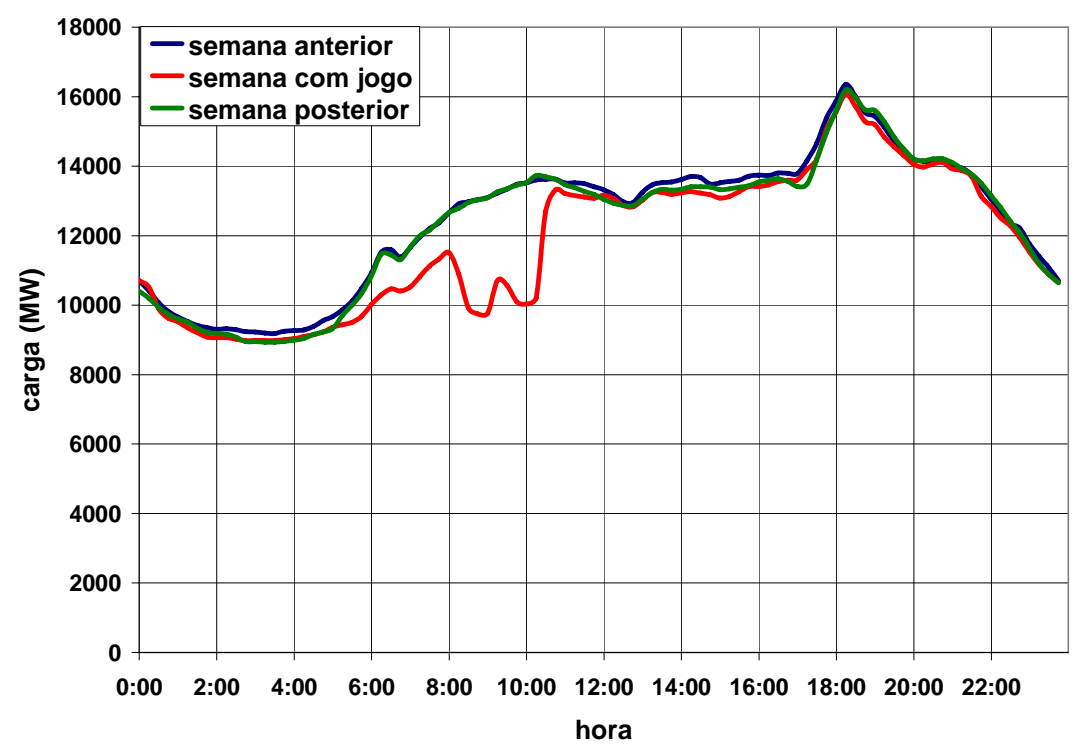

Figura 3-25 - Curva de carga durante jogo da copa do mundo

Apesar do efeito significativo nas curvas de carga, esses eventos são esporádicos e difíceis de serem incorporados a algum modelo de previsão. Lamedica [6] apresenta uma análise da dificuldade da previsão da carga em dias anômalos comparando diversos métodos.

\subsection{Análise de Padrões nos Dados de Carga}

Os métodos de previsão de carga procuram encontrar ou aprender o padrão complexo e não-linear do comportamento da curva de carga. Desse modo, é conveniente uma análise nos dados de carga a fim de verificar se padrões de comportamento são identificáveis e agrupáveis a fim de facilitar o trabalho do sistema de previsão.

Podem-se observar algumas curvas de carga do estado de São Paulo em diversos intervalos de tempo. A Figura 3-26 com 1 ano, a Figura 3-27 com 1 mês e a Figura 3-28 com as segundas-feiras de 1 ano. 


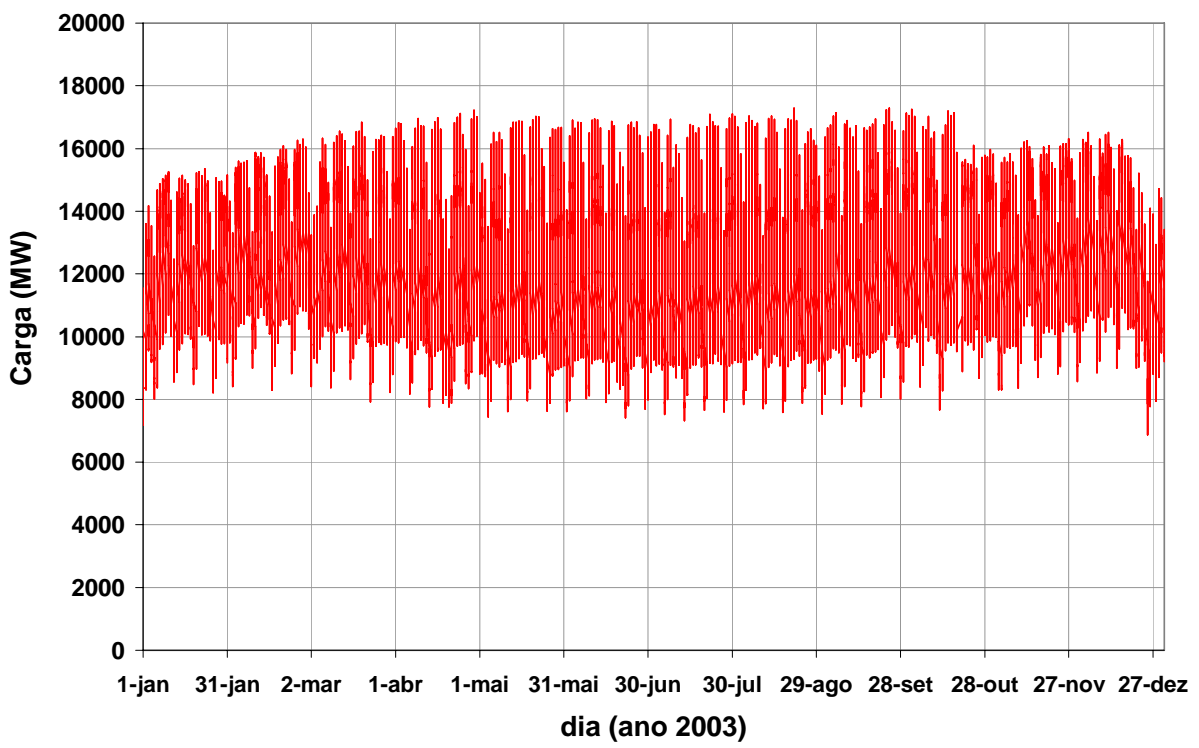

Figura 3-26 - Curva de carga de São Paulo para 2003

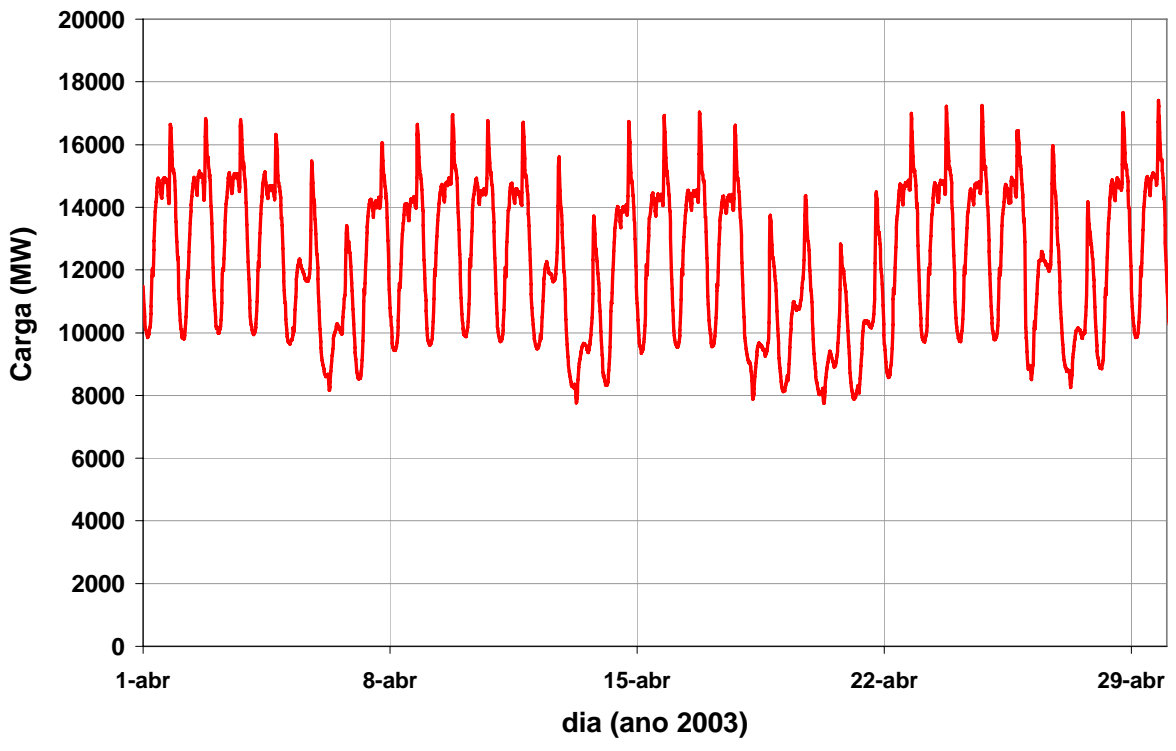

Figura 3-27 - Curva de carga de São Paulo em Abril de 2003 


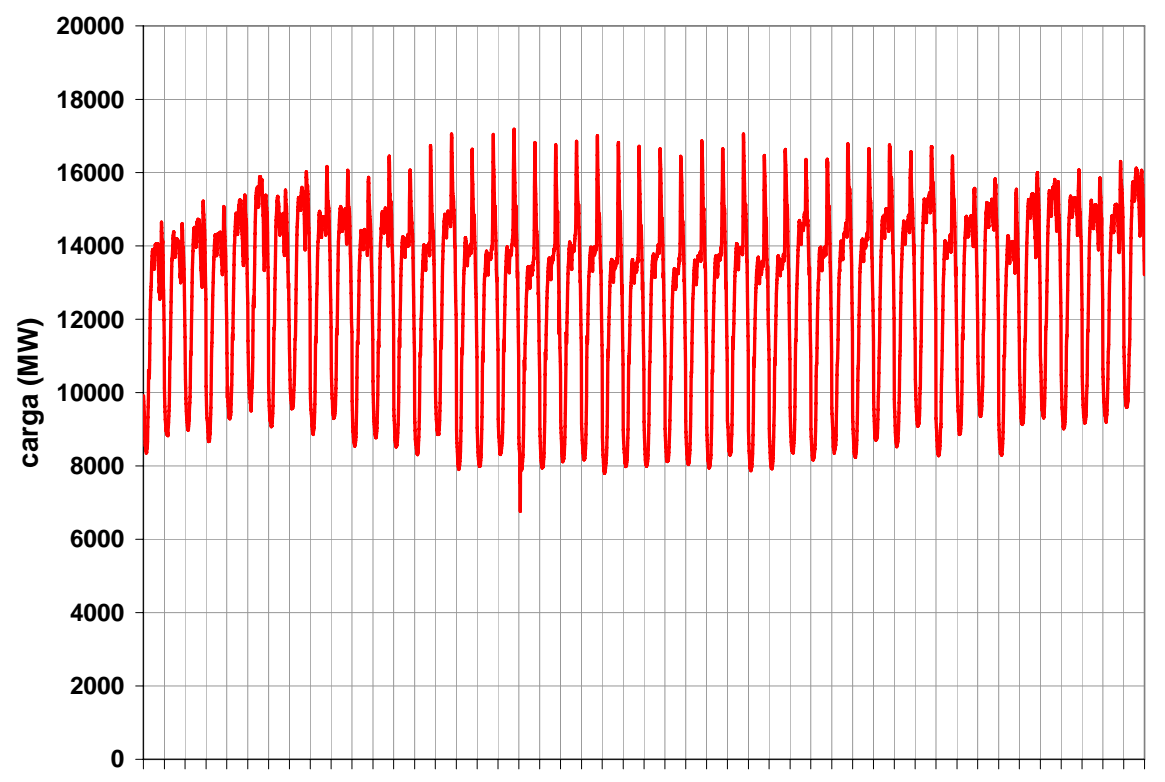

Figura 3-28 - Curva de carga de segundas-feiras de 2003

A análise de todas as curvas de carga do período 2001 a 2004 revela alguns fatos importantes relativo ao comportamento da carga no estado de São Paulo:

- Os dias de semana possuem curvas semelhantes;

- Sábados são semelhantes;

- Domingos são semelhantes;

- Dias da semana com feriados ou pontes possuem curvas diferentes do dia da semana em que caem;

- Feriados se assemelham aos Domingos;

- Há um padrão cíclico das curvas de cada dia da semana ao longo do ano.

Além da análise visual dos padrões das curvas de carga, pode-se utilizar técnicas como a clusterização de dados a fim de tentar agrupar as curvas de carga. A clusterização é um processo de agrupamento de dados em classes similares segundo algum critério definido. 
A utilização do algoritmo de clusterização "da montanha" [29] permitiu observar grupos distintos para cada dia da semana e que os perfis dos domingos, segundas e sábados são similares ao longo do ano, mas os demais dias possuam uma variação. Variações nos parâmetros da clusterização fornecem resultados similares indicando a possibilidade de agrupar cada dia da semana separadamente.

Essa informação é relevante por indicar o uso de sistemas de previsão independentes para dias com curvas semelhantes. 


\section{Previsão da Carga através de Inteligência Artificial}

Entre as diversas técnicas de inteligência artificial disponíveis, as mais difundidas para o uso na previsão de carga são as redes neurais e a lógica Fuzzy.

Este capítulo apresenta as bases das redes neurais e da lógica fuzzy para sua aplicação na previsão da carga.

\subsection{Lógica Fuzzy}

Ao observar o mundo real, vê-se que ele está cheio de imprecisões e incertezas. Isso não é um problema para as pessoas, pois a mente humana possui uma grande capacidade de resumir informações e focar nas que são necessárias para a solução de um problema. Assim, as pessoas possuem uma tolerância à imprecisão, incerteza e verdade parcial que permite atingir tratabilidade, robustez e eficiência na solução de problemas.

Por outro lado, as teorias matemáticas que modelam sistemas como, por exemplo, a teoria de controle, são extremamente precisas e não toleram incertezas.

A fim de aproximar o mundo teórico do real, permitindo o tratamento da imprecisão, incerteza e a linguagem humana na matemática, foi desenvolvida uma teoria chamada de lógica nebulosa ou lógica Fuzzy.

A lógica fuzzy foi criada em 1965 por Lofti Zadeh e aplicada em problemas do controle de motores onde as teorias convencionais de controle apresentavam dificuldades. Sua simplicidade frente às teorias convencionais fez com que fosse muito criticada no início, mas sua grande capacidade de resolver problemas de aplicações práticas acabou difundindo seu uso.

A palavra Fuzzy (confuso, vago, indistinto) passa erroneamente uma idéia incorreta de algo incerto, confuso e portanto não confiável. Ainda hoje, apesar de muito estudada e difundida, a lógica fuzzy ainda é discriminada devido ao nome. 


\subsubsection{Conceitos Básicos}

A lógica nebulosa ou lógica Fuzzy é uma lógica de valores múltiplos sendo que hoje em dia o termo é usado como sinônimo para a teoria dos conjuntos nebulosos.

Diferente da lógica convencional que trabalha apenas com sim e não, 0 e 1 , verdadeiro ou falso, a lógica fuzzy aceita conceitos como quase-verdadeiro, nem sim nem não, etc.

Um conjunto clássico define seus elementos através de regras claras que não deixam dúvidas sobre seus componentes. Podemos, por exemplo, definir o conjunto dos dias da semana $S=\{$ segunda,terça, quarta,quinta,sexta $\}$.

Já em um conjunto fuzzy (Fuzzy Set), qualquer elemento pertence ao conjunto com um grau de pertinência que vai de 0 (não pertence completamente) até 1 (pertence completamente).

Um exemplo clássico de um conjunto fuzzy é o conjunto das pessoas altas. Definimos, por exemplo, como alto alguém com mais de 1,8m. Mas com isso, uma pessoa com $1,79 \mathrm{~m}$ seria considerada baixa. Com o uso de um conjunto fuzzy, podemos definir uma função que indica o quanto uma pessoa pertence ao conjunto das pessoas altas, conforme visto na Figura 4-1.

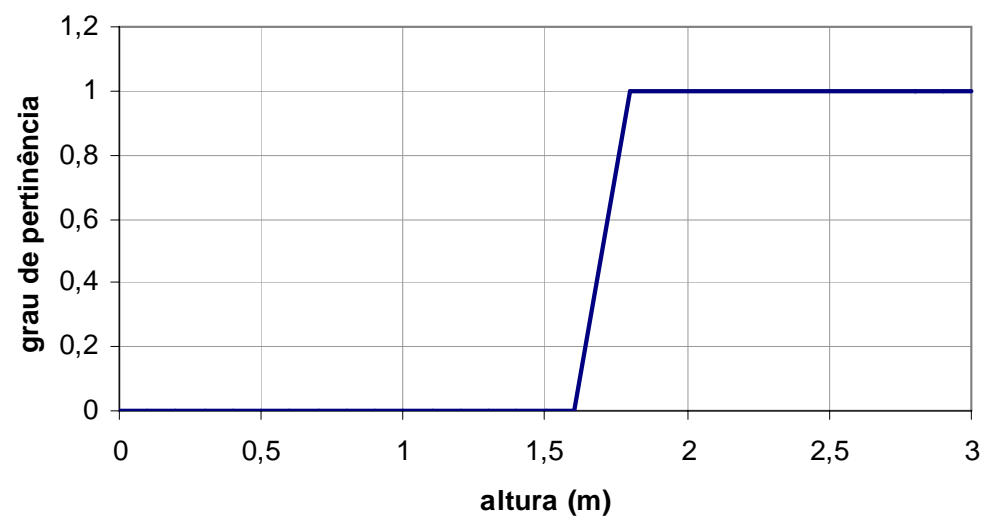

Figura 4-1 - Exemplo de conjunto fuzzy 
Assim, uma pessoa com 1,79 m não é nem alta nem baixa, mas sim alta com uma pertinência de 95\%. Na lógica fuzzy não temos verdadeiro ou falso, mas graus de verdade ou pertinência.

A curva que relaciona uma variável com o seu grau de pertinência ao conjunto fuzzy é chamada de função de pertinência (membership function). Entre as muitas funções usadas temos as curvas de Gauss, funções triangulares, trapezoidais, etc.

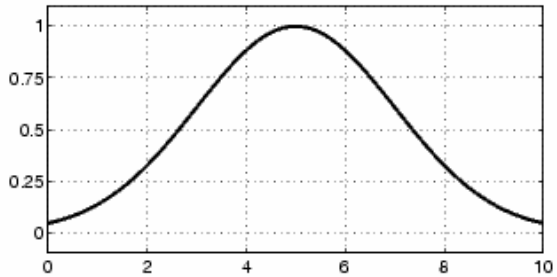

Figura 4-2 - Função de pertinência Gausiana

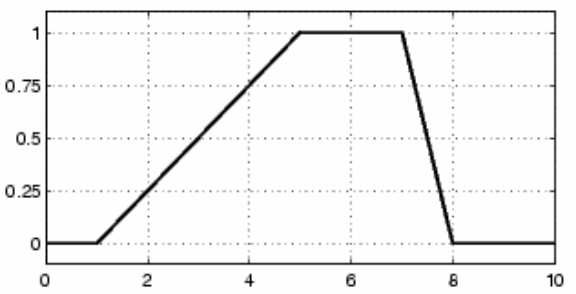

Figura 4-3 - Função de pertinência Trapezoidal

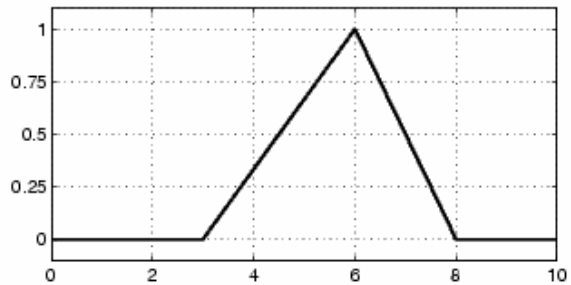

Figura 4-4 - Função de pertinência Triangular

Os teoremas, definições, etc. que formam a teoria dos conjuntos nebulosos são amplamente discutidos na literatura [42]. 


\subsubsection{Sistema de inferência fuzzy}

A aplicação direta da lógica fuzzy pode ser vista nos sistemas de inferência fuzzy. Um sistema de inferência permite mapear um conjunto de entradas em um conjunto de saídas funcionando assim como um interpolador.

Foi demonstrado [19] que um sistema fuzzy pode funcionar como um interpolador universal capaz de aproximar qualquer função real com a exatidão desejada.Um dos primeiros e mais simples sistemas de inferência foi desenvolvido por Mandani em 1975.

Um sistema de inferência fuzzy trabalha com um conjunto de regras do tipo:

\section{SE antecedente ENTÃO conseqüência}

E executa as seguintes etapas:

- 'Fuzzifica' as entradas: converte a informação de entrada em informação para lógica fuzzy através das funções de pertinência;

- Calcula os antecedentes das regras: agrega as entradas fuzzificadas, normalmente através de lógica fuzzy AND ou OR;

- Calcula as conseqüências das regras: calcula a resposta de uma regra a um conjunto de entradas;

- Agregar os resultados das regras: combina através de teoria fuzzy as saídas de cada regra a fim de obter um resultado global;

- 'Defuzzifica' a solução: converte a saída Fuzzy em um escala adequada.

Um diagrama de sistema de inferência pode ser visto na Figura 4-5 


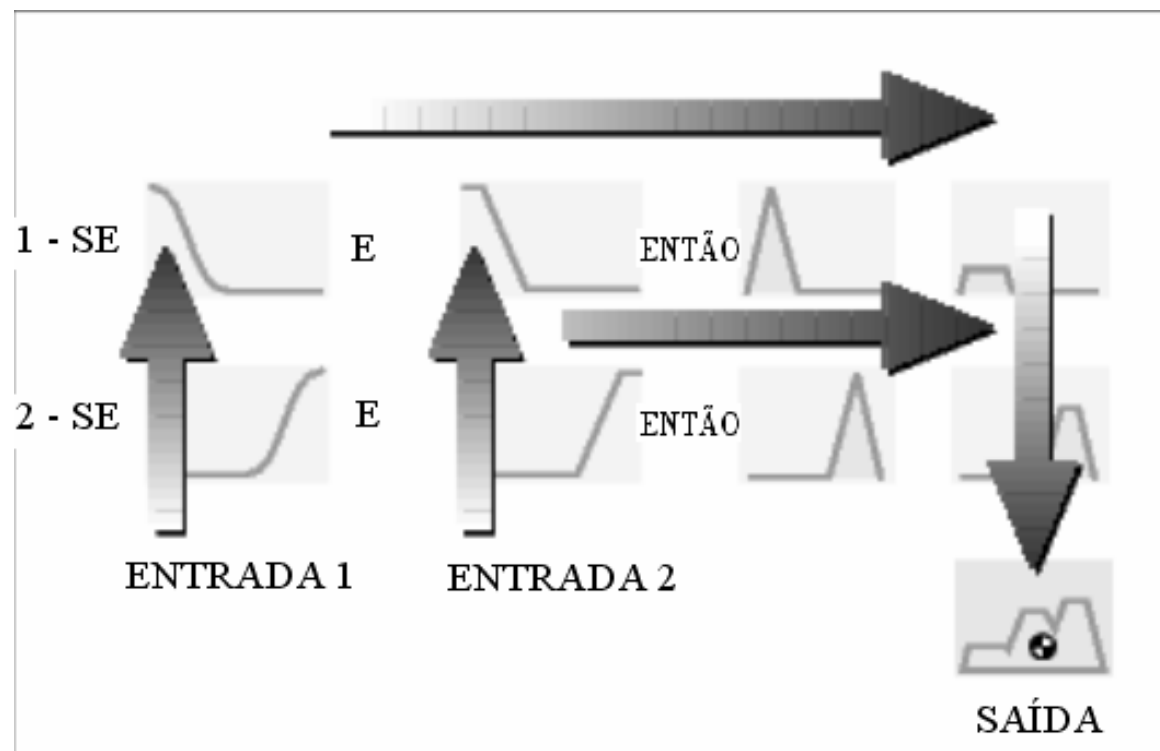

Figura 4-5 - Sistema de Inferência Fuzzy

Um exemplo simples de sistema de inferência é um sistema para cálculo da gorjeta em um restaurante [43].

A gorjeta deve ser algum valor entre 0 e $30 \%$ da conta e deve ser em função da qualidade do serviço e da comida. Assim, podem-se ter as seguintes regras em linguagem normal:

1. SE o serviço é fraco OU a comida é ruim ENTÃo a gorjeta é pequena

2. SE o serviço é bom ENTÃO a gorjeta é média

3. SE o serviço é excelente OU a comida é deliciosa ENTÃO a gorjeta é alta

Graduando a qualidade da comida e do serviço de 0 a 10 , pode-se ter um sistema de inferência com o da Figura 4-6. 

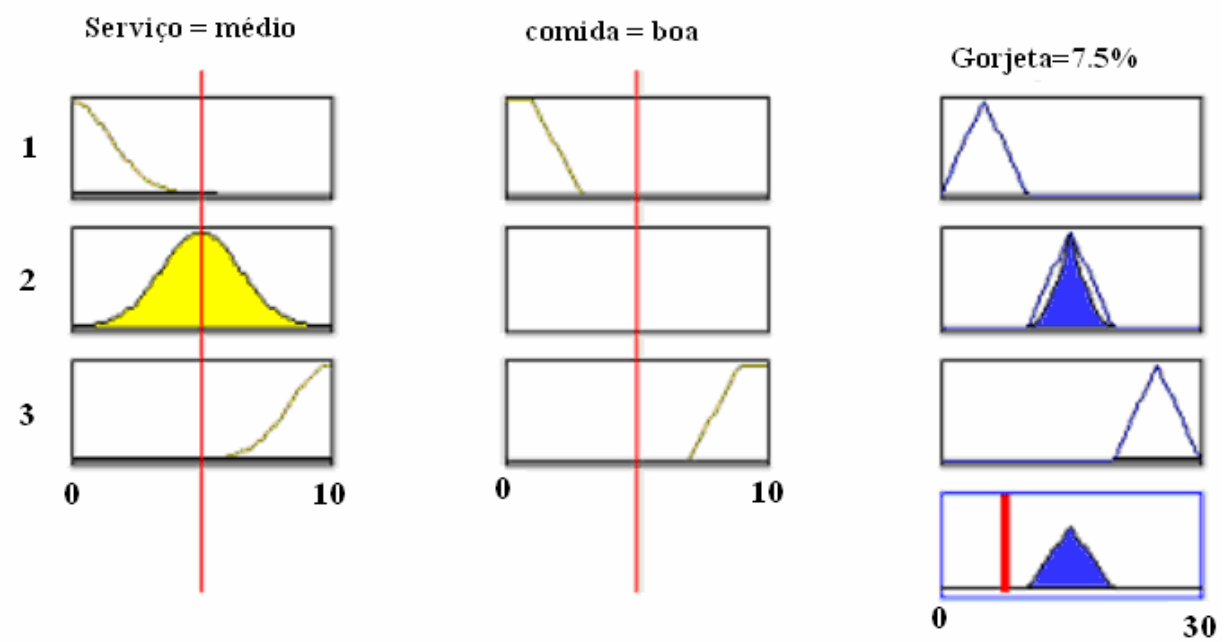

Figura 4-6 - Exemplo de sistema de inferência Fuzzy para cálculo de gorjeta

A dificuldade no uso do sistema de inferência consiste em se determinar o número de regras a ser usado, as variáveis de entradas, as funções de pertinência, processo lógico para agregar as regras e o método de defuzificação.

Em sistemas simples, um especialista é capaz de determinar todos os parâmetros do sistema de inferência e através de testes, refinar o sistema.

Já para um sistema complexo, com muitas entradas e saídas e um grande histórico de dados como na previsão de carga, é necessário um processo para a determinação automática do modelo do sistema de inferência (anexo $\mathrm{B} \mid$ ). Ainda assim, alguns fatores como o tipo de função de pertinência a ser usado, têm de ser determinados e ajustados manualmente. 


\subsubsection{Previsão de Carga Através de Lógica Fuzzy}

Além de funcionar como um interpolador da mesma forma que outras técnicas de previsão baseadas em IA, a lógica Fuzzy nos permite utilizar informação lingüística juntamente com a numérica. Assim, as complexas relações não-lineares entre as variáveis de previsão da carga podem ser substituídas por relações lógicas do tipo SE...ENTÃO.

Podemos, por exemplo, compilar regras do tipo :

SE pico de carga de ontem é x E temperatura máxima é y ENTÃo pico de hoje é z.

Condições novas do sistema, que em outros métodos resultariam na necessidade de novos e complexos treinamentos do interpolador, podem ser mais facilmente incorporadas ao interpolador Fuzzy apenas como uma nova regra.

No caso de sistemas de previsão de carga, devido ao grande número de dados, entradas, saídas e variáveis do sistema, a criação e ajuste de um sistema de interpolação seriam extremamente difíceis sendo assim necessário o uso de processo automáticos de determinação do modelo fuzzy. Sugeno desenvolveu em 1985 [41] um sistema prático para determinação automática de modelos para sistemas de inferência fuzzy. O processo foi sendo aprimorado e utilizado em sistemas de previsão de carga em diversas publicações como por $\mathrm{Wu}$ [29]. 


\subsubsection{Aplicação prática da previsão de carga através de lógica fuzzy}

Um programa computacional capaz de executar o processo de determinação automática de modelos fuzzy e realizar previsões de carga, baseado no método descrito no Anexo B, foi implementado a fim de avaliar o método. O programa é capaz de ler um conjunto de dados de treinamento, gerar um modelo Fuzzy utilizando clusterização dos dados e executar previsões. $\mathrm{Na}$ Figura 4-7 temos uma amostra da tela do programa.

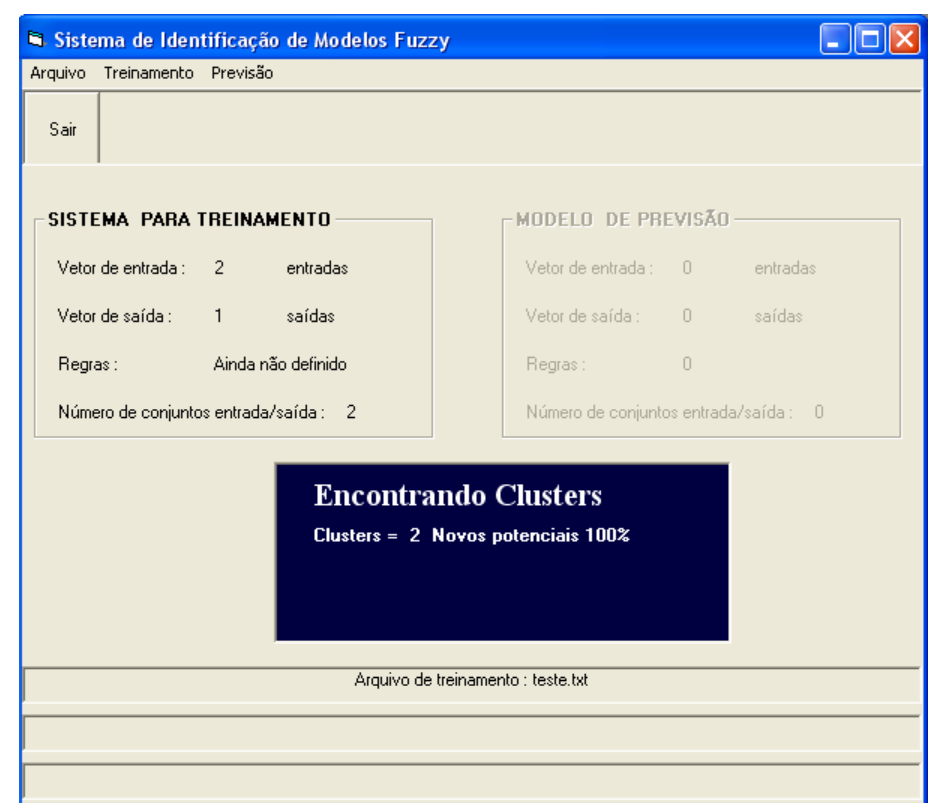

Figura 4-7 - Tela do software de determinação automática de modelos Fuzzy

Os sistemas de inferência fuzzy mais comuns trabalham com diversas entradas e apenas uma saída, tornando-o adequado a previsão de instantes específicos da curva de carga e não completa.

Para o desenvolvimento do sistema de inferência foi utilizado:

- Um sistema de inferência Fuzzy específico para cada dia da semana;

- Foram utilizados dados amostrados a cada 15 minutos e já filtrados da carga do estado de São Paulo (CTEEP Transmissão Paulista) :

o O conjunto de treinamento vai de $1 / 7 / 01$ a $30 / 9 / 02$;

o O conjunto de teste vai de 1/10/02 a 12/2/03; 
Inicialmente foram treinados sistemas de inferência utilizando como entradas a carga dos últimos 8 instantes e saída o instante seguinte, conforma e Figura 4-8.

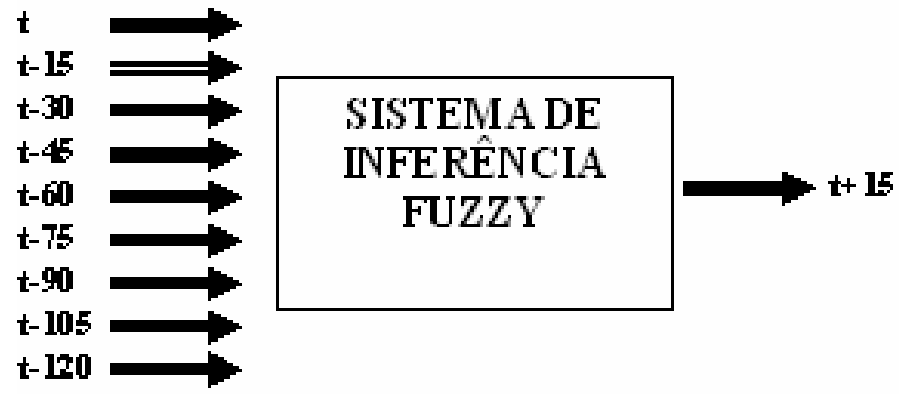

Figura 4-8 - Sistema de Inferência Fuzzy para previsão da carga

O número de clusters dos treinamentos e os erros médios das previsões (anexo A) estão na Tabela 4-1.

Tabela 4-1 - Resultados da previsão da carga 15 minutos a frente, com sistema Fuzzy

\begin{tabular}{|c|c|c|c|}
\hline \multirow{2}{*}{ Dia da semana } & \multirow{2}{*}{ Clusters obtidos } & \multicolumn{2}{|c|}{ Previsão } \\
\cline { 3 - 4 } & & Erro (\%) & Desvio padrão (\%) \\
\hline segunda & 5 & 1,14 & 1,76 \\
\hline terça & 5 & 0,92 & 1,10 \\
\hline quarta & 5 & 0,98 & 1,26 \\
\hline quinta & 4 & 0,89 & 1,50 \\
\hline sexta & 5 & 0,91 & 1,34 \\
\hline sábado & 4 & 0,79 & 1,32 \\
\hline domingo & 8 & 0,86 & 1,09 \\
\hline
\end{tabular}

Na Figura 4-9 pode-se observar a distribuição dos erros de previsão para todos os dias de semana juntos e verificar que mais de $90 \%$ dos erros estão abaixo de $2 \%$, garantindo uma ótima qualidade ao sistema de previsão. 


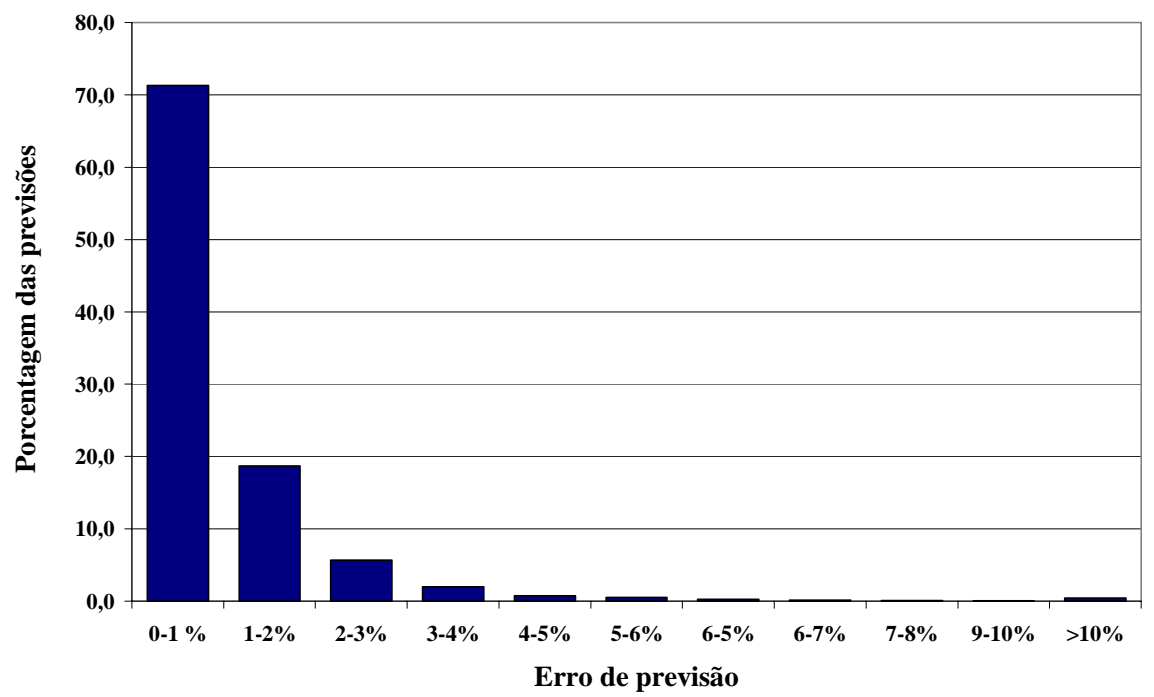

Figura 4-9 - Distribuição dos erros da previsão fuzzy para t+1

Utilizando o mesmo processo e dados, foi treinado um sistema de inferência para prever a carga no instante $\mathrm{t}+4$ ( 1 hora à frente), que apresentou os resultados da Tabela 4-2.

Tabela 4-2 - Resultados da previsão de carga 1 hora a frente, com sistema fuzzy

\begin{tabular}{|c|c|c|c|}
\hline \multirow{2}{*}{ Dia da semana } & \multirow{2}{*}{ Clusters obtidos } & \multicolumn{2}{|c|}{ Previsão } \\
\cline { 3 - 4 } & & Erro (\%) & Desvio padrão (\%) \\
\hline segunda & 7 & 2,47 & 2,76 \\
\hline terça & 5 & 1,87 & 1,72 \\
\hline quarta & 6 & 2,19 & 1,98 \\
\hline quinta & 4 & 1,79 & 2,12 \\
\hline sexta & 4 & 1,76 & 1,80 \\
\hline sábado & 4 & 1,60 & 1,84 \\
\hline domingo & 8 & 1,72 & 1,96 \\
\hline
\end{tabular}

Na Figura 4-10 pode-se observar a distribuição dos erros de previsão para todos os dias de semana juntos, e verificar que $80 \%$ dos erros estão abaixo de $3 \%$, garantindo ainda uma boa qualidade ao sistema de previsão. 


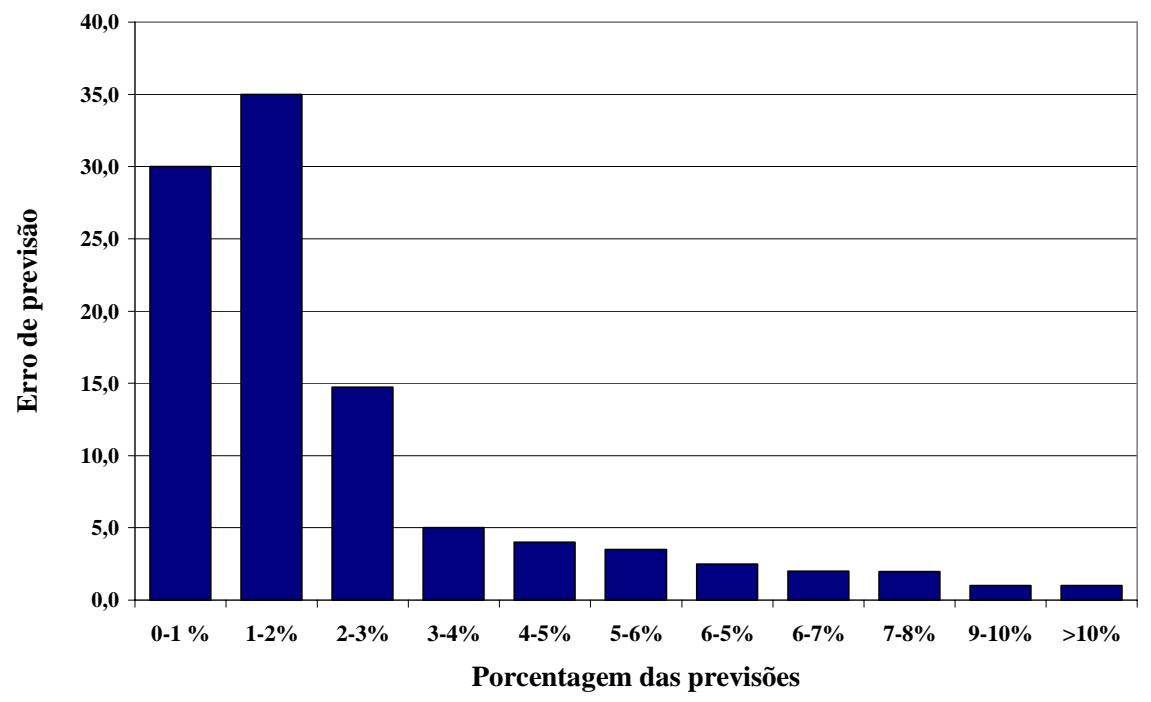

Figura 4-10 - Distribuição dos erros da previsão fuzzy para $t+4$

Para verificar o efeito da temperatura ambiente na previsão, as simulações para a previsão de $t+1$, acrescentando como entradas a temperatura ambiente de cada instante, fornecendo um total de 16 entradas.

Os resultados obtidos encontram-se na Tabela 4-3.

Tabela 4-3 - Previsão de carga 1 hora a frente através de lógica fuzzy com uso de temperatura ambiente

\begin{tabular}{|c|c|c|}
\hline \multirow{2}{*}{ Dia } & \multicolumn{2}{|c|}{ Erro \% médio } \\
\cline { 2 - 3 } & Previsão sem temperatura & Previsão com temperatura \\
\hline Segunda & 0,94 & 1,14 \\
\hline Terça & 1,35 & 0,92 \\
\hline Quarta & 1,16 & 0,98 \\
\hline Quinta & 0,88 & 0,89 \\
\hline Sexta & 0,87 & 0,91 \\
\hline Sábado & 0,66 & 0,79 \\
\hline Domingo & 0,96 & 0,86 \\
\hline
\end{tabular}

Verifica-se que na maioria dos casos pode-se ter alguma melhoria na previsão, mas muito pequena. 


\subsection{Redes Neurais}

Uma rede neural é uma ferramenta matemática inspirada na maneira que o cérebro humano processa informações. O seu desenvolvimento iniciou-se em 1949 com o desenvolvimento de teorias de aprendizado por D. O. Hebb e se desenvolveu nas décadas de 50 e 60 com a combinação de estudos de biologia e psicologia e o desenvolvimento dos circuitos eletrônicos. O campo das redes neurais parecia muito promissor até que Marvin Minsky, em 1969 provou matematicamente uma série de limitações aparentemente insolúveis das redes neurais de uma camada o que causou quase que uma parada total nos estudos de redes neurais nas décadas de 70 e inicio da década de 80 . Apenas alguns pesquisadores seguiram seus estudos chegando finalmente a novas estruturas de redes e algoritmos de treinamento que superaram os problemas iniciais e reavivaram o interesse nas redes neurais. Desde então seu estudo e aplicações vêm aumentando cada vez mais.

$\mathrm{O}$ uso de redes neurais para a previsão de carga vem sendo estudado desde o final dos anos 80 e apesar de haver discussões sobre suas bases matemáticas e desempenho, o número de publicações envolvendo o assunto vem aumentando mostrando que seu uso foi amplamente aceito sendo a técnica de IA mais difundida para a previsão de carga. Diversos estudos e aplicações práticas desenvolvidas ao longo dos anos mostram que as RNAs apresentam performances tão boas ou melhores que as demais técnicas disponíveis. 


\subsubsection{Conceitos Básicos}

A unidade básica de uma RNA é o neurônio artificial que procura imitar as funções básicas de um neurônio biológico. O seu diagrama se encontra na Figura 4-11.

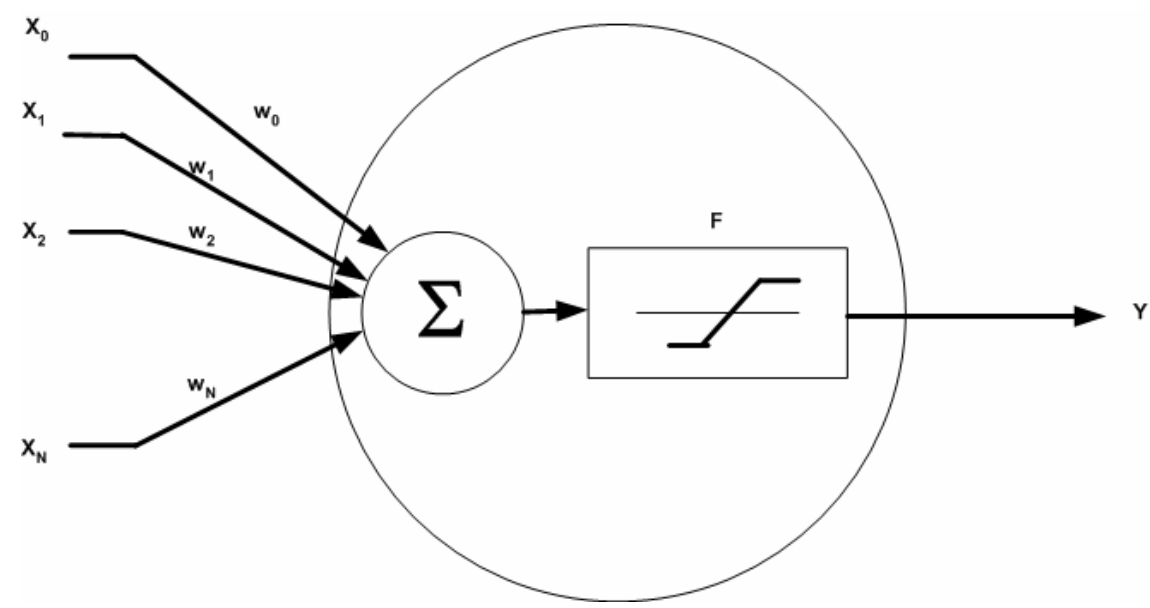

Figura 4-11 - Neurônio Artificial

O neurônio artificial é composto de:

- Uma série de entradas $\left(\mathrm{x}_{0}, \mathrm{x}_{1}, \ldots \mathrm{x}_{\mathrm{N}}\right)$ provenientes de sinais externos ou outros neurônios;

- Uma série de pesos $\left(\mathrm{w}_{0}, \mathrm{w}_{1} \ldots \mathrm{w}_{\mathrm{N}}\right)$, análogos a intensidade das sinapses biológicas;

- Uma função $\Sigma$ que soma as entradas ponderadas pelos pesos;

- Uma função de ativação F que simula a característica não-linear da transferência entre neurônicos biológicos;

Uma função muito utilizada é a sigmoidal $y(x)=\frac{1}{1+e^{-x}}$

- O sinal de saída $y$.

O neurônio artificial também é denominado de perceptron. Assim como os neurônios biológicos, os perceptrons têm de ser agrupados em estruturas a fim de que sejam capazes de desempenhar funções complexas. 
Uma das estruturas mais comuns e utilizadas é o MLP, multi-layer perceptron, ou perceptron de camada múltipla. Uma rede MLP pode ser vista na Figura 4-12.

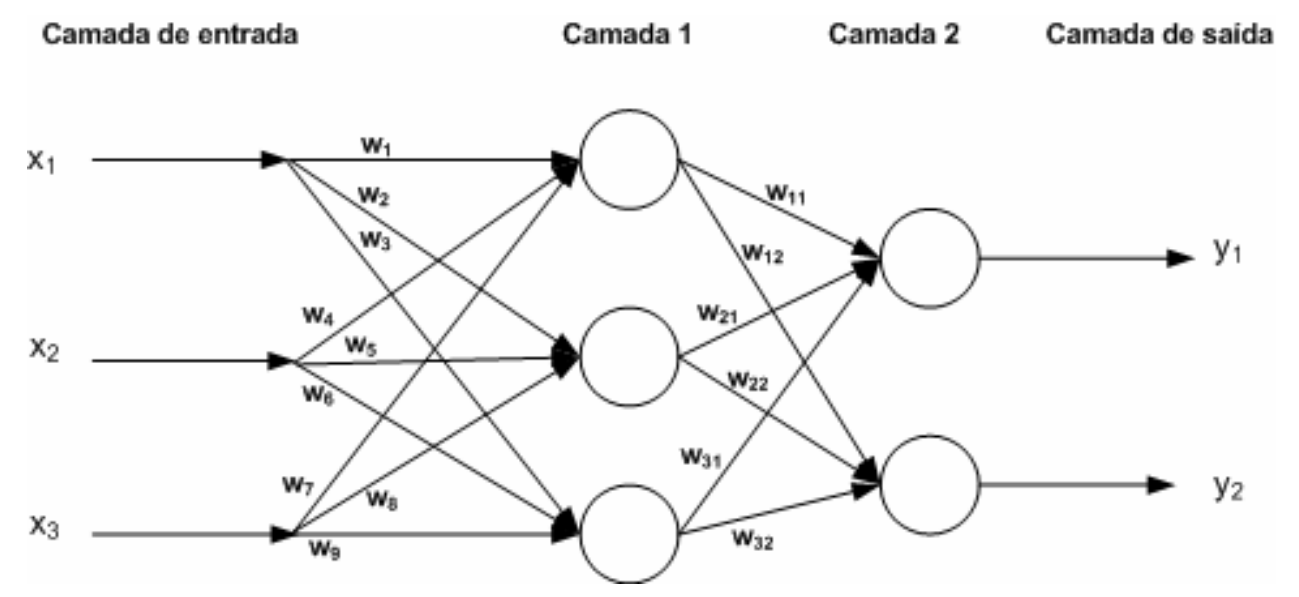

Figura 4-12 - Rede Neural tipo MLP

A rede MLP possui uma série de entradas, uma série de camadas com neurônios interligados às camadas anteriores e posteriores e às saídas.

A função a ser desempenhada pela rede depende não apenas da estrutura, mas principalmente dos pesos nas ligações entre os perceptrons.

Inicialmente parecia não haver algoritmo capaz de treinar uma rede neural, limitando muito seu uso, o que ajudou a eclipsar o campo das redes neurais na década de 70 .

Parte da responsabilidade do ressurgimento das redes neurais se deve ao desenvolvimento de um algoritmo capaz de treinar uma rede MLP, o método backpropagation. Este método foi desenvolvido independentemente por pesquisadores diferentes em 3 ocasiões: 1974, 1982 e 1986. Apesar de certas limitações, o algoritmo se mostrou fundamentado matematicamente e de uso prático.

Com o passar dos anos, uma série de novas estruturas para rede e métodos de treinamento foram desenvolvidos, solidificando o campo das redes neurais.

Entre as estruturas de redes tem-se: counterpropagation networks, recourent networks (Hopfield Nets), ART networks (Adaptative Resonance Theory), etc. 
Apesar do desenvolvimento do campo das redes neurais, ainda existem dificuldades como a determinação da estrutura da rede neural ( tipo, número de camadas, número de neurônios, etc.) a ser usada para um determinado problema. Não havendo forma teórica de determiná-la, a solução é a tentativa e erro.

O treinamento de uma rede neural também é crítico, pois, uma rede pode ser treinada em excesso (overfitting) fazendo com que apresente resultados muito bons apenas para dados semelhantes aos de treinamento. A rede perde a capacidade de generalizar. De maneira oposta, uma rede também pode ser pouco treinada sendo incapaz de aprender a função desejada.

Apenas o uso prático de uma rede neural pode indicar se o treinamento foi eficiente para a função esperada.

\subsubsection{Previsão de Carga através de Redes Neurais}

As redes neurais são provavelmente a técnica de IA mais utilizada na previsão da carga sendo que trabalhos na área têm sido publicados desde o final da década de 80 .

As duas principais razões para o uso de redes neurais como ferramenta de previsão de carga são o fato das redes neurais poderem aproximar numericamente qualquer função desejada e o fato de não serem dependentes de modelos.

A maioria dos estudos de previsão com redes neurais pode ser dividida em previsões de uma variável de saída para previsões de curtíssimo prazo ou de múltiplas saídas para a previsão da curva de carga.

A adequada validação dos modelos depende de:

- Comparação com modelos de eficiência reconhecida

- Uso de amostras de tamanho adequado 


\subsubsection{Aplicação prática da previsão de carga através de redes neurais}

Será feito através de programa computacional capaz de treinar e executar redes neurais MLP através de backpropagation [125]. Além de permitir o ajuste da topologia da rede neural (número de camadas e de neurônios por camada), o software permite o ajuste dos parâmetros de treinamento do backpropagation: tais como número de iterações no treinamento, taxa de aprendizado, etc.

A tela de treinamento do software pode ser vista na Figura 4-13.

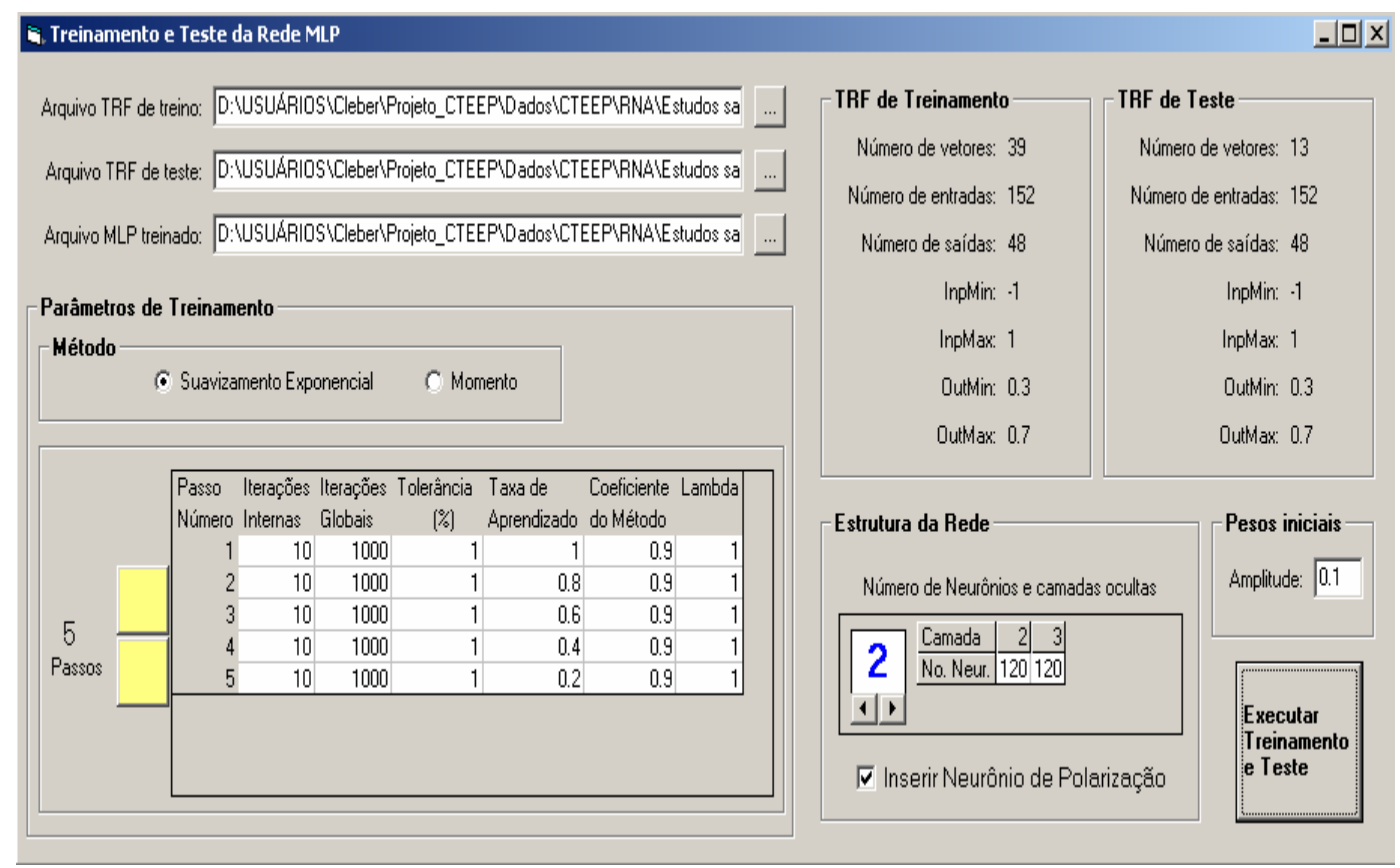

Figura 4-13 - Software para treinamento de Redes Neurais

Uma série de testes com dados de carga do estado de São Paulo foram realizadas a fim de validar o método de previsão.

Foram utilizadas diversas combinações de dados de entrada: carga filtrada e amostrada a cada 15 minutos, temperatura ambiente máxima e mínima e energia diária. As RNAs foram testadas com estrutura variando de 1 a 4 camadas internas e 10 a 100 neurônios em cada camada interna. 
Conforme indicação da análise dos dados, cada dia da semana possui padrões próprios, sugerindo o uso de RNAs específicas para cada dia da semana. Para efeito de testes, foram utilizados apenas os dados das segundas-feiras.

Os resultados obtidos estão na Tabela 4-4.

Tabela 4-4 - Melhores RNAs para previsão de carga nas Segundas-feiras

\begin{tabular}{|c|c|c|c|}
\hline Dados de entrada & $\begin{array}{c}\text { Melhor } \\
\text { configuração da } \\
\text { RNA obtida (*) }\end{array}$ & $\begin{array}{c}\text { Erro médio } \\
\text { das } \\
\text { previsões } \\
\text { (\%) }\end{array}$ & $\begin{array}{c}\text { Desvio } \\
\text { Padrão médio } \\
\text { das previsões } \\
\text { (\%) }\end{array}$ \\
\hline $\begin{array}{c}\text { Carga, energia e temperatura dos 3 } \\
\text { dias anteriores de mesmo tipo. Energia } \\
\text { e temperatura do dia a prever }\end{array}$ & $20 \_20$ & 2,97 & 1,18 \\
\hline $\begin{array}{c}\text { Carga e energia dos 3 dias anteriores } \\
\text { de mesmo tipo. Energia do dia a } \\
\text { prever }\end{array}$ & $60 \_60$ & 3,60 & 1,48 \\
\hline $\begin{array}{c}\text { Carga e temperatura dos 2 dias } \\
\text { anteriores de mesmo tipo. } \\
\text { Temperatura do dia a prever }\end{array}$ & $20 \_20 \_20 \_20$ & 3,64 & 1,64 \\
\hline $\begin{array}{c}\text { Carga e temperatura dos 3 dias } \\
\text { anteriores de mesmo tipo. } \\
\text { Temperatura do dia a prever }\end{array}$ & $100 \_100$ & 3,77 & 2,47 \\
\hline $\begin{array}{c}\text { Carga dos 3 dias anteriores de mesmo } \\
\text { tipo }\end{array}$ & $100 \_100 \_100$ & 4,15 & 2,82 \\
\hline $\begin{array}{c}\text { Carga dos 2 dias anteriores de mesmo } \\
\text { tipo }\end{array}$ & $10 \_10$ & 4,37 & 2,64 \\
\hline $\begin{array}{c}\text { Carga dos 2 dias anteriores de mesmo } \\
\text { tipo e do dia anterior }\end{array}$ & $20 \_20 \_20 \_20$ & 4,66 & 2,83 \\
\hline
\end{tabular}

* A notação xx_yy..._zz indica o número de camadas ocultas de uma rede neural e o número de neurônios em cada camada. 100_50 é uma rede de 2 camadas com 100 e 50 neurônios respectivamente.

A distribuição dos erros para os testes da melhor rede da Tabela 4-4 está na Figura 4-14. 


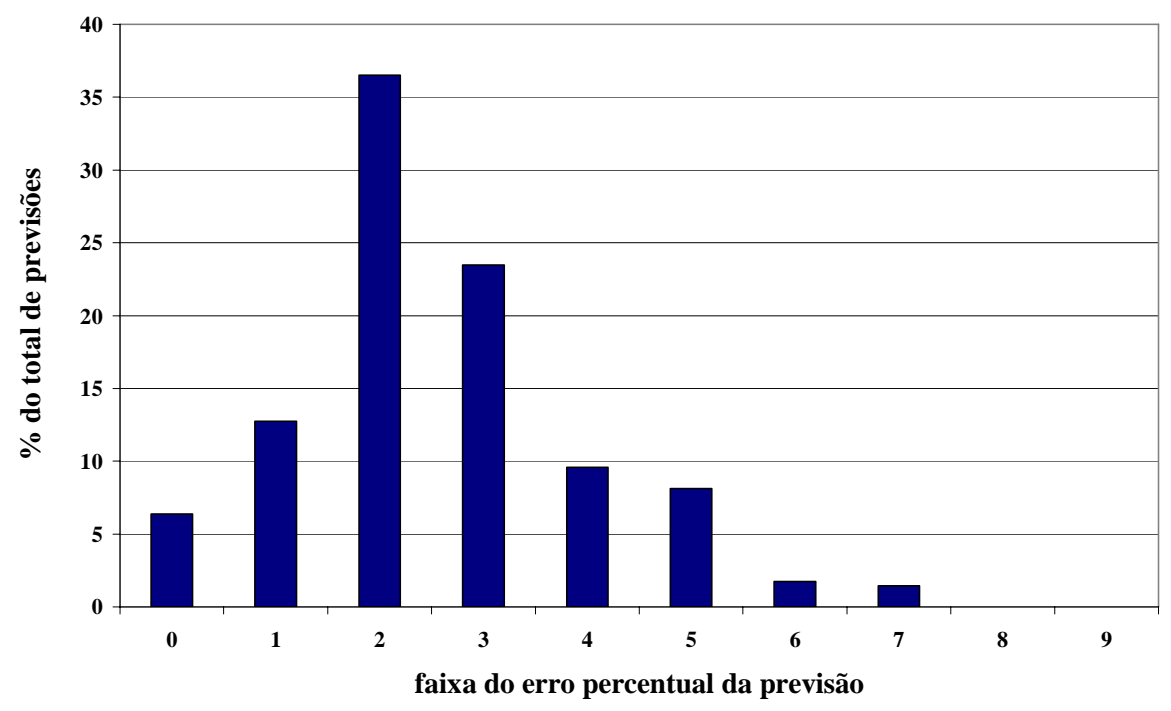

Figura 4-14 - Distribuição dos erros da previsão dos pontos de carga

Pode-se verificar que a melhor configuração encontrada para as RNAs depende dos dados de entrada, bem como de ajustes nos parâmetros do algoritmo de treinamento.

Essa análise inicial indica que o uso da temperatura ambiente e da energia diária melhora consideravelmente a qualidade da previsão, mas é necessário o valor previsto para a temperatura ambiente e energia do dia a ser previsto. A previsão de temperatura é muito complexa para ser executada e pode ser obtida de serviços especializados. Já a previsão da energia pode ser obtida através de RNAs.

De forma similar a previsão de carga, foram testadas diversas configurações de dados de entrada e RNAs para a previsão de energia.

A análise das curvas de energia diária, agrupadas por dia da semana, indica um comportamento quase linear, a menos nos dias com feriado. Podem-se observar exemplos do fato nas Figura 4-15 e Figura 4-16. 


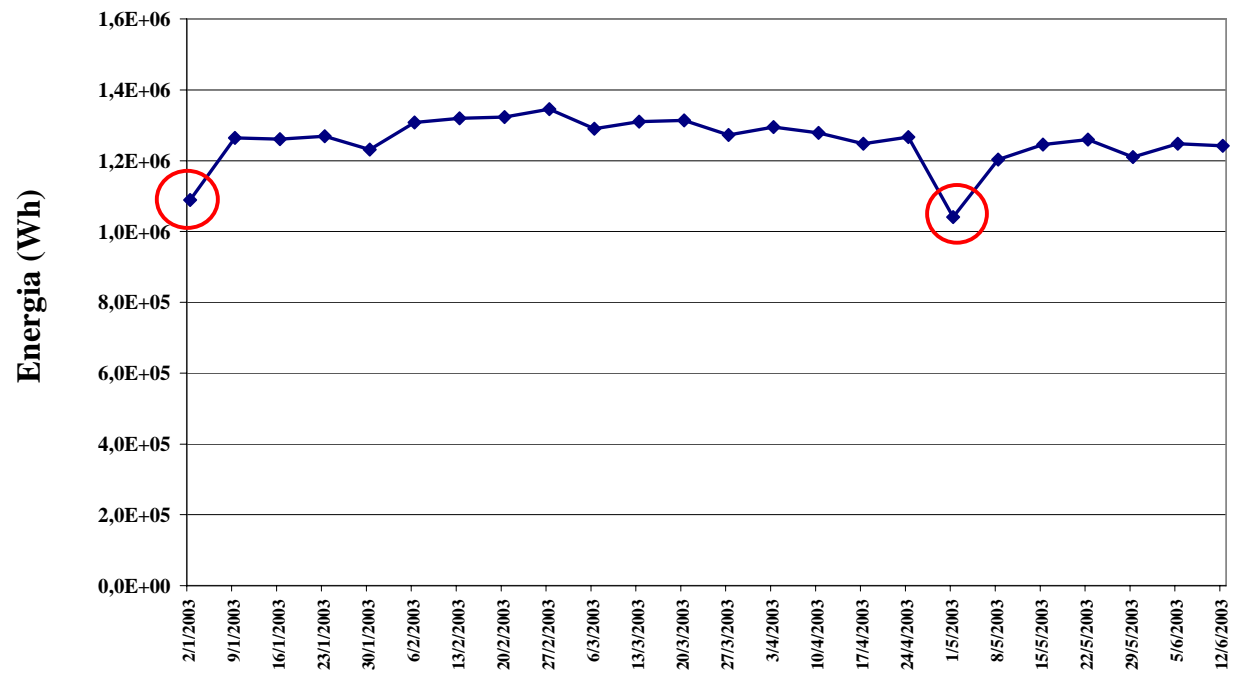

Figura 4-15 - Energia diária das quintas-feiras, indicados os feriados

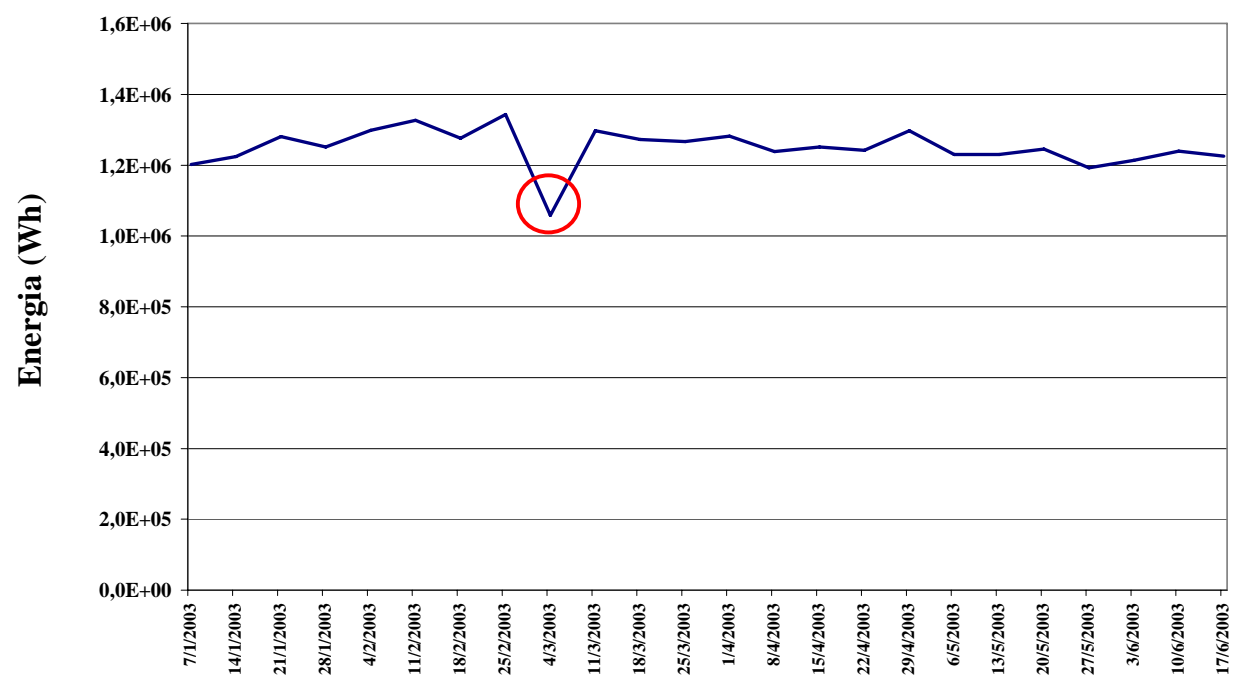

Figura 4-16 - Energia diária das terças-feiras, indicados os feriados

A informação se o dia é anômalo (feriado, ponte, etc. ) é relevante na previsão de energia.

O uso de RNAs com 2 camadas de 10 e 6 neurônios respectivamente e 13 entradas apresentaram os melhores resultados de previsão. As entradas utilizadas foram: 
- Energia do dia de mesmo tipo de 3 semanas atrás;

- Indicação de feriado do dia de mesmo tipo de 3 semanas atrás;

- Energia do dia de mesmo tipo de 2 semanas atrás;

- Indicação de feriado do dia de mesmo tipo de 2 semanas atrás;

- Energia do dia de mesmo tipo de 1 semana atrás;

- Indicação de feriado do dia de mesmo tipo de 1 semana atrás;

- Energia e indicação de feriado dos 2 dias imediatamente anteriores ao que deseja prever;

- Indicação de feriado do dia a ser previsto;

- Indicação de feriado do dia seguinte a ser previsto;

- Indicação de feriado de 2 dias a frente do dia a ser previsto;

A média dos erros obtidos para a RNA de previsão de energia de cada dia da semana estão na Tabela 4-5.

Tabela 4-5 - Erros médios da previsão de energia para cada dia da semana

\begin{tabular}{|c|c|c|}
\cline { 2 - 3 } \multicolumn{1}{c|}{} & Erro (\%) & Desvio padrão \\
\hline seg & 0,84 & 0,78 \\
\hline ter & 0,89 & 0,72 \\
\hline qua & 1,10 & 0,61 \\
\hline qui & 1,05 & 0,80 \\
\hline sex & 1,17 & 0,97 \\
\hline sáb & 1,21 & 1,30 \\
\hline dom & 0,97 & 0,93 \\
\hline
\end{tabular}

A distribuição dos erros de previsão, para todas as RNAs da Tabela 4-5, encontra-se na Figura 4-17.

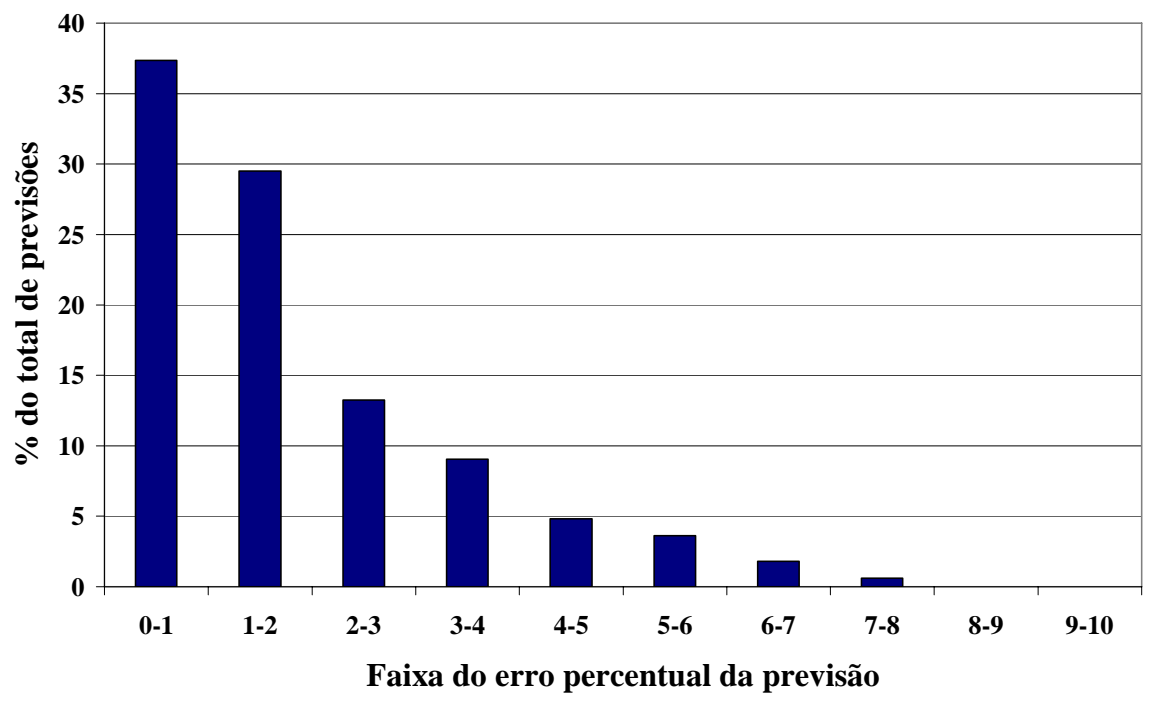

Figura 4-17 - Distribuição dos erros da previsão de energia diária 


\subsubsection{Previsão de carga através de redes neurais e Wavelets}

Em 1998, [126] Ning apresenta o uso de Wavelets e redes neurais na previsão de carga. A carga é decomposta em componentes Wavelets que são previstas e o sinal da carga é reconstituído.

Em Onsivilai [127] em 1999 e Bashir [128] em 2002, utilizam Redes Neurais Wavelet na previsão de carga com qualidade de previsão similar ou melhor a outros métodos mas computacionalmente mais eficiente.

Redes Neurais Wavelet são redes neurais onde a primeira camada de neurônios incorpora funções de transformada Wavelet, conforme a Figura 4-18.

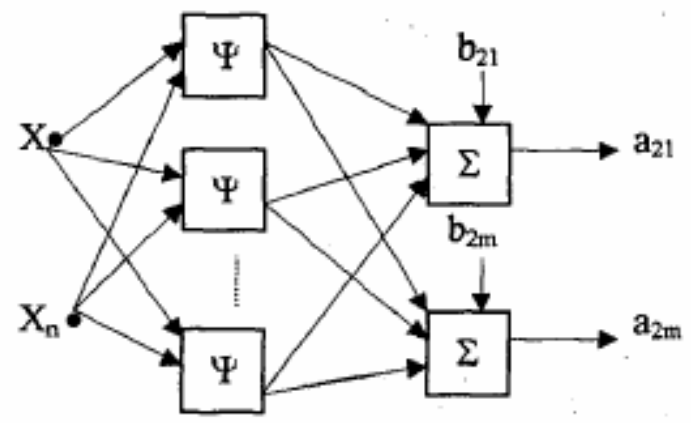

Figura 4-18 - Rede Neural Wavelet

Posteriormente entre 2001 e 2005 alguns poucos trabalhos foram publicados sobre previsão de carga com redes neurais e Wavelets, entre eles temos, Tao [131], Zheng-Hua [132], Yanqiu [133], Reis [134] e Lu[135].

Zhao [130] apresenta um algoritmo genético combinado com rede neural e transformadas Wavelet em séries temporais.

Todas as publicações apresentam o método das redes neurais combinado com a transformada Wavelet como um processo flexível, computacionalmente eficiente e com resultados de previsão similares ou até melhores a outros métodos.

A fim de combinar o uso de redes neurais e Wavelets, diferentemente dos trabalhos pesquisados, a idéia proposta consiste em utilizar a transformada 
Wavelet para decompor a curva de carga, executar a filtragem, mas ao invés de recompor o sinal, treinar as redes neurais com as componentes Wavelet. O sinal só seria recomposto após a previsão de suas componentes.

As vantagens do método são:

- Compactação da informação de carga, facilitando a manipulação de grandes quantidades de dados;

- Filtragem eficiente dos dados de carga;

- Redução do número de entradas das redes neurais, reduzindo assim os tempos de treinamento e processamento;

O processo consiste nas seguintes etapas:

1. A curva de carga é decomposta pela transforma Wavelet. Pode-se ver na Figura 4-19 a decomposição de uma curva de carga com a Wavelet Daubechies de ordem 4 (db4) e 5 níveis de decomposição.

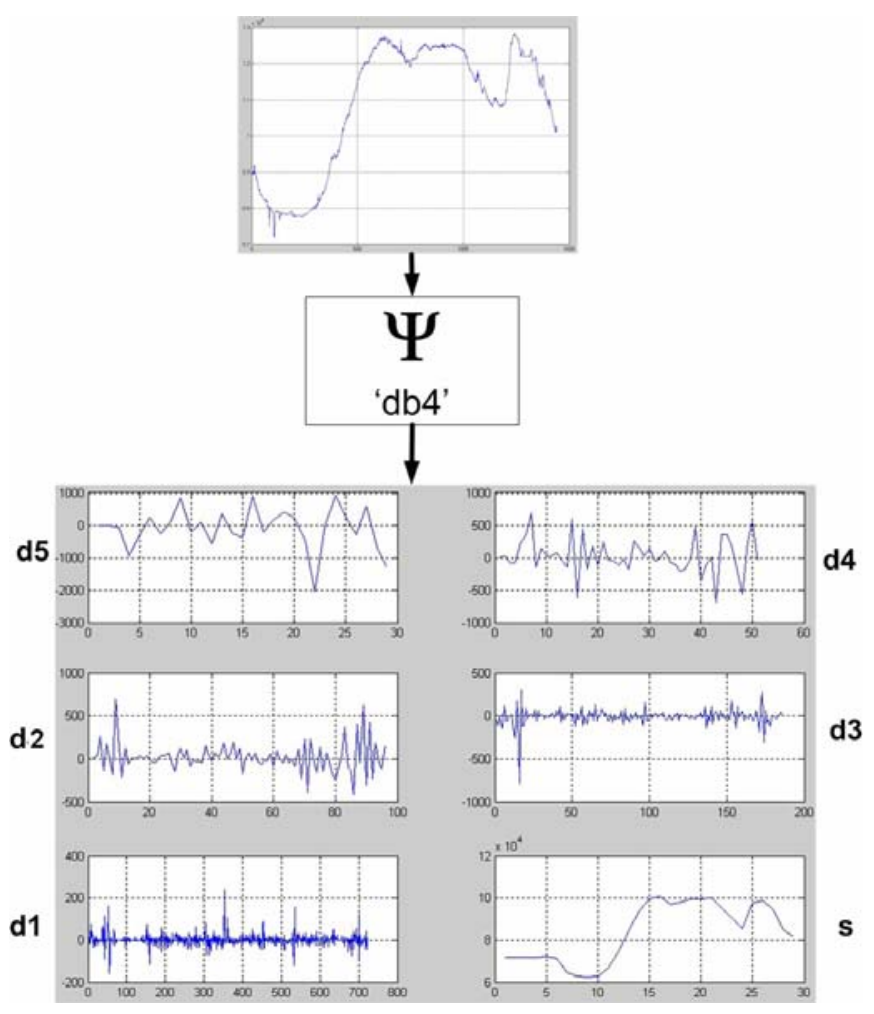

Figura 4-19 - Curva de carga decomposta por Wavelet db4 
As curvas $d 1, d 2, d 3, d 4$ e $d 5$ seriam as componentes do ruído do sinal e $s$ as componentes do sinal filtrado. É mantida apenas a componente $s$, o que reduz os 1440 pontos da curva a 29 pontos da decomposição Wavelet.

2. O processo é repetido para todo o histórico de curva de carga e os dados usados para treinar redes neurais.

3. Com as redes neurais treinadas, podem-se executar previsões que irão fornecer a componente $s$ da curva de carga.

4. A curva é recomposta pela anti-transformada Wavelet considerando as componentes $d n$ como tendo valor nulo, como visto na Figura 4-20.

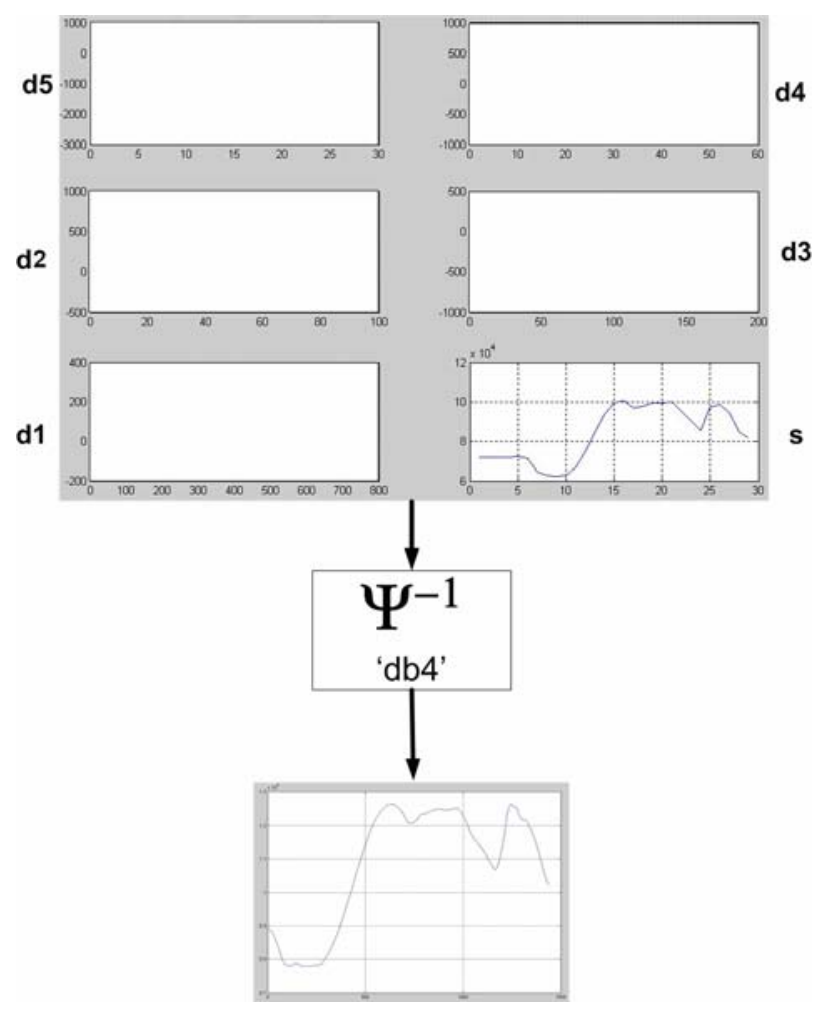

Figura 4-20 - Recomposição de curva de carga por anti-transformada Wavelet

A fim de avaliar o processo, de maneira similar as rede neurais convencionais, o processo descrito foi testado nas curvas de cargas da CTEEP. Testes com diversas Wavelets sugeriram o uso das db4 com 5 níveis de decomposição, por apresentarem boa filtragem sem deformação da curva de carga filtrada e grande compactação de dados (de 1440 para 29 pontos). 
Os dados de entrada utilizados foram as componentes filtradas, energia diária, temperatura ambiente máxima e mínima dos 3 últimos dias de mesmo tipo e as previsões de temperatura e energia para o dia que se deseja prever.

Foram testadas diversas configurações de RNAs, conforme a Tabela 4-6. Pode-se observar que os resultados dos testes apresentaram ótimos resultados, sendo a melhor rede a com 1 camada de 125 neurônios.

Tabela 4-6 - Testes para RNAs de previsão com Wavelets

\begin{tabular}{|c|c|c|}
\hline Estrutura da RNA & Erro médio das previsões & Desvio padrão dos erros \\
\hline 125 & 1,97 & 1,81 \\
\hline 100 & 2,03 & 1,74 \\
\hline $10 \_10$ & 2,05 & 2,18 \\
\hline 64 & 2,10 & 6,54 \\
\hline 150 & 2,12 & 1,65 \\
\hline 25 & 2,12 & 1,93 \\
\hline 75 & 2,14 & 1,70 \\
\hline 50 & 2,18 & 1,87 \\
\hline 10 & 2,45 & 2,36 \\
\hline
\end{tabular}

A comparação entre as curvas de carga reais e previstas está na Figura 4-21.

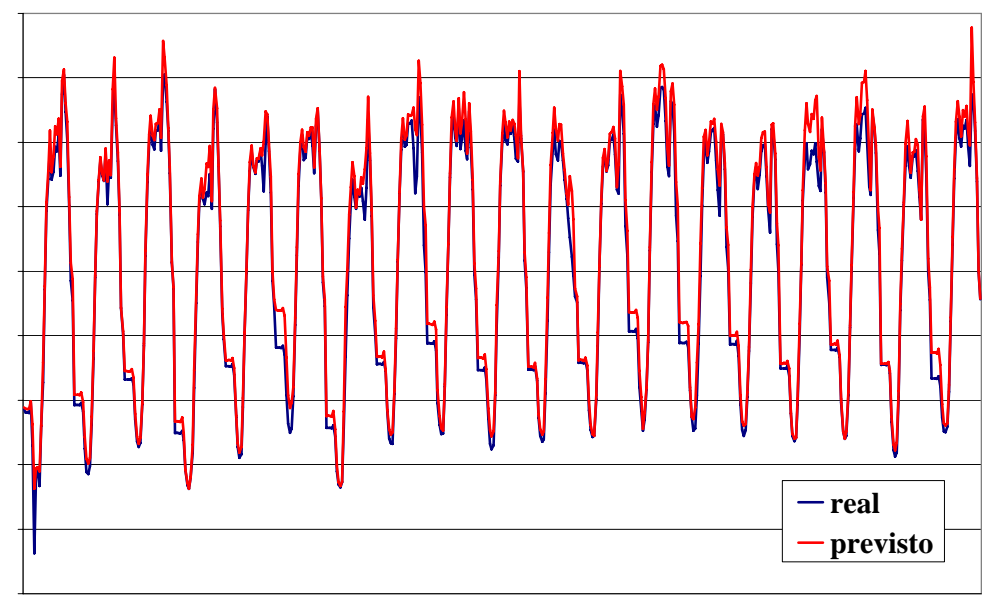

Figura 4-21 - Comparação entre curvas reais e prevista por previsão Wavelet

E a distribuição dos erros obtidos com as previsões está na Figura 4-22. 


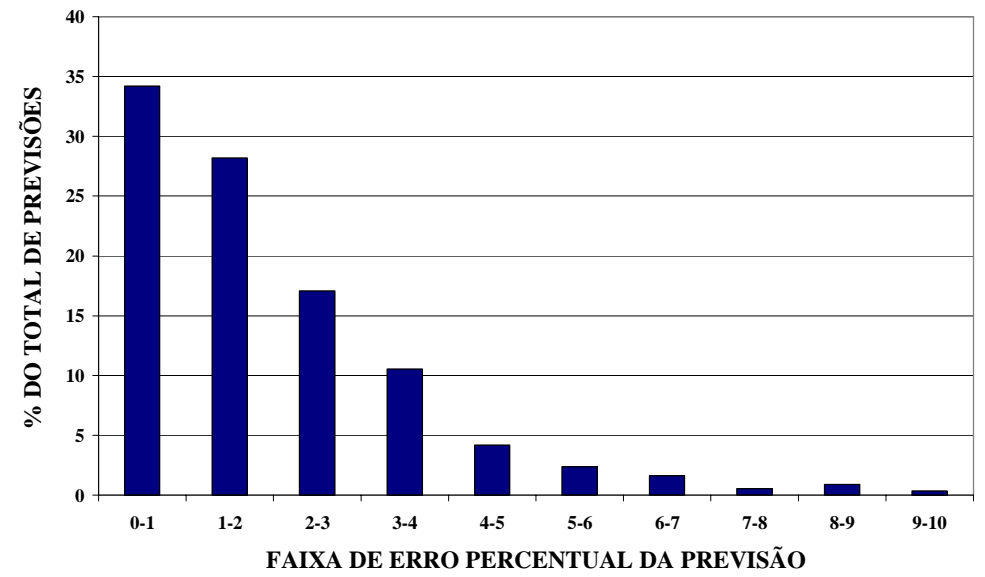

Figura 4-22 - Distribuição dos erros da previsão Wavelet

Os testes realizados indicam que o uso de transformada Wavelet combinada às redes neurais como ferramenta de filtragem e compactação de dados se mostra como mais uma ferramenta na busca de processos de previsão de carga com menores erros. 


\section{Integração em sistema corporativos}

Foi desenvolvida uma pesquisa conjunta entre a USP e a CTEEP Transmissão Paulista com o objetivo de analisar as técnicas de IA disponíveis para a previsão de carga, escolher a mais adequada e desenvolver um sistema computacional para a previsão da curva de carga diária do sistema de transmissão do estado de São Paulo com uma antecedência de pelo menos 48 horas.

Este capítulo apresenta as experiências adquiridas com os testes de previsão, o desenvolvimento do sistema de previsão, sua integração ao sistema SCADA da CTEEP e seu uso.

\subsection{Introdução}

Atualmente a CTEEP executa a previsão da curva de carga do sistema (potência ativa em MW) de uma maneira manual baseada na experiência adquirida pelos operadores ao longo dos anos.

A fim de substituir o sistema utilizado por um sistema computacional baseado em IA, foram analisadas as técnicas conhecidas e, conforme apresentado previamente, as redes neurais e a lógica Fuzzy apareceram como as técnicas melhor indicadas e mais utilizadas para o problema.

A necessidade da previsão da curva de carga diária (múltiplas entradas $\mathrm{x}$ múltiplas saídas) e os bons resultados iniciais em testes, levaram a escolha das RNAs do tipo MLP ( multi-layer perceptron ) com treinamento por backpropagation. 


\subsection{Dados para a previsão}

Os únicos dados disponíveis na concessionária são o histórico de curvas de carga com amostragem de 1 minuto, desde julho de 2001. A carga pode ser obtida para 4 regiões:

- CTEEP, que corresponde a toda a região do estado de São Paulo;

- CESP, que corresponde a carga entregue pela CTEEP a antiga região da CESP, antes da reestruturação;

- $\mathrm{CPLF}$, que corresponde a carga entregue pela CTEEP a antiga região da CPFL, antes da reestruturação;

- ELETROPAULO, que corresponde a carga entregue pela CTEEP a antiga região da ELETROPAULO, antes da reestruturação;

Conforme previamente determinado, para uma previsão de carga precisa, ainda são necessários os históricos de temperatura ambiente, energia diária e informações sobre dias anômalos, além de previsões de temperatura ambiente e energia para o período de previsão.

A energia diária pode ser facilmente calculada pela curva de carga e prevista por uma rede neural própria (cap. 4.2.3.).

Diversos serviços meteorológicos como o CPTEC (Centro de Previsão do Tempo e Estudos Científicos), podem fornecer históricos de temperatura para todo o estado bem como previsões precisas com antecedência de até 3 dias. Inicialmente, para o desenvolvimento do projeto, foi usado o histórico de temperatura ambiente da cidade de São Paulo para o mesmo período do histórico de carga, fornecido pelo IAG-USP (Instituto Astronômico e Geofísico da USP).

A informação se algum dia é anômalo, isto é, feriado, ponte, etc, é de conhecimento comum e pode ser fornecido ao sistema manualmente. 


\subsection{O Software}

O sistema computacional para a previsão da curva de carga desenvolvido foi denominado PCT - Previsão do Carregamento da Transmissão.

A fim de realizar a previsão da carga, o PCT deve executar os seguintes módulos:

1) Aquisição de dados

Obtenção do histórico e atualizações periódicas da carga, temperatura ambiente e sua previsão.

2) Tratamento dos dados

Filtragem dos dados de carga através de um filtro de dados corrompidos e cálculo da energia diária

3) Previsão

Execução das redes neurais para previsão da energia diária e da curva de carga.

4) Visualização dos resultados

Interface gráfica que permite a visualização gráfica das curvas de carga, energia e temperatura.

5) Treinamento de Redes Neurais

Para a execução das previsões, é necessário definir e treinar as redes neurais de energia e carga para cada região. Com a evolução da carga, o treinamento deve ser periodicamente refeito.

Fisicamente, o sistema é composto de dois módulos principais, um deles denominado cliente, responsável pela apresentação gráfica dos resultados e um outro chamado de servidor, responsável pelo armazenamento das informações e cálculos.

A aquisição de dados, seu tratamento, as previsões e treinamento das RNAs são instaladas e processadas no servidor e a parte de visualização em qualquer computador que tenha acesso ao servidor via rede TCP/IP.

A Figura 5-1 mostra o diagrama da configuração do sistema na rede TCP/IP. 


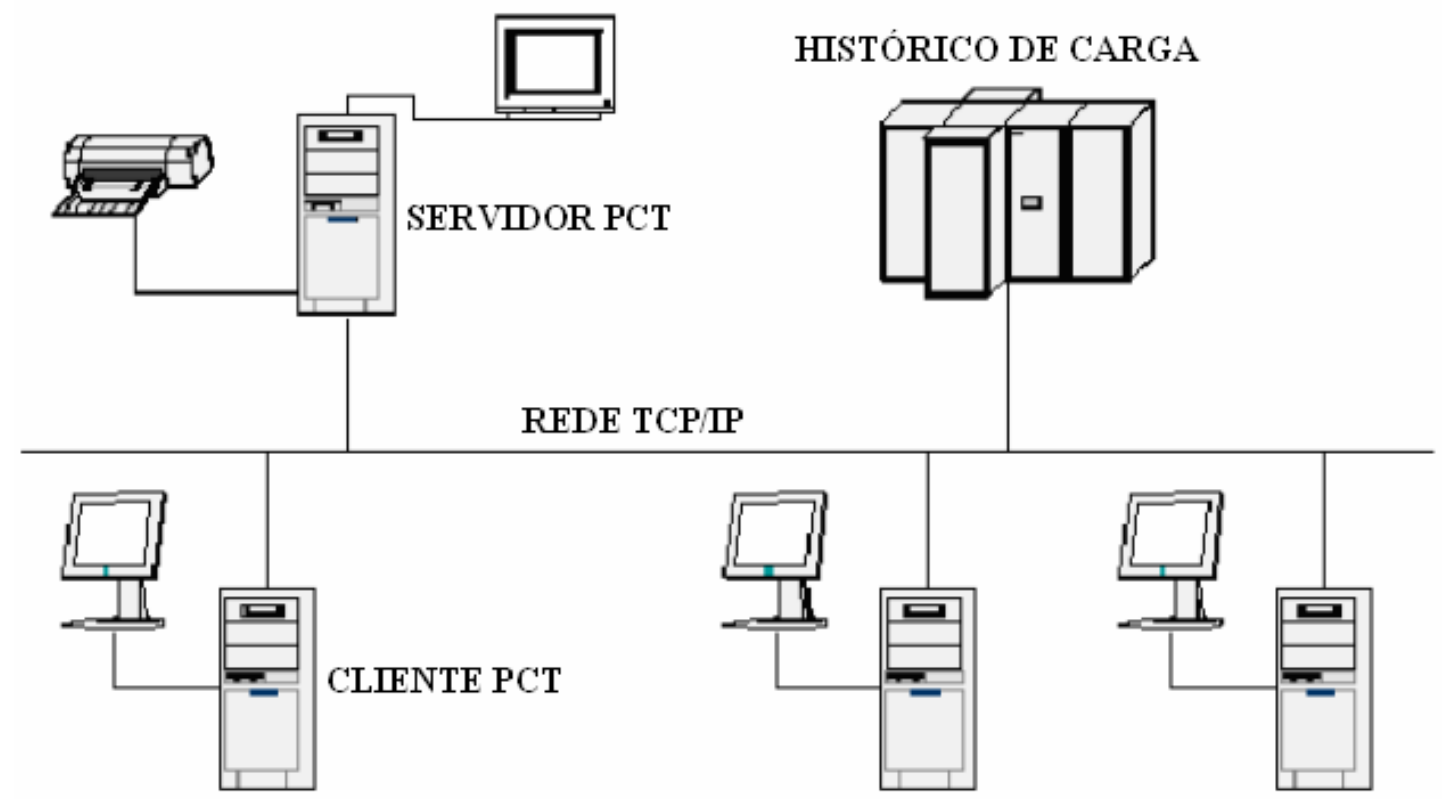

Figura 5-1 - Configuração do sistema na rede TCP/IP

Devido à necessidade de interfaces gráficas para o sistema e capacidade computacional para as redes neurais, as interfaces, acesso a Internet e rede local foram desenvolvidos em Microsoft Visual Basic 6.0 e o processamento das redes neurais em Microsft Visual $\mathrm{C}++6.0$. Os dados necessários obtidos pelo sistema são armazenados em uma base local Oracle. 


\subsubsection{Aquisição de dados}

\subsubsection{Aquisição de dados de carga}

O PCT necessita do histórico de cargas do sistema e de dados atualizados constantemente. Todas as medições do sistema da CTEEP ficam armazenadas no historiador que utiliza o sistema PI da OSIsoft. Para obtenção dessas informações, a cada 15 minutos o PCT lê as seguintes grandezas :

- Potência ativa da CTEEP (MW)

- Potência ativa da CESP (MW)

- Potência ativa da CPFL (MW)

- Potência ativa da ELETROPAULO (MW)

Essas medições são amostradas com freqüência de 1 minuto e armazenadas na base de dados local. É feita a aquisição de dados das regiões da CTEEP, CESP, CPFL e ELETROPAULO.

Se a base local estiver defasada com o historiador, o PCT garante a equiparação das bases.

\subsubsection{Aquisição de dados de temperatura}

O PCT necessita de um histórico e de previsões da temperatura ambiente máxima e mínima das regiões onde a carga será prevista.

O histórico das temperaturas, obtido de serviços meteorológicos, pode ser transferido diretamente a base de dados local do PCT.

Atualizações do histórico podem ser fornecidas diretamente a base de dados local, se disponíveis no historiador. A instalação de sensores de temperatura ao longo da região de previsão da carga pode fornecer melhores informações sobre a influência da temperatura da previsão da carga da região.

As previsões de temperatura podem ser obtidas de 3 formas : 
- Automaticamente através da Internet, sempre à zero hora, caso uma conexão esteja disponível;

- Entrada manual dos dados;

- Média histórica mensal.

A fim de prevenir a indisponibilidade de dados, o sistema cria e atualiza um histórico médio mensal das temperaturas de cada região. Os resultados de previsão de carga obtidos com dados médios não são tão precisos, mas dessa forma garante-se a execução das previsões.

Como as medições de temperatura são específicas para cidades ou regiões delas, o PCT é capaz de obter dados de diversas cidades e permite associar cidades a uma região elétrica. Para cada região será usada a média as temperaturas das cidades selecionadas.

Como a região da grande São Paulo responde com cerca de $60 \%$ da carga do estado, sua temperatura tem um efeito muito maior que das demais cidades.

\subsubsection{Filtragem da Carga}

Os dados obtidos do historiador PI precisam de tratamento para uso pelas RNAs pois podem ocorrer problemas como medições incorretas ocasionados por falhas de medidores ou do canal de comunicação de dados. As cargas são filtradas e reduzidas a uma freqüência de amostragem de 15 minutos, conforme processo descrito no item 3.2.1, e armazenadas em uma tabela da base de dados Oracle.

A não disponibilidade de medições de carga no PI, quer por problemas do historiador ou falhas de comunicação com o mesmo, impossibilita a filtragem dos dados e por conseqüência a previsão.

A filtragem dos dados ocorre da seguinte forma : 
- O filtro é ativado quando se registra uma medição de carga nos minutos xxh14, xxh29, xxh44 ou xxh59;

- Para cada concessionária:

o São lidos os valores de carga dos últimos 15 minutos e aplicado o filtro;

o É feita uma média da carga filtrada nos 15 minutos. Os intervalos lidos e a hora correspondente gravada na base de dados local estão na Tabela 5-1.

Tabela 5-1 - Inserção de dados de carga filtrados

\begin{tabular}{|c|c|}
\hline Intervalo lido & Hora gravada \\
\hline xxh00 a xxh14 & xxh00 \\
\hline xxh15 a xxh29 & xxh15 \\
\hline xxh30 a xxh44 & xxh30 \\
\hline xxh45 a xxh59 & xxh45 \\
\hline
\end{tabular}

A hora gravada foi adotada, podendo ser qualquer horário no intervalo lido, desde que o intervalo entre elas seja de 15 minutos.

\subsubsection{Cálculo da Energia}

A energia diária é calculada pela integração da curva de potência ativa que será a área de cada retângulo de altura igual à potência e largura 15 minutos, conforme vemos na Figura 5-2.

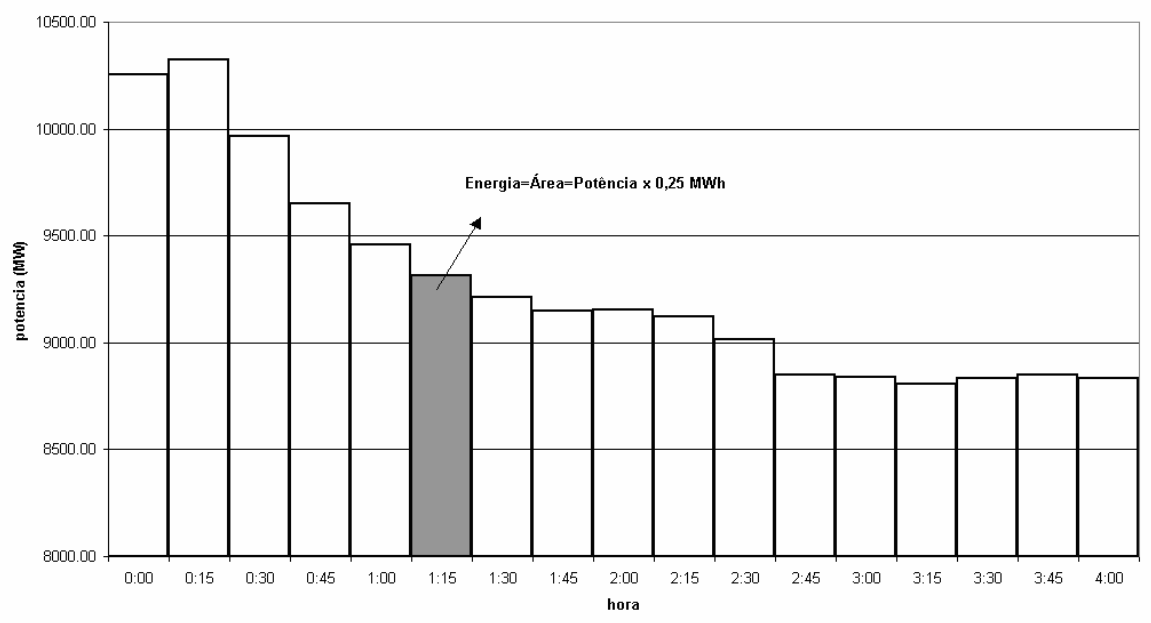

Figura 5-2 - Cálculo da Energia Diária 
Assim temos :

$$
\begin{aligned}
& E=\sum_{n=0}^{96} P_{n} \times 0,25 \mathrm{MWh} \\
& \text { onde : } \begin{array}{ll}
E & \text { é a energia calculada em MWh } \\
n & \text { é o índice das } 96 \text { divisões do dia ( intervalos de } \\
& 15 \text { minutos) } \\
P_{n} \quad \text { é a potência filtrada no instante } n \text { dada em MW }
\end{array}
\end{aligned}
$$

\subsubsection{Previsões}

\subsubsection{Previsão de energia}

A energia prevista para o dia para o qual queremos prever a carga é uma das entradas das RNAs de previsão de carga.

Para obter esse valor, utiliza-se um conjunto de redes neurais próprio, sendo uma para cada concessionária e para cada dia da semana.

Essas RNAs possuem um total de 13 entradas:

- a energia e indicação de feriado dos 3 dias anteriores de mesmo tipo;

- a energia e indicação de feriado dos 2 dias imediatamente anteriores;

- a indicação de feriado para o dia para o qual se quer prever a energia;

- Indicação de feriado para os dois dias seguintes ao que se quer prever a energia.

Os resultados da previsão de energia são gravados na base de dados local. A previsão de energia é executada toda vez que for calculada a energia diária, ao final de um dia. 
Os testes de treinamento das redes neurais indicaram uma configuração de 2 camadas internas de 10 e 6 neurônios respectivamente como adequada para todas as redes neurais de energia.

Os erros totais (anexo A) obtidos para as previsões de todos os dias da semana para cada concessionária estão na Tabela 5-2.

Tabela 5-2 - Erros médios das RNAs de previsão de energia

\begin{tabular}{|c|c|c|c|c|}
\hline & CTEEP & CESP & CPFL & Eletropaulo \\
\hline Erro total das previsões (\%) & 1,7 & 4,9 & 5,8 & 2,1 \\
\hline Desvio padrão dos erros (\%) & 1,6 & 4,0 & 8,4 & 2,6 \\
\hline
\end{tabular}

A distribuição dos erros de previsão para cada concessionária encontra-se na Figura 5-3, Figura 5-4, Figura 5-5 e Figura 5-6.

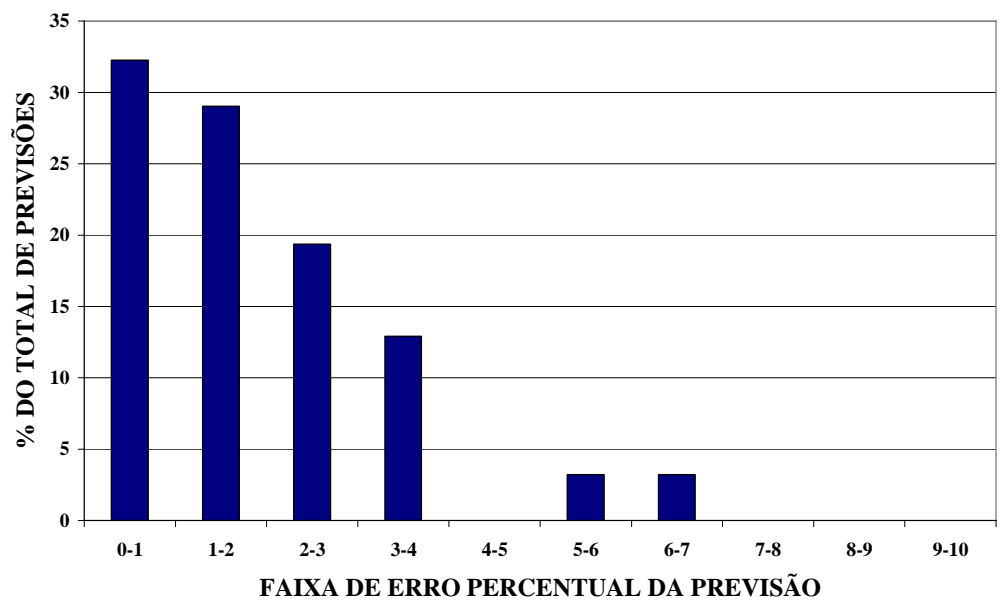

Figura 5-3 - Distribuição dos erros de previsão de energia da CTEEP 


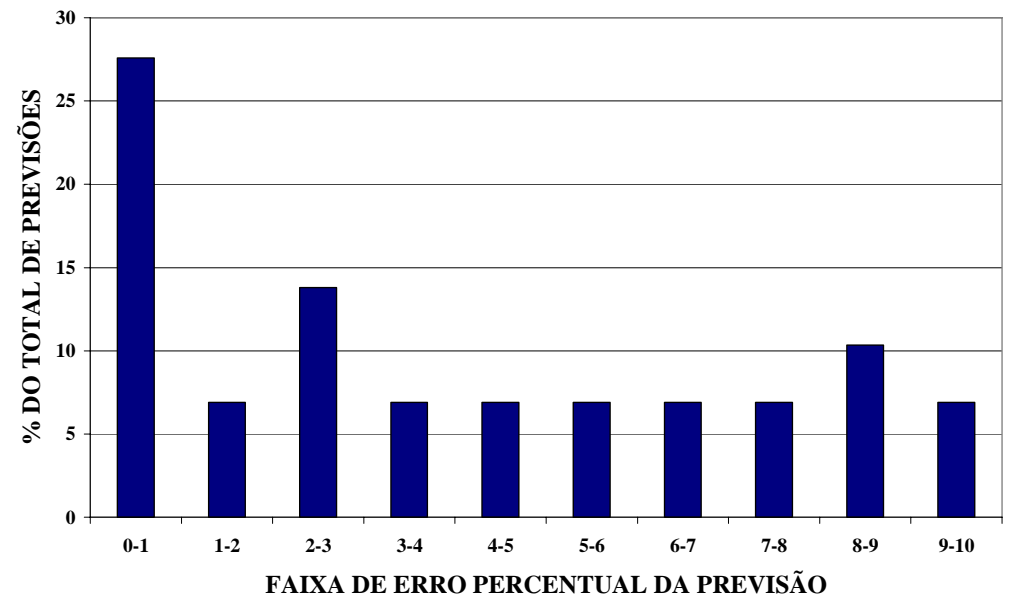

Figura 5-4 - Distribuição dos erros de previsão de energia da CPFL

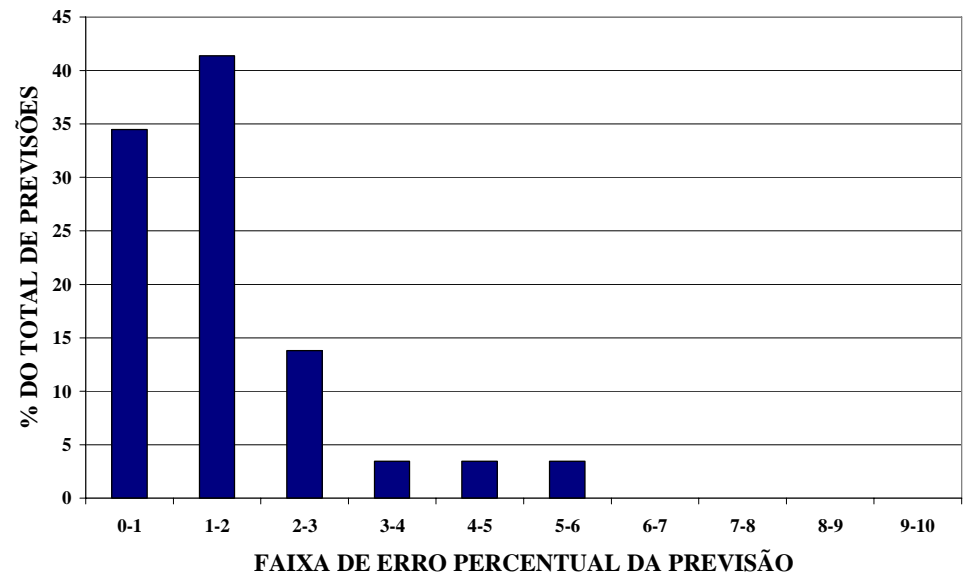

Figura 5-5 - Distribuição dos erros de previsão de energia da ELETROPAULO

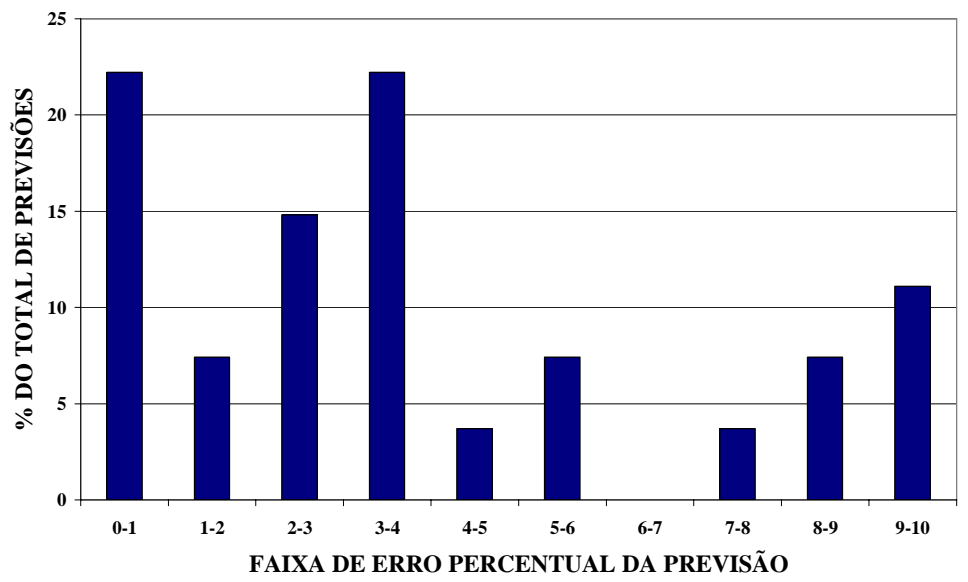

Figura 5-6 - Distribuição dos erros de previsão de energia da CESP 
A precisão das previsões da CTEEP e ELETROPAUPLO se deve a melhor qualidade dos dados de carga dessas regiões. O histórico das regiões CESP e CPFL dependem em parte de informações das mesmas fornecidas a CTEEP, podendo assim haver falhas nos dados. 


\subsubsection{Previsão da Carga}

Para cada dia da semana e para cada concessionária há uma RNA previamente treinada para a previsão da carga. Cada rede possui 300 entradas:

- Curvas de carga filtrada para os três dias anteriores de mesmo tipo;

- Temperatura ambiente máxima e mínima de cada um dos três dias anteriores de mesmo tipo;

- Energia diária de cada um dos três dias anteriores de mesmo tipo;

- Previsão de temperatura máxima e mínima para o dia a ser previsto;

- Previsão da energia para o dia a ser previsto.

A previsão de carga é executada após a previsão com sucesso da energia diária. Devido a maior complexidade das redes de previsão de carga em relação às de energia, para cada dia da semana e concessionária foram obtidas configurações diferentes. As configurações foram obtidas através de testes e estão na Tabela 5-3.

Tabela 5-3 - Melhores configurações de RNA para a previsão da carga

\begin{tabular}{|c|c|c|c|c|}
\hline dia da semana & CTEEP & CESP & CPFL & ELETROPAULO \\
\hline segunda & $100 \_100 \_100$ & $100 \_100 \_100 \_100$ & $30 \_30 \_30$ & 20 \\
\hline terça & $100 \_100$ & $100 \_100 \_100$ & $30 \_30 \_30$ & $100 \_100 \_100$ \\
\hline quarta & $100 \_100$ & $100 \_100$ & $100 \_100$ & $50 \_50 \_50$ \\
\hline quinta & $100 \_100 \_100$ & $100 \_100$ & $30 \_30$ & 100_100_100_100 \\
\hline sexta & 20 & 20_20_20_20 & $50 \_50 \_50$ & 30_30_30 \\
\hline sábado & $10 \_10 \_10 \_10$ & $50 \_50 \_50$ & $50 \_50$ & 10 \\
\hline domingo & $50 \_50 \_50 \_50$ & 10 & $30 \_30 \_30 \_30$ & $50 \_50 \_50$ \\
\hline
\end{tabular}




\subsubsection{Apresentação dos resultados}

O módulo de apresentação dos dados pode ser instalado e executado em qualquer computador com acesso ao servidor via rede TCP/IP.

Pode-se ver as curvas dos históricos de carga, energia e temperatura para todas as regiões e as previsões de carga e energia.

Na Figura 5-7 tem-se um exemplo da tela de visualização dos dados.

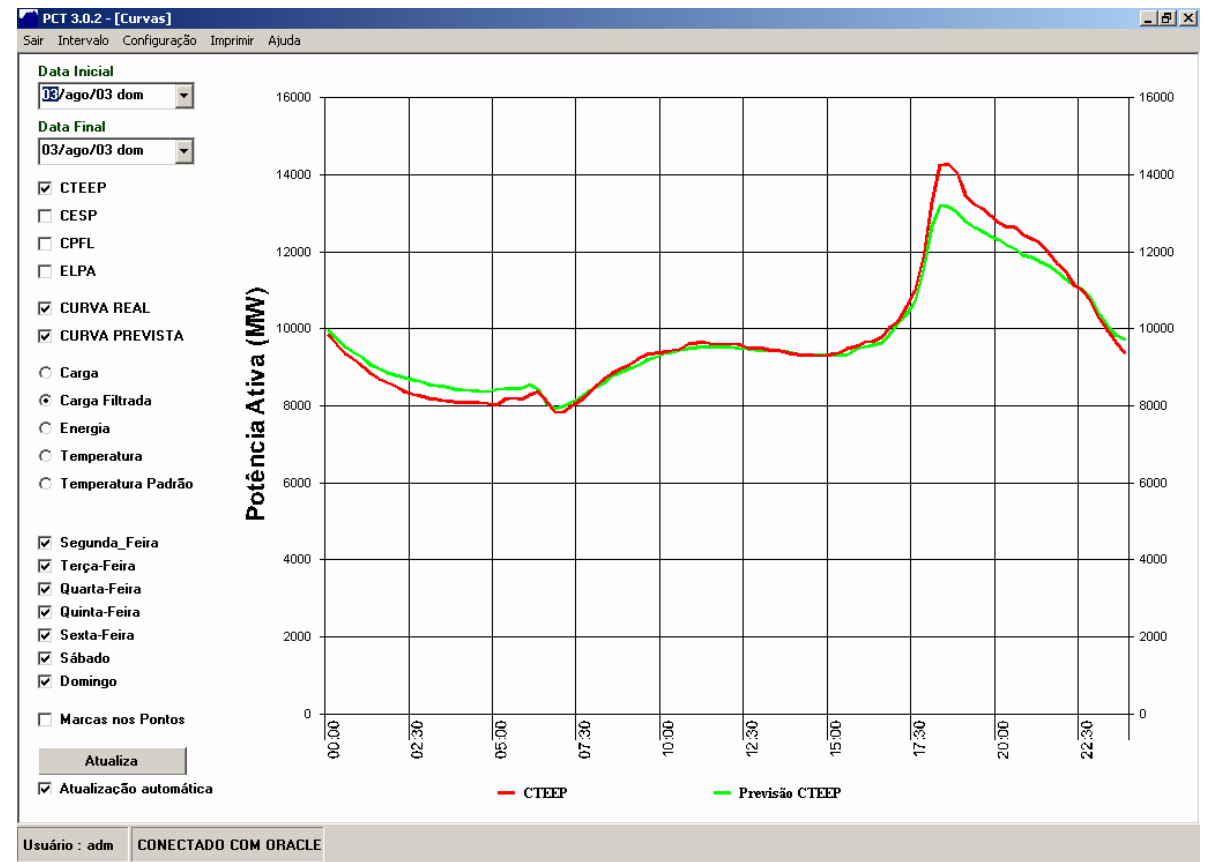

Figura 5-7 - Tela de visualização da curva real (vermelha) e prevista (verde)

Facilidades como definição do intervalo de tempo do gráfico, concessionárias e dias da semana estão disponíveis. 


\subsubsection{Correção da previsão}

A análise de diversas previsões executadas mostra que muitas vezes a curva de carga prevista possui um perfil muito semelhante à carga real, mas deslocada para mais ou menos. A soma de um offset a curva pode diminuir o erro da previsão.

Assim, o PCT utilizado um processo simples para a correção das curvas previstas, baseado na média das diferenças percentuais entre as curvas real e prevista, calculado ponto a ponto. Esse processo apresenta uma melhoria significativa da curva de previsão ao longo do dia, fato que auxilia a operação do sistema CTEEP.

Ao longo do dia, conforme vão sendo tomadas medidas reais da curva de carga, cada ponto da curva prevista é comparado com a curva real e calculada a diferença percentual entre elas. A média das diferenças entre cada ponto fornece um valor que é multiplicado na curva prevista reduzindo assim sua diferença com a curva real.

O processo não altera o perfil da curva, apenas causa um deslocamento no eixo da potência aproximando mais acurva prevista da real.

Assim para cada ponto da curva prevista temos:

$$
P_{n}^{\prime}=P_{n} *\left(1+\frac{\sum_{x=1}^{96} \frac{\left(P_{P R E V x}-P_{R E A L x}\right)}{P_{R E A L x}}}{96}\right)
$$

Onde $\quad \mathrm{P}_{\mathrm{n}} \quad$ ponto da curva de carga prevista corrigido

$\mathrm{P}_{\mathrm{n}} \quad$ ponto da curva de carga prevista

$\mathrm{P}_{\text {PREVx }} \quad \mathrm{x}$-éssimo ponto da curva de carga prevista

$\mathrm{P}_{\mathrm{REALx}} \mathrm{x}$-éssimo ponto da curva de carga real

Podemos observar a correção na Figura 5-8 onde uma previsão não muito boa pode ser significativamente melhorada. 


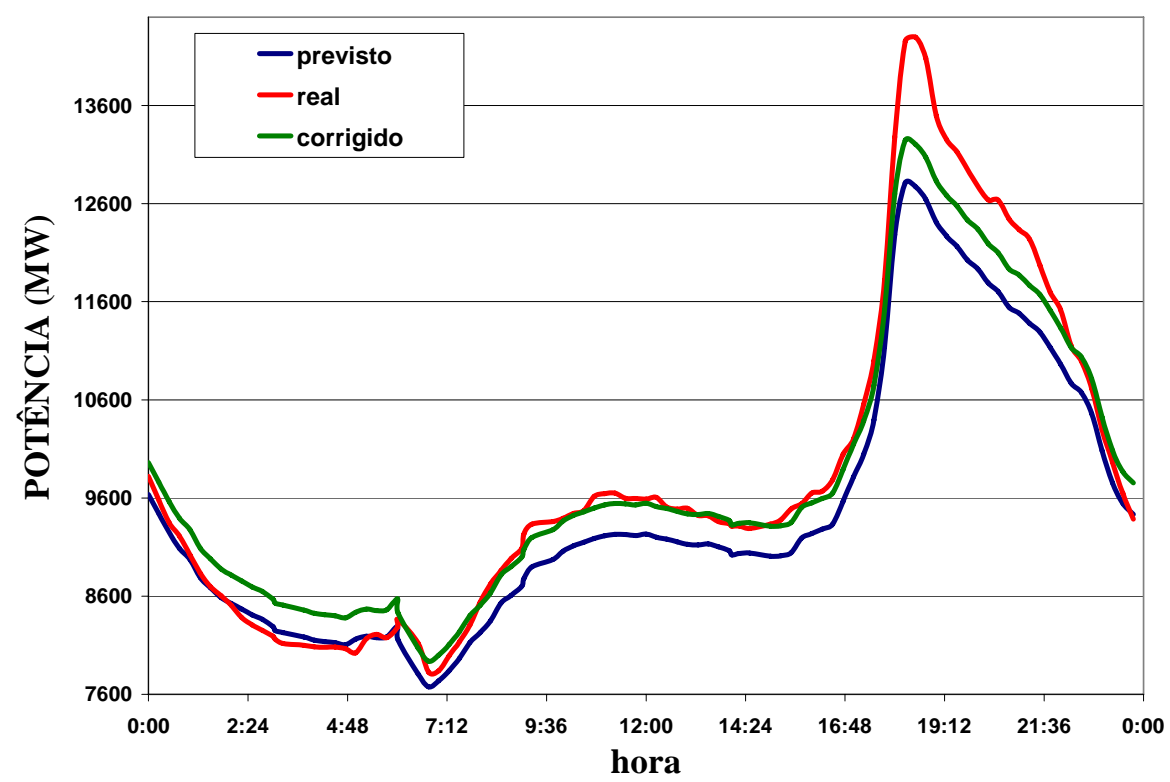

Figura 5-8 - Correção da Previsão

O processo de correção foi executado em uma série de curvas e os resultados estão na Tabela 5-4, onde se vê a melhoria da previsão com a correção.

Tabela 5-4 - Correção da previsão

\begin{tabular}{|l|c|c|}
\hline & Curva prevista & Curva prevista corrigida \\
\hline ERRO MÉDIO (\%) & 3,49 & 2,23 \\
\hline DESVIO PADRÃO & 2,40 & 1,80 \\
\hline ERRO MÁXIMO (\%) & 10,67 & 7,64 \\
\hline ERRO MÍNIMO (\%) & 0,10 & 0,10 \\
\hline
\end{tabular}




\subsubsection{Treinamento de Redes Neurais}

A fim de executar as previsões, as redes neurais precisam ser treinadas com o histórico de dados. Com o passar do tempo, como há uma evolução do consumo, o comportamento do sistema elétrico absorvido pelas redes neurais deixa de ser válido e precisam ser treinadas novamente com os dados novos.

O PCT permite definir um conjunto de treinamento de dados automaticamente definindo:

- $\quad$ Região a ser utilizada (CTEEP, CESP, CPFL ou ELETROPAULO);

- Intervalo de tempo dos dados. O historiador possui dados a partir de julho de 2001;

- Dias da semana a serem utilizados;

Na Figura 5-9 tem-se a tela de definição de dados de treinamento do PCT.

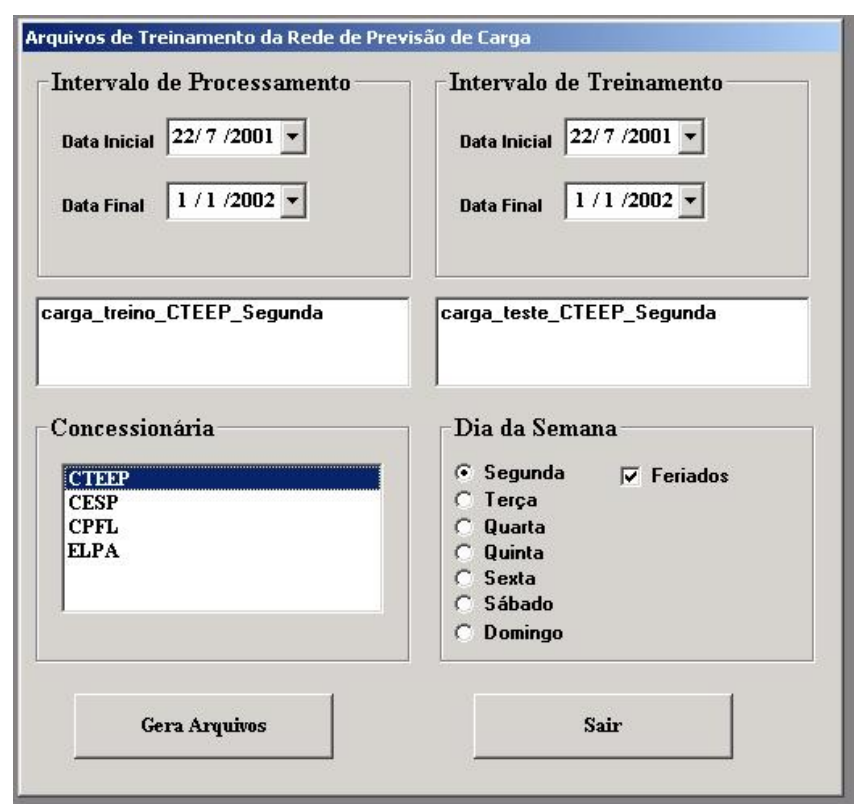

Figura 5-9 - Geração de arquivos de treinamento para redes neurais

Feriados podem ser incluídos ou não no conjunto de dados.

$\mathrm{O}$ treinamento da rede propriamente dito permite o ajuste da: 
- Estrutura de rede neural (número de camadas e neurônios em cada uma);

- Parâmetros do algoritmo de treinamento: número de iterações, coeficiente de aprendizado, etc.

Um exemplo da tela de treinamento do PCT pode ser observado na Figura $5-10$.

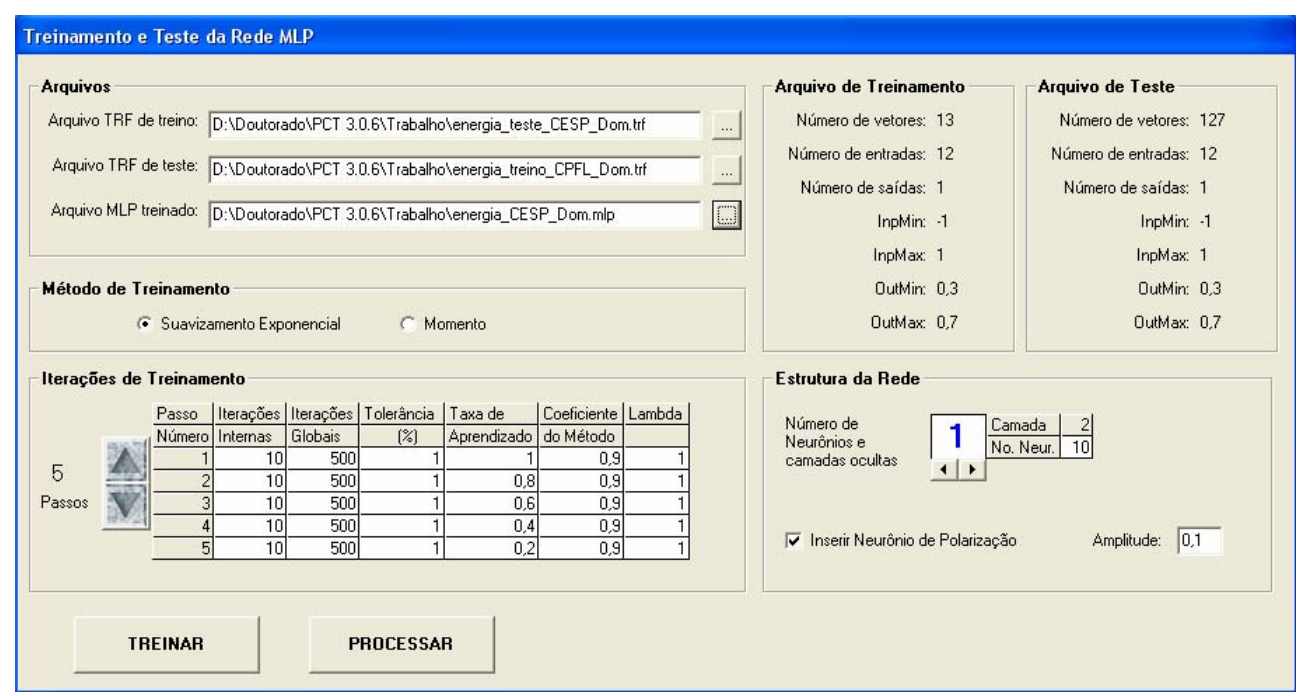

Figura 5-10 - Tela de treinamento das redes neurais

Com as redes neurais treinadas, é preciso associar cada rede neural a uma concessionária e dia da semana. O sistema ainda permite que dias especiais como feriados possam ter redes neurais específicas associadas a eles. A tela de configuração pode ser vista na Figura 5-11. 


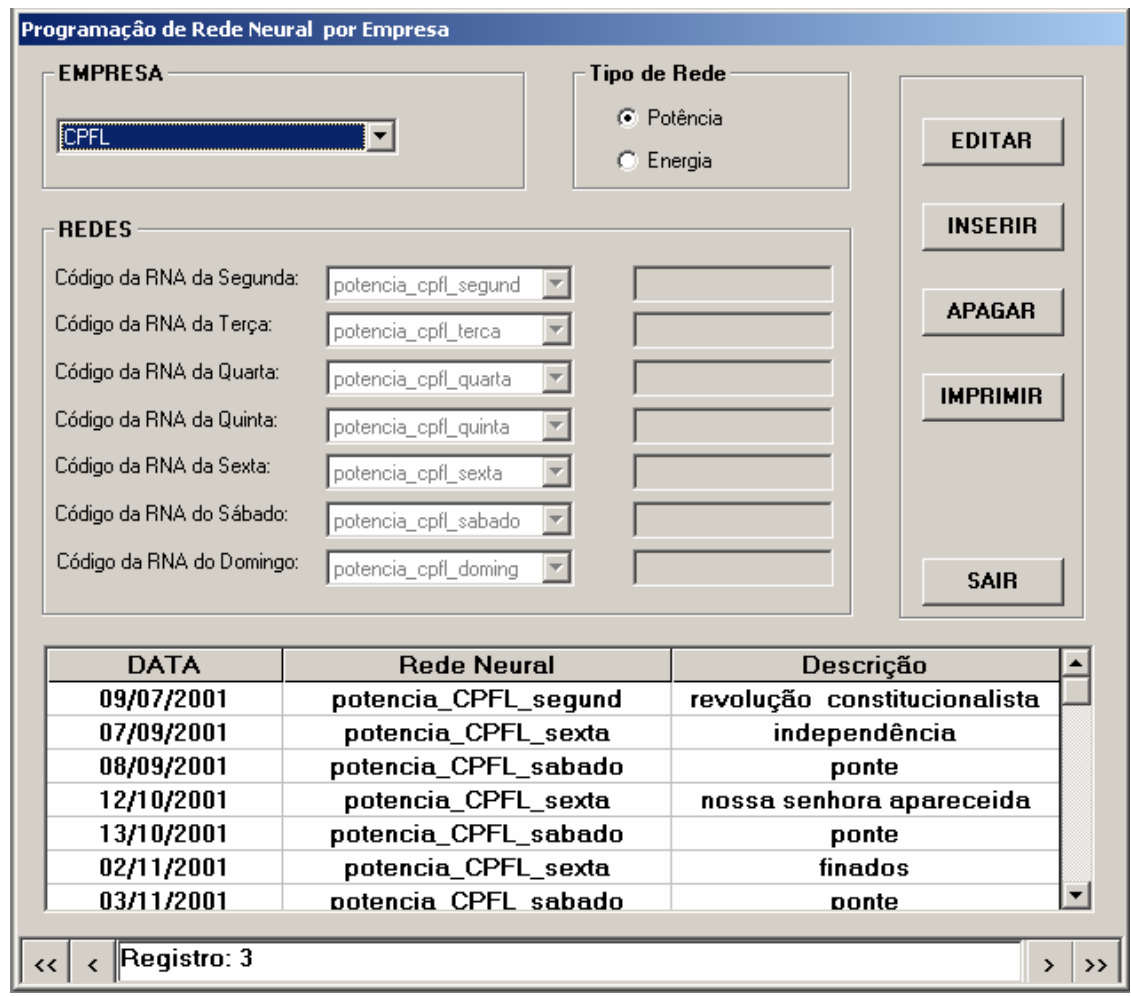

Figura 5-11 - Configuração de redes neurais/concessionária 


\subsection{Resultados obtidos}

Os resultados mais importantes fornecidos pelo PCT se referem à região da CTEEP, que engloba o estado de São Paulo. Para as redes neurais de previsão de energia diária, o erro médio das previsões encontra-se na Tabela 5-5.

Tabela 5-5 - Desempenho das redes neurais de previsão de energia

\begin{tabular}{|c|c|c|}
\hline Dia semana & Erro médio da previsão & Desvio padrão \\
\hline segunda-feira & 0,8 & 0,8 \\
\hline terça-feira & 0,9 & 0,7 \\
\hline quarta-feira & 1,1 & 0,6 \\
\hline quinta-feira & 1,1 & 0,8 \\
\hline sexta-feira & 1,2 & 1,0 \\
\hline sábado & 1,2 & 1,3 \\
\hline domingo & 1,0 & 0,9 \\
\hline
\end{tabular}

Para as redes neurais de previsão de carga tem-se a Tabela 5-6.

Tabela 5-6 - Desempenho das redes neurais de previsão de carga

\begin{tabular}{|c|c|c|}
\hline Dia semana & Erro médio da previsão & Desvio padrão \\
\hline segunda-feira & 2,6 & 1,4 \\
\hline terça-feira & 2,1 & 1,2 \\
\hline quarta-feira & 1,7 & 0,9 \\
\hline quinta-feira & 1,8 & 1,7 \\
\hline sexta-feira & 2,4 & 1,6 \\
\hline sábado & 2,3 & 1,4 \\
\hline domingo & 2,7 & 1,1 \\
\hline
\end{tabular}

E a distribuição geral de erros conforme a Figura 5-12.

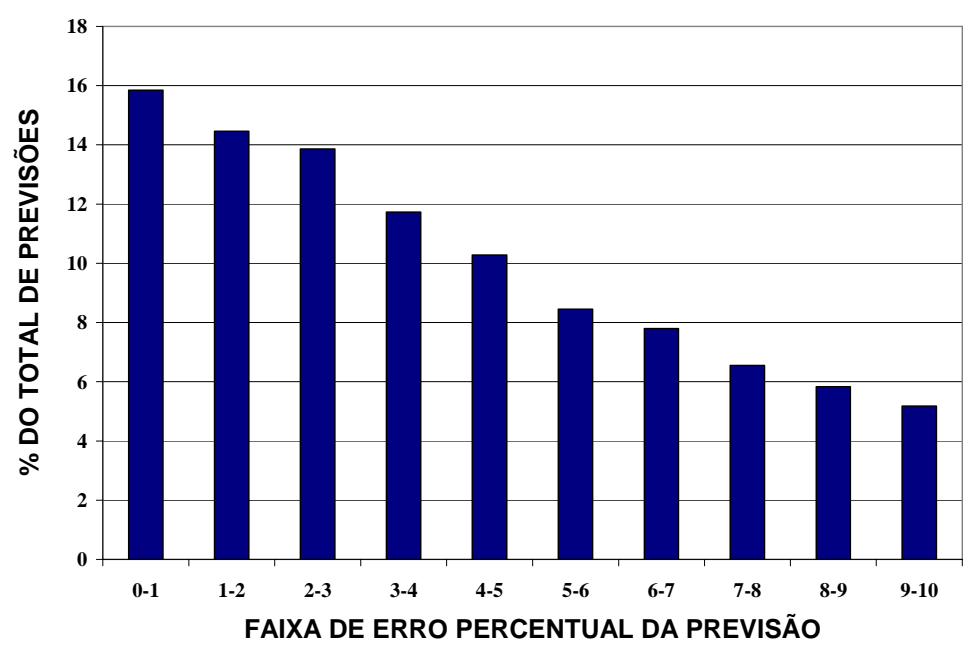

Figura 5-12 - Distribuição de erros da previsão de carga da CTEEP 
Devido a menor confiabilidade dos dados das demais regiões e um histórico de temperaturas menor disponível, os erros obtidos foram maiores mas, passíveis de melhora com ajuste dos dados e retreinamento das redes.

Nas Tabela 5-7, Tabela 5-8 e Tabela 5-9 tem-se os resultados médios das previsões e na Figura 5-13, Figura 5-14 e Figura 5-15 a distribuição geral dos erros das previsões.

Tabela 5-7 - Desempenho das redes neurais de previsão de carga da CPFL

\begin{tabular}{|c|c|c|}
\hline Dia semana & Erro médio da previsão & Desvio padrão \\
\hline segunda-feira & 5,9 & 6,4 \\
\hline terça-feira & 5,7 & 5,6 \\
\hline quarta-feira & 3,6 & 3,2 \\
\hline quinta-feira & 4,9 & 4,9 \\
\hline sexta-feira & 4,4 & 4,6 \\
\hline sábado & 6,5 & 4,0 \\
\hline domingo & 5,9 & 4,9 \\
\hline
\end{tabular}

Tabela 5-8 - Desempenho das redes neurais de previsão de carga da CESP

\begin{tabular}{|c|c|c|}
\hline Dia semana & Erro médio da previsão & Desvio padrão \\
\hline segunda-feira & 5,9 & 5,9 \\
\hline terça-feira & 3,7 & 3,6 \\
\hline quarta-feira & 7,5 & 5,9 \\
\hline quinta-feira & 4,4 & 5,1 \\
\hline sexta-feira & 7,8 & 6,4 \\
\hline sábado & 7,8 & 4,7 \\
\hline domingo & 4,5 & 6,0 \\
\hline
\end{tabular}

Tabela 5-9 - Desempenho das redes neurais de previsão de carga da ELETROPAULO

\begin{tabular}{|c|c|c|}
\hline Dia semana & Erro médio da previsão & Desvio padrão \\
\hline segunda-feira & 4,6 & 6,1 \\
\hline terça-feira & 5,1 & 5,7 \\
\hline quarta-feira & 4,5 & 4,9 \\
\hline quinta-feira & 5,8 & 6,0 \\
\hline sexta-feira & 4,7 & 6,8 \\
\hline sábado & 6,0 & 6,1 \\
\hline domingo & 5,8 & 4,5 \\
\hline
\end{tabular}




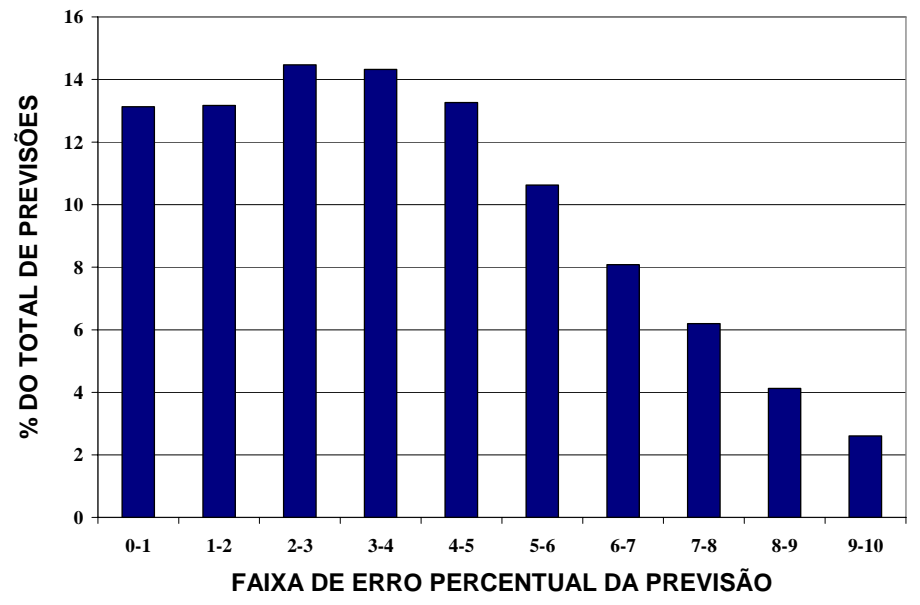

Figura 5-13 - Distribuição dos erros para previsões da ELETROPAULO

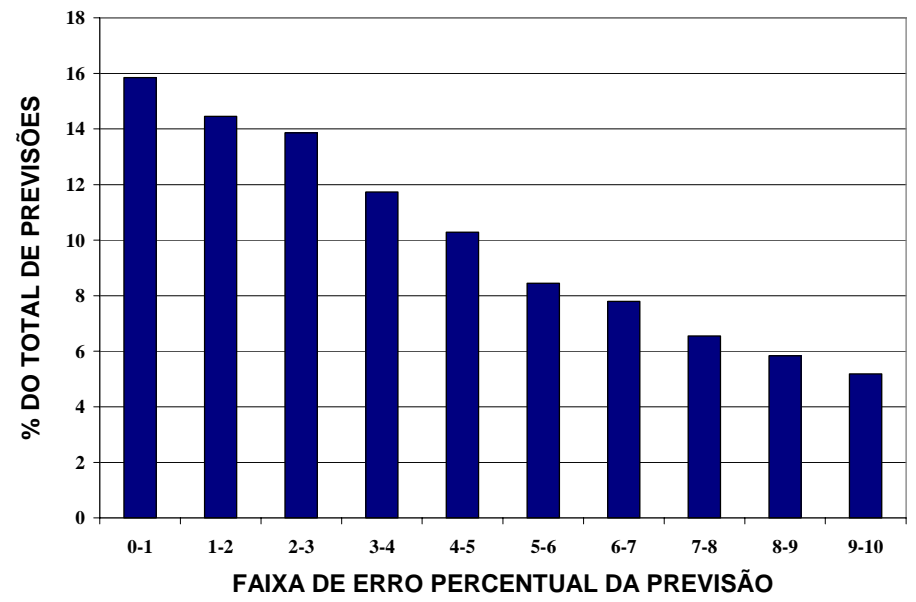

Figura 5-14 - Distribuição dos erros para previsões da CESP

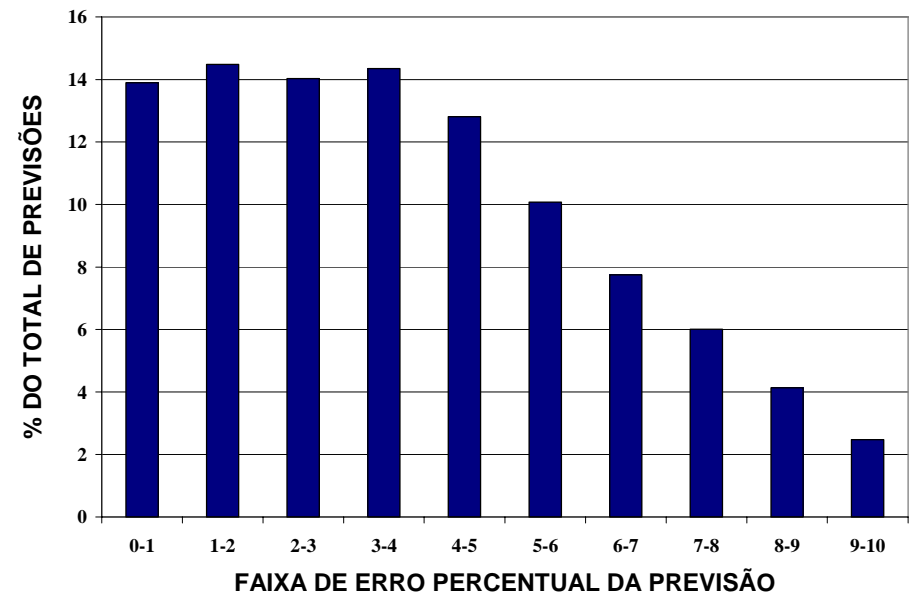

Figura 5-15 - Distribuição dos erros para previsões da CPFL 


\subsection{Resultados obtidos em trabalhos semelhantes}

Uma análise da bibliografia atualizada sobre o uso apenas de redes neurais MLP com backpropagation, revela um número pequeno de trabalhos, mas indica que o método é capaz de fornecer bons resultados..

Afkhami [70] mostra uma aplicação que prevê a curva de carga diária com uma antecedência de 24 horas. As curvas de carga diárias são agrupadas de acordo com a temperatura média diária havendo redes neurais para cada grupo. Cada curva de carga ainda é dividida em 3 períodos de 8 horas com redes neurais próprias para cada período. Temperatura ambiente e umidade são parte das entradas das redes. Os resultados obtidos indicam erros médios menores que $2 \%$.

Yu-Jun [72] agrupa dias semelhantes através de um 'índice de semelhança' e obtém erros da ordem de $2.5 \%$.

Ramezani [73] apresenta um sistema capaz de prever a curva de carga diária do dia seguinte, o pico de carga do dia seguinte e a carga na hora seguinte. Utilizando dados de 3 dias semelhantes passados e temperatura ambiente, as previsões de curva diária e pico obtiveram erros médios de 1,2 e 2.5\% respectivamente. A previsão teve erro de $2 \%$.

Barghinia [76] agrupa as curvas de carga semelhantes e utiliza a temperatura ambiente obtendo erros de até $2.5 \%$.

Esses exemplos confirmam a exatidão do backpropagation. Novamente o agrupamento das curvas de carga em grupos semelhantes por algum critério e o uso de temperatura ambiente garante uma melhoria na qualidade das previsões. 


\section{Conclusão}

Pode-se verificar que as técnicas de inteligência artificial, em especial as redes neurais, se consolidaram como ferramentas para a previsão de carga em sistemas de potência.

O desenvolvimento e testes de um sistema de previsão em conjunto com a concessionária CTEEP Transmissão Paulista verificou que:

- É possível obter erros de previsão da ordem de $2 \%$ utilizando-se redes neurais tipo MLP com treinamento do tipo backpropagation, mesmo sendo um dos primeiros e mais simples processos na área das redes neurais;

- O agrupamento de curvas de carga em classes e uso de redes neurais específicas para cada uma delas garante melhores previsões;

- A temperatura ambiente é sem dúvida a variável exógena de maior influência na previsão da carga;

- A energia diária é uma variável importante para fornecer informações sobre sazonalidades anuais e dias especiais;

- O tratamento de dias especiais como feriados é um problema constante e ainda não totalmente resolvido;

Devido à dificuldade de determinação das configurações das redes neurais para as previsões e longos períodos de treinamento e testes, o tratamento e redução da quantidade de dados utilizados podem auxiliar em muito o processo de previsão.

A transformada Wavelet aparece como uma ferramenta capaz de filtrar e compactar os dados utilizados pelas redes neurais. Com a redução da quantidade de informação processada pelas redes neurais, seu treinamento e uso se tornam mais simples, além do esforço computacional ser reduzido. 


\section{Bibliografia}

\subsection{Efeito de variáveis climáticas}

[1] Yi Yuri Wen; Zhou Hong Jiang; A Practical Model Of Daily Power Load Forecasting Based On Weather Variables; Systems, Man, and Cybernetics, 1988, Proceedings of the 1988 IEEE International Conference on; Volume 1; August 8-12; Page(s) 310-313; 1988.

[2] Peng, T.M.; Hubele, N.F.; Karady, G.G.; Advancement in the application of neural networks for short-term load forecasting; Power Systems, IEEE Transactions on; Volume 7; Issue 1; Page(s) 250-257; 1992.

[3] Ho, K.L.; Hsu, Y.-Y.; Yang, C.-C.; Short term load forecasting using a multilayer neural network with an adaptive learning algorithm; Power Systems, IEEE Transactions on; Volume 7; Issue 1; Page(s) 141-149; 1992.

[4] Chen, S.-T.; Yu, D.C.; Moghaddamjo, A.R.; Weather sensitive short-term load forecasting using nonfully connected artificial neural network; Power Systems, IEEE Transactions on; Volume 7; Issue 3; Page(s) 1098-1105; 1992.

[5] Papalexopoulos, A.D.; Shangyou Hao; Tie-Mao Peng; An implementation of a neural network based load forecasting model for the EMS; Power Systems, IEEE Transactions on; Volume 9; Issue 4; Page(s) 1956-1962; 1994.

[6] Lamedica, R.; Prudenzi, A.; Sforna, M.; Caciotta, M.; Cencellli, V.O.; $A$ neural network based technique for short-term forecasting of anomalous load periods; Power Systems, IEEE Transactions on; Volume 11; Issue 4; Page(s) 1749-1756; 1996

[7] Chow, T.W.S.; Leung, C.T.; Neural network based short-term load forecasting using weather compensation; Power Systems, IEEE Transactions on; Volume 11; Issue 4; Page(s) 1736-1742; 1996

[8] Hara, K.; Fukui, S.; Iba, K.; A new environment for improving accuracy of load forecasting using load and weather data; Advances in Power System Control, Operation and Management, 1997. APSCOM-97. Fourth International Conference on (Conf. Publ. No. 450); Volume 1; Page(s) 135$138 ; 1997$

[9] Wang Feng; Yu Er Keng; Liu Yong Qi; Liu Jun; Yan Chen Shan; Shortterm load forecasting based on weather information; Power System Technology, 1998. Proceedings. POWERCON '98. 1998 International Conference on; Volume 1; Page(s) 572-575; 1988.

[10] Palacio, D.R.; Simple model for load forecast weather sensitive; Electricity Distribution, 2001. Part 1; Contributions. CIRED. 16th International Conference and Exhibition on (IEE Conf. Publ No. 482); Page(s) 288- 288; 2001.

[11] Taylor, J.W.; Buizza, R.; Neural network load forecasting with weather ensemble predictions; Power Systems, IEEE Transactions on; Volume 17; Issue 3; Aug. 2002; Page(s) 626-632; 2002. 
[12] Ruzic, S.; Vuckovic, A.; Nikolic, N.; Weather sensitive method for short term load forecasting in Electric Power Utility of Serbia; Power Systems, IEEE Transactions on; Volume 18; Issue 4; Page(s) 1581-1586; 2003.

[13] Contaxi, E.G.; Kavatza, S.; Application of a weather-sensitive peak load forecasting model to the Hellenic system; Electrotechnical Conference, 2004. MELECON 2004. Proceedings of the 12th IEEE Mediterranean; Volume 3; Page(s) 819-822; Vol.3; 2004.

[14] Qia Ding; Hui Zhang; Tao Huang; Junyi Zhang; A Holiday Short Term Load Forecasting Considering Weather Information; Power Engineering Conference, 2005. IPEC 2005. The 7th International; Page(s) 1-4; 2005.

[15] Ching-Lai Hor; Watson, S.J.; Majithia, S.; Analyzing the impact of weather variables on monthly electricity demand; Power Systems, IEEE Transactions on ;Volume 20; Issue 4; Page(s) 2078-2085; 2005.

[16] Hanjie Chen; Yijun Du; Jiang, J.N.; Weather sensitive short-term load forecasting using knowledge-based ARX models; Power Engineering Society General Meeting, 2005. IEEE; volume 1; Page(s) 190-196; Vol. 1; 2005.

[17] Lima, W. S., Ohishi, T.; Uso de variáveis climáticas em previsão de carga no periodo de demanda de ponta utilizando redes neurais artificial, XIV SNPTEE; 1997.

\subsection{Lógica fuzzy}

[18] Teixeira, M.A.; Zaverucha, G.; Fuzzy Markov predictor in electric load forecasting; Neural Networks, 2002. IJCNN '02. Proceedings of the 2002 International Joint Conference on; Volume: 3; 12-17 May 2002; Page(s) 2416-2421; 2002

[19] Kosko, B.; Fuzzy systems as universal approximators; Computers, IEEE Transactions on; Volume: 43; Issue: 11; Nov. 1994; Pages 1329-1333; 1994.

[20] Chiu, S.L.; A cluster estimation method with extension to fuzzy model identification; Fuzzy Systems, 1994. IEEE World Congress on Computational Intelligence. Proceedings of the Third IEEE Conference on; 26-29 June 1994; Pages 1240-1245; vol.2; 1994.

[21] Bansal, R.C.; Bibliography on the fuzzy set theory applications in power systems (1994-2001); Power Systems, IEEE Transactions on; Volume: 18; Issue: 4; Nov. 2003; Pages 1291-1299; 2003.

[22] Al-Kandari, A.M.; Soliman, S.A.; El-Hawary, M.E.; Fuzzy systems application to electric short-term load forecasting. I. Problem formulation; Power Engineering, 2003 Large Engineering Systems Conference on; 7-9 May 2003; Pages 125-130; 2003.

[23] Al-Kandari, A.M.; Soliman, S.A.; El-Hawary, M.E.; Fuzzy systems application to electric short-term load forecasting. II. Computational results; Power Engineering, 2003 Large Engineering Systems Conference on; 7-9 May 2003; Pages 131-137; 2003. 
[24] Ozveren, C.S.; Vechakanjana, C.; Birch, A.P.; Fuzzy classification of electrical load demand profiles-a case study; Power System Management and Control, 2002; Fifth International Conference on (Conf. Publ. No. 488); 17-19 April 2002; Pages 353-358; 2002.

[25] Angelov, P.; Buswell, R.; Identification of evolving fuzzy rule-based models; Fuzzy Systems, IEEE Transactions on; Volume: 10; Issue: 5; Oct. 2002; Pages 667-677; 2002.

[26] Mori, H.; Sone, Y.; Moridera, D.; Kondo, T.; A parallel tabu search based fuzzy inference method for short-term load forecasting; Power Engineering Society Winter Meeting, 2000. IEEE; Volume: 3; 23-27 Jan. 2000; Pages 1702-1707; vol.3; 2000.

[27] Runkler, T.A.; Bezdek, J.C.; Alternating cluster estimation: a new tool for clustering and function approximation; Fuzzy Systems, IEEE Transactions on, Volume: 7; Issue: 4; Aug. 1999; Pages 377-393; 1999.

[28] Nazarko, J.; Zalewski, W.; An evaluation of an accuracy of the fuzzy regression analysis in the electrical load estimation; Fuzzy Systems Conference Proceedings, 1999. FUZZ-IEEE '99. 1999 IEEE International; Volume: 2; 22-25 Aug. 1999; Pages 732-737; vol.2; 1999.

[29] Wu, H.-C.; Lu, C.; Automatic fuzzy model identification for short-term load forecast; Generation, Transmission and Distribution, IEE Proceedings, Volume: 146 , Issue: 5 , Sept. 1999 ; Pages:477 - 482; 1999.

[30] Mori, H.; Sone, Y.; Moridera, D.; Kondo, T.; Fuzzy inference models for short-term load forecasting with tabu search; Systems, Man, and Cybernetics, 1999. IEEE SMC '99 Conference Proceedings. 1999 IEEE International Conference on; Volume: 6; 12-15 Oct. 1999; Pages 551-556; vol 6; 1999.

[31] Mastorocostas, P.A.; Theocharis, J.B.; Bakirtzis, A.G.; Fuzzy modeling for short term load forecasting using the orthogonal least squares method; Power Systems, IEEE Transactions on; Volume: 14; Issue: 1; Feb. 1999; Pages 29-36; 1999.

[32] Nazarko, J.; Zalewski, W.; The fuzzy regression approach to peak load estimation in power distribution systems; Power Systems, IEEE Transactions on; Volume: 14; Issue: 3; Aug. 1999; Pages 809-814; 1999.

[33] Birch, A.P.; Ozveren, C.S.; Sapeluk, A.T.; A generic load profiling technique using fuzzy classification; Metering and Tariffs for Energy Supply, Eighth International Conference on (Conf. Publ. No. 426); 3-5 July 1996; Pages 203-207; 1996.

[34] D. K. Ranaweera, N. F. Hubele and G. G. Karady; Fuzzy logic for short term load forecasting; International Journal of Electrical Power \& Energy Systems; Volume 18; Issue 4; May 1996; Pages 215-222; 1996.

[35] Mori, H.; Kobayashi, H.; Optimal fuzzy inference for short-term load forecasting; Power Systems, IEEE Transactions on; Volume: 11; Issue: 1; Feb. 1996; Pages 390-396; 1996.

[36] van der Lubbe, J.C.A.; Backer, E.; Hierarchical classification inference for fuzzy data analysis; Proceedings of ISUMA - NAFIPS '95 The Third International Symposium on Uncertainty Modeling and Analysis and Annual Conference of the North American Fuzzy Information Processing Society; 17-20 Sept. 1995; Pages 402-407; 1995. 
[37] Zadeh, L.A.; Soft computing and fuzzy logic; Software, IEEE, Volume: 11; Issue: 6; Nov. 1994; Pages 48-56; 1994.

[38] Elkan, C; The paradoxical success of fuzzy logic; IEEE Expert; Volume: 9; Issue: 4; Aug 1994; Pages 3-49; 1994.

[39] Mamdani, E.H.; Twenty years of fuzzy control: experiences gained and lessons learnt; Fuzzy Systems, 1993; Second IEEE International Conference on; 28 March-1 April 1993; Pages 339-344; vol 1; 1993.

[40] Nomura, H.; Hayashi, I.; Wakami, N.; A learning method of fuzzy inference rules by descent method; Fuzzy Systems, 1992, IEEE International Conference on; 8-12 March 1992; Pages 203-210; 1992.

[41] Tomohiro T., Sugeno, M.; Fuzzy Identification of Systems and Its Applications to Modeling and Control; IEEE Transactions on Systems, Man and Cybernetics; vol. 15; no 1; 1985.

[42] Mohamed E. El-Hawary; Electric Power Applications of Fuzzy Systems (IEEE Press Series on Power Engineering); Wiley-IEEE Press; 1998.

[43] Fuzzy Logic Toolbox, Software Matlab;

\subsection{Redes neurais}

[44] Chen, Q; Milligan, J.; Germain, E.H.; Raub, R.; Shamsollahi, P.; Cheung, K.W.; Implementation and performance analysis of very short term load forecaster based on the electronic dispatch project in ISO New England; Power Engineering, 2001. LESCOPE '01. 2001 Large Engineering Systems Conference on; 11-13 July 2001; Page(s) 98-104; 2001.

[45] Chicco, G.; Napoli, R.; Piglione, F.; Load pattern clustering for short-term load forecasting of anomalous days; Power Tech Proceedings, 2001 IEEE Porto; Volume: 2; 10-13 Sept. 2001; 6 pp; vol 2; 2001.

[46] Hippert, H.S.; Pedreira, C.E.; Souza, R.C.; Neural networks for short-term load forecasting: a review and evaluation; Power Systems, IEEE Transactions on; Volume: 16; Issue: 1; Feb 2001; Page(s) 44-55; 2001.

[47] Senjyu, T.; Takara, H.; Uezato, K.; Funabashi, T.; One-hour-ahead load forecasting using neural network; Power Systems, IEEE Transactions on; Volume: 17; Issue: 1; Feb. 2002; Page(s) 113 -118; 2002.

[48] Siwek, K.; Osowski, S.; Regularization of neural networks for improved load forecasting in power system; Electronics, Circuits and Systems, 2001. ICECS 2001. The 8th IEEE International Conference on; Volume: 3; 2-5 Sept. 2001; Page(s) 1255-1258; vol.3; 2001.

[49] Park, D.; Mohammed, O.; Merchant, R.; Dinh, T.; Tong, C.; Azeem, A.; Farah, J.; Drake, C.; Forecasting abnormal load conditions with neural networks; Neural Networks to Power Systems, 1993. ANNPS '93, Proceedings of the Second International Forum on Applications of; 19-22 April 1993; Pages 73-78; 1993.

[50] Lima, W. S., et al; Mapas auto-organizáveis não-parametricos para análise da influencia climática nas curvas de carga; XV SNPTEE; 1999.

[51] Soares, A P., Nascimento, F. J. L. Modelagem Neural na Previsão Diária da Carga; XIV SNPTEE; 1997. 
[52] Silva, A O A, et al; Oráculo - Uma ferramenta para Previsão de carga; XVI SNPTEE 2001.

[53] Júnior, A L., Vasconcelos, G. C.; Previsão da demanda máxima mensal baseada em redes neurais; XV SNPTEE; 1999.

[54] Marra, W. , et al; Previsão de carga de curto prazo; XV SNPTEE; 1999.

[55] Yoo, H.; Pimmel, R.L.; Short term load forecasting using a self-supervised adaptive neural network; Power Systems, IEEE Transactions on; Volume: 14; Issue: 2; May 1999; Pages 779-784; 1999.

[56] Lee, K.Y.; Cha, Y.T.; Park, J.H.; Short-term load forecasting using an artificial neural network; Power Systems, IEEE Transactions on; Volume: 7; Issue: 1; Feb. 1992; Pages 124-132; 1992.

[57] Choueiki, M.H.; Mount-Campbell, C.A.; Ahalt, S.C.; Building a ‘quasi optimal' neural network to solve the short-term load forecasting problem; Power Systems, IEEE Transactions on; Volume: 12; Issue: 4; Nov. 1997; Pages 1432-1439; 1997.

[58] Hippert, H.S.; Pedreira, C.E.; Souza, R.C.; Neural networks for short-term load forecasting: a review and evaluation; Power Systems, IEEE Transactions on; Volume: 16; Issue: 1; Feb 2001; Page(s): 44 -55.

[59] Senjyu, T.; Takara, H.; Uezato, K.; Funabashi, T.; One-hour-ahead load forecasting using neural network; Power Systems, IEEE Transactions on; Volume: 17; Issue: 1; Feb. 2002; Page(s) 113-118.

[60] Tsakoumis, A.C.; Vladov, S.S.; Mladenov, V.M.; Electric load forecasting with multilayer perceptron and Elman neural network; Neural Network Applications in Electrical Engineering, 2002. NEUREL '02. 2002 6th Seminar on; 26-28 Sept. 2002; Page(s) 87-90.

[61] Marin, F.J.; Garcia-Lagos, F.; Joya, G.; Sandoval, F.; Global model for short-term load forecasting using artificial neural networks; Generation, Transmission and Distribution, IEE Proceedings-; Volume: 149; Issue 2; March 2002; Page(s): 121-125.

[62] da Silva, A.P.A.; Moulin, L.S.; Confidence intervals for neural network based short-term load forecasting ; Power Systems, IEEE Transactions on; Volume: 15; Issue: 4; Nov. 2000; Page(s) 1191-1196.

[63] Tsakoumis, A.C.; Vladov, S.S.; Mladenov, V.M.; Daily load forecasting based on previous day load; Neural Network Applications in Electrical Engineering, 2002. NEUREL '02. 2002 6th Seminar on; 26-28 Sept. 2002; Page(s) 83-86.

[64] Swarup, K.S.; Satish, B.; Integrated ANN approach to forecast load; Computer Applications in Power, IEEE; Volume: 15; Issue: 2; April 2002; Page(s) 46-51.

[65] Taylor, J.W.; Buizza, R.; Neural network load forecasting with weather ensemble predictions; Power Systems, IEEE Transactions on; Volume: 17; Issue: 3; Aug. 2002; Page(s) 626-632.

[66] Iizaka, T.; Matsui, T.; Fukuyama, Y.; A novel daily peak load forecasting method using analyzable structured neural network; Transmission and Distribution Conference and Exhibition 2002: Asia Pacific. IEEE/PES; Volume: 1; 6-10 Oct. 2002; Page(s) 394-399; vol.1. 
[67] Aboul-Magd, M.A.; Ahmed, E.E.-D.E.-S.; An artificial neural network model for electrical daily peak load forecasting with an adjustment for holidays; Power Engineering, 2001. LESCOPE '01. 2001 Large Engineering Systems Conference on; 11-13 July 2001; Page(s) 105-113.

[68] Matsui, T.; Iizaka, T.; Fukuyama, Y.; Peak load forecasting using analyzable structured neural network; Power Engineering Society Winter Meeting, 2001. IEEE; Volume: 2; 28 Jan.-1 Feb. 2001; Page(s) 405-410; vol.2.

[69] Wasserman, P. D.; Neural Computing Theory and Practice; Van Nostraand Reinhold; 1999.

[70] Afkhami, R.; Yazdi, F.M.; Application of neural networks for short-term load forecasting; Power India Conference, 2006 IEEE; 10-12 April 2006; Page(s) 5 pp.

[71] Methaprayoon, K.; Lee, W.J.; Rasmiddatta, S.; Liao, J.; Ross, R.; MultiStage Artificial Neural Network Short-term Load Forecasting Engine with Front-End Weather Forecast; Industrial and Commercial Power Systems Technical Conference; 2006 IEEE; 30-05 April 2006; Page(s) 1-7.

[72] Yu-Jun He; You-Chan Zhu; Jian-Cheng Gu; Cheng-Qun Yin; Similar day selecting based neural network model and its application in short-term load forecasting; Machine Learning and Cybernetics, 2005. Proceedings of 2005 International Conference on; Volume 8; 18-21 Aug. 2005; Page(s) 47604763; Vol. 8.

[73] Ramezani, M.; Falaghi, H.; Haghifam, M.-R.; Shahryari, G.A.; Short- Term Electric Load Forecasting Using Neural Networks; Computer as a Tool, 2005. EUROCON 2005. The International Conference on; Volume 2; 21-24 Nov. 2005; Page(s) 1525-1528.

[74] Munkhjargal, S.; Manusov, V.Z.; Artificial neural network based shortterm load forecasting; Science and Technology, 2004. KORUS 2004. Proceedings. The 8th Russian-Korean International Symposium on; Volume 1; 26 June-3 July 2004; Page(s) 262-264; vol. 1.

[75] Marin, F.J.; Garcia-Lagos, F.; Joya, G.; Sandoval, F.; Global model for short-term load forecasting using artificial neural networks; Generation, Transmission and Distribution, IEE Proceedings-; Volume 149; Issue 2; March 2002; Page(s) 121-125.

[76] Barghinia, S.; Ansarimehr, P.; Habibi, H.; Vafadar, N.; Short term load forecasting of Iran national power system using artificial neural network; Power Tech Proceedings, 2001 IEEE Porto; Volume 3; 10-13 Sept. 2001; Page(s) 5 pp; vol.3.

\subsection{Wavelets}

[77] Du Tao; Wang Xiuli; Wang Xifan; A combined model of wavelet and neural network for short term load forecasting ; Power System Technology, 2002. Proceedings. PowerCon 2002. International Conference on; Volume: 4; 13-17 Oct. 2002; Page(s): 2331 -2335; vol.4. 
[78] Zhao-Yang Dong; Bai-Ling Zhang; Qian Huang; Adaptive neural network short term load forecasting with wavelet decompositions; Power Tech Proceedings, 2001 IEEE Porto; Volume: 2; 10-13 Sept. 2001; Page(s) 6 pp.; vol.2.

[79] Huang, C.-M.; Yang, H.-T.; Evolving wavelet-based networks for shortterm load forecasting; Generation, Transmission and Distribution, IEE Proceedings-; Volume: 148; Issue: 3; May 2001; Page(s) 222-228.

[80] Zhang, Q.; Benveniste, A.; Wavelet networks Neural Networks, IEEE Transactions on; Volume: 3; Issue: 6; Nov. 1992; Pages 889-898; 1992.

[81] Ma Ning; Chen Yunping; An ANN and wavelet transformation based method for short term load forecast; Energy Management and Power Delivery, 1998. Proceedings of EMPD '98. 1998 International Conference on; Volume: 2; 3-5 March 1998; Pages 405-410; vol.2; 1998.

[82] Swee, E.G.T.; Elangovan, S.; Applications of symlets for denoising and load forecasting; Higher-Order Statistics, 1999. Proceedings of the IEEE Signal Processing Workshop on; 14-16 June 1999; Pages 165-169; 1999.

[83] Bashir, Z.; El-Hawary, M.E.; Short term load forecasting by using wavelet neural networks; Electrical and Computer Engineering, 2000 Canadian Conference on; Volume 1; 7-10 March 2000; Pages 163-166; vol.1; 2000.

[84] Graps, A; An Introduction to Wavelets; Computational Science and Engineering, IEEE; Volume 2; Issue 2; Summer 1995; Pages 50-61; 1995.

[85] Zheng Hua; Zhang Lizi; The factor analysis of short-term load forecast based on wavelet transform; Power System Technology, 2002. Proceedings. PowerCon 2002. International Conference on; Volume: 2; 13 17 Oct. 2002; Pages 1073-1076; vol.2; 2002.

\subsection{Híbridos}

[86] Ma-WenXiao; Bai-XiaoMin; Mu-LianShun; Short-term load forecasting with artificial neural network and fuzzy logic; Power System Technology, 2002. Proceedings. PowerCon 2002. International Conference on; Volume 2; 13-17 Oct. 2002; Page(s) 1101-1104; vol.2.

[87] Gavrilas, M.; Sfintes, V.C.; Filimon, M.N.; Identifying typical load profiles using neural-fuzzy models; Transmission and Distribution Conference and Exposition, 2001 IEEE/PES; Volume: 1; 28 Oct.-2 Nov. 2001; Pages 421426; vol.1; 2001.

[88] Kwang-Ho Kim; Hyoung-Sun Youn; Yong-Cheol Kang; Short-term load forecasting for special days in anomalous load conditions using neural networks and fuzzy inference method; Power Systems, IEEE Transactions on; Volume: 15; Issue 2; May 2000; Page(s) 559-565.

[89] Srinivasan, D.; Swee Sien Tan; Cheng, C.S.; Eng Kiat Chan; Parallel neural network-fuzzy expert system strategy for short-term load forecasting: system implementation and performance evaluation; Power Systems, IEEE Transactions on; Volume: 14; Issue: 3; Aug. 1999; Pages 1100-1106; 1999. 
[90] Dash, P.K.; Liew, A.C.; Rahman, S.; Fuzzy neural network and fuzzy expert system for load forecasting; Generation, Transmission and Distribution, IEE Proceedings-; Volume: 143; Issue: 1; Jan. 1996; Pages 106-114; 1996.

[91] Dipti Srinivasan; Chang, C.S.; Swee Sien Tan; One-day ahead electric load forecasting with hybrid fuzzy-neural networks; Fuzzy Information Processing Society, 1996. NAFIPS. 1996 Biennial Conference of the North American; 19-22 June 1996; Pages 160-163; 1996.

[92] Sun, C.-T.; Jang, J.-S.; Fuzzy modeling based on generalized neural networks and fuzzy clustering objective functions; Decision and Control, 1991., Proceedings of the 30th IEEE Conference on; 11-13 Dec. 1991; Pages 2924-2929; vol.3; 1991.

[93] El Desouky, A.A.; Elkateb, M.M.; Hybrid adaptive techniques for electricload forecast using ANN and ARIMA; Generation, Transmission and Distribution, IEE Proceedings-; Volume: 147; Issue 4; July 2000; Pages 213-217; 2000.

[94] Ran-chang Lu; Dong-xiao Niu; Zheng-yuan Jia; A study of short-term load forecasting based on ARIMA-ANN; Machine Learning and Cybernetics, 2004. Proceedings of 2004 International Conference on; Volume: 5; Aug. 26-29; 2004; Pages 3183-3187; 2004.

[95] Kwang-Ho Kim; Hyoung-Sun Youn; Yong-Cheol Kang; Short-term load forecasting for special days in anomalous load conditions using neural networks and fuzzy inference method; Power Systems, IEEE Transactions on; Volume: 15; Issue: 2; May 2000; Page(s) 559-565.

[96] Ling, S.H.; Lam, H.K.; Leung, F.H.F.; Tam, P.K.S.; A novel GA-based neural network for short-term load forecasting; Neural Networks, 2002. IJCNN '02. Proceedings of the 2002 International Joint Conference on; Volume: 3; 12-17 May 2002; Page(s) 2761-2766.

[97] El Desouky, A.A.; Elkateb, M.M.; Hybrid adaptive techniques for electricload forecast using ANN and ARIMA; Generation, Transmission and Distribution, IEE Proceedings-; Volume: 147; Issue 4; July 2000; Page(s) 213-217.

[98] YanXi Yang; Gang Zheng; Ding Liu; BP-GA mixed algorithms for shortterm load forecasting; Info-tech and Info-net, 2001. Proceedings. ICII 2001 - Beijing. 2001 International Conferences on; Volume: 4; 29 Oct.-1 Nov. 2001; Page(s) 334-339; vol.4.

[99] Abu-El-Magd, M.A.; Findlay, R.D.; A new approach using artificial neural network and time series models for short term load forecasting, Electrical and Computer Engineering, 2003. IEEE CCECE 2003. Canadian Conference on; Volume 3; 4-7 May 2003; Page(s) 1723-1726; vol.3.

\subsection{Sistemas Especialistas}

[100] Dong Chen; Bingxin Chen; Tonghao Li; An expert system for short-term load forecasting; Advances in Power System Control, Operation and Management, 1991; APSCOM-91., 1991 International Conference on; 5-8 Nov 1991; Pages 330-334; vol.1; 1991. 
[101] Rahman, S.; Bhatnagar, R. An expert system based algorithm for short term load forecast; Power Systems, IEEE Transactions on; Volume: 3; Issue: 2; May 1988; Pages 392-399; 1988.

[102] Kandil, M.S.; El-Debeiky, S.M.; Hasanien, N.E.; Long-term load forecasting for fast developing utility using a knowledge-based expert system; power Systems, IEEE Transactions on; Volume: 17; Issue: 2; May 2002; Pages 491-496; 2002.

[103] Kab-Ju Hwan; Gwang-Won Kim; A short-term load forecasting expert system; Science and Technology, 2001. KORUS '01. Proceedings. The Fifth ussian-Korean International Symposium on; Volume: 1; 26 June-3 July 2001; Pages 112-116; vol.1; 2001.

[104] Rahman, S.; Hazim, O. A generalized knowledge-based short-term loadforecasting technique; Power Systems, IEEE Transactions on; Volume: 8; Issue: 2; May 1993; Pages 508-514; 1993.

\subsection{Regressão e série temporal}

[105] Papalexopoulos, A.D.; Hesterberg, T.C.; A regression-based approach to short-term system load forecasting; Power Industry Computer Application Conference, 1989. PICA '89, Conference Papers; 1-5 May 1989; Pages 414$423 ; 1989$.

[106] Moghram, I.; Rahman, S.; Analysis and evaluation of five short-term load forecasting techniques; Power Systems, IEEE Transactions on; Volume: 4; Issue: 4; Nov. 1989; Pages 1484-1491; 1989.

[107] Chao-Ming Huang; Hong-Tzer Yang; A time series approach to short term load forecasting through evolutionary programming structures; Energy Management and Power Delivery, 1995. Proceedings of EMPD '95., 1995 International Conference on; Volume: 2; 21-23 Nov. 1995; Pages 583-588; vol.2; 1995.

[108] Cho, M.Y.; Hwang, J.C.; Chen, C.S.; Customer short term load forecasting by using ARIMA transfer function model; Energy Management and Power Delivery, 1995. Proceedings of EMPD '95., 1995 International Conference on; Volume: 1; 21-23 Nov. 1995; Pages 317-322; vol.1; 1995.

[109] Juberias, G.; Yunta, R.; A new ARIMA model for hourly load forecasting; Transmission and Distribution Conference; 1999 IEEE; Volume: 1; 11-16 April 1999; Pages 314-319; vol.1; 1999.

[110] Perry, C.; Short-term load forecasting using multiple regression analysis; Rural Electric Power Conference, 1999; 2-4 May 1999; Pages B3/1-B3/8; Pages:B3/1 - B3/8; 1999.

[111] Amjady, N.; Short-term hourly load forecasting using time-series modeling with peak load estimation capability; Power Systems, IEEE Transactions on; Volume: 16; Issue: 3; Aug. 2001; Pages 498-505; 2001. 
[112] Shyh-Jier Huang; Kuang-Rong Shih; Short-term load forecasting via ARMA model identification including non-Gaussian process considerations; Power Systems, IEEE Transactions on; Volume: 18; Issue: 2; May 2003; Pages 673-679; 2003.

\subsection{Algoritmo genético}

[113] Shinn-Ying Ho; Tai-Kang Chen; Shinn-Jang Ho; Designing an efficient fuzzy classifier using an intelligent genetic algorithm; Computer Software and Applications Conference, 2000. COMPSAC 2000. The 24th Annual International; 25-27 Oct. 2000; Pages 293-298; 2000.

\subsection{Geral}

[114] Liu, K.; Subbarayan, S.; Shoults, R.R.; Manry, M.T.; Kwan, C.; Lewis, F.I.; Naccarino, J.; Comparison of very short-term load forecasting techniques; Power Systems, IEEE Transactions on; Volume: 11; Issue: 2; May 1996; Pages 877-882; 1996.

[115] Douglas, A.P.; Breipohl, A.M.; Lee, F.N.; Adapa, R.; Risk due to load forecast uncertainty in short term power system planning; Power Systems, IEEE Transactions on; Volume: 13; Issue: 4; Nov. 1998; Pages 1493-1499; 1998.

[116] Wang Feng; Yu Er Keng; Liu Yong Qi; Liu Jun; Yan Chen Shan; Shortterm load forecasting based on weather information; Power System Technology, 1998. Proceedings. POWERCON '98. 1998 International Conference on; Volume: 1; 18-21 Aug. 1998; Pages 572-575; vol.1; 1998.

[117] V. S. Kodogiannis and E. M. Anagnostakis; A study of advanced learning algorithms for short-term load forecasting; Engineering Applications of Artificial Intelligence; Volume 12; Issue 2; April 1999; Pages 159-173; 1999.

[118] Chen, C.S.; Kang, M.S.; Hwang, J.C.; Huang, C.W.; Temperature effect to distribution system load profiles and feeder losses; Power Systems, IEEE Transactions on; Volume: 16; Issue: 4; Nov. 2001; Pages 916-921; 2001.

[119] Chen, C.S.; Wang, J.C.; Kang, M.S.; Hwang, J.C.; Huang, C.W.; Temperature sensitivity analysis of system power profiles; Power Engineering Society Summer Meeting, 2001. IEEE; Volume: 2; 15-19 July 2001; Pages 854-859; vol.2; 2001.

[120] V. S. Kodogiannis and E. M. Anagnostakis; Soft computing based techniques for short-term load forecasting; Fuzzy Sets and Systems,; Volume 128; 2002.

[121] Mu, G.; Chen, Y.H.; Liu ZF; Fan, W.D.; Studies on the forecasting errors of the short term load forecast; Power System Technology, 2002. Proceedings. PowerCon 2002. International Conference on; Volume: 1; 1317 Oct. 2002; Pages 636-640; vol.1; 2002. 
[122] K. Metaxiotis, A. Kagiannas, D. Askounis and J. Psarras; Artificial intelligence in short term electric load forecasting: a state-of-the-art survey for the researcher; Energy Conversion and Management; Volume 44; Issue 9; June 2003; Pages 1525-1534; 2003.

[123] Jun Xiao; Yi Zhang; Chengshan Wang; A study and implementation of an intelligent load forecast support system; Power System Technology, 2002. Proceedings. PowerCon 2002. International Conference on; Volume: 2; 1317 Oct. 2002; Page(s) 858-862; vol.2

[124] Wood, Allen J., Wollenberg, Bruce F., Power Generation, Operation and Control; John Wiley \& Sons

[125] SCHMIDT, H. P.; MLP2 - Multi-Layer Perceptron. 1993.

\subsection{Wavelets na previsão de carga}

[126] Ma Ning; Chen Yunping; An ANN and wavelet transformation based method for short term load forecast; Energy Management and Power Delivery, 1998. Proceedings of EMPD '98. 1998 International Conference on; Volume 2; 3-5 March 1998; Page(s) 405-410; vol.2

[127] Oonsivilai, A.; El-Hawary, M.E.; Wavelet neural network based short term load forecasting of electric power system commercial load; Electrical and Computer Engineering, 1999 IEEE Canadian Conference on; Volume 3; 912 May 1999; Page(s) 1223-1228; vol.3.

[128] Bashir, Z.; El-Hawary, M.E.; Short term load forecasting by using wavelet neural networks; Electrical and Computer Engineering, 2000 Canadian Conference on; Volume 1; 7-10 March 2000; Page(s) 163-166; vol.1.

[129] Huang, C.-M.; Yang, H.-T.; Evolving wavelet-based networks for shortterm load forecasting; Generation, Transmission and Distribution, IEE Proceedings-; Volume 148; Issue 3; May 2001; Page(s) 222-228.

[130] Zhao-Yang Dong; Bai-Ling Zhang; Qian Huang; Adaptive neural network short term load forecasting with wavelet decompositions; Power Tech Proceedings; 2001 IEEE Porto; Volume 2; 10-13 Sept. 2001; Page(s) 6 pp.; vol.2.

[131] Du Tao; Wang Xiuli; Wang Xifan; A combined model of wavelet and neural network for short term load forecasting; Power System Technology, 2002. Proceedings. PowerCon 2002. International Conference on; Volume 4; 13-17 Oct. 2002; Page(s) 2331-2335; vol.4.

[132] Zheng Hua; Zhang Lizi; The factor analysis of short-term load forecast based on wavelet transform; Power System Technology, 2002. Proceedings. PowerCon 2002. International Conference on; Volume 2; 1317 Oct. 2002; Page(s) 1073-1076; vol.2.

[133] Yanqiu Bi; Jianguo Zhao; Dahai Zhang; Power load forecasting algorithm based on wavelet packet analysis; Power System Technology, 2004. PowerCon 2004. 2004 International Conference on; Volume 1; 21-24 Nov. 2004; Page(s) 987-990; Vol.1.

[134] Reis, A.J.R.; da Silva, A.P.A.; Feature extraction via multiresolution analysis for short-term load forecasting; Power Systems, IEEE Transactions on; Volume 20; Issue 1; Feb. 2005; Page(s) 189-198. 
[135] Jian-Chang Lu; Zhi-Hong Gu; Hui-Qing Wang; Research on the Application of the Wavelet Neural Network Model in Peak Load Forecasting Considering of the Climate Factors; Machine Learning and Cybernetics, 2005. Proceedings of 2005 International Conference on; Volume 1; 18-21 Aug. 2005; Page(s) 538-543. 


\section{ANEXO A - Erro Percentual das Previsões}

Para um dado instante $t$, dado um valor de carga medida e seu valor previsto, define-se o erro percentual da previsão como:

$$
E_{t}=\left|\frac{C_{\text {medidat }}-C_{\text {prevista }}}{C_{\text {medidat }}}\right| \times 100
$$

onde $C_{t}$ é a carga no instante $t$.

Para a curva de carga de um dia, define-se o erro da previsão da curva de carga diária como a média dos erros da previsão de cada instante:

$$
E_{\text {dia }}=\frac{\sum_{t=1}^{n} E_{t}}{n}
$$

Onde $n$ é o número de medições na curva de carga diária. Nos estudos realizados, $n$ é igual a 1440 ou 96, dependendo da freqüência de amostragem da carga.

Pode-se ainda definir o erro total do sistema como a média dos erros diários do período considerado:

$$
E_{\text {total }}=\frac{\sum_{i=1}^{n} E_{\text {dia } i}}{n}
$$

onde $\mathrm{n}$ é o número de dias considerados no período.

O desvio padrão dos erros é dado por:

$$
\sigma=\sqrt{\frac{n \sum E^{2}-\left(\sum E\right)^{2}}{n(n-1)}}
$$




\section{ANEXO B - Determinação automática de modelos fuzzy}

A determinação automática de sistemas de inferência fuzzy e sua aplicação à previsão de carga são detalhadas por Sugeno [41] e Wu [29].

Como exemplo, deseja-se desenvolver um sistema de inferência fuzzy que seja capaz de receber como entradas as cargas nos instantes $t-3, t-2$ e $t-1$ e prever no instante $t$, tendo sido treinado com o conjunto de dados fornecido (Tabela 7-1).

Tabela 7-1 - Dados para desenvolvimento de sistema de inferência fuzzy

\begin{tabular}{|c|c|c|c|c|}
\hline \multirow{2}{*}{ conjunto } & \multicolumn{4}{|c|}{ carga (MW) } \\
\cline { 2 - 5 } & $\mathbf{t}-3$ & $\mathbf{t}-2$ & $\mathbf{t}-\mathbf{1}$ & $\mathbf{t}$ \\
\hline 1 & 12838,80 & 13136,80 & 13349,70 & 13481,80 \\
\hline 2 & 13743,40 & 13959,70 & 14178,20 & 14390,50 \\
\hline 3 & 13505,30 & 13884,40 & 14040,70 & 14150,90 \\
\hline 4 & 13715,10 & 13991,10 & 14263,70 & 14380,80 \\
\hline 5 & 14115,50 & 14480,20 & 14673,40 & 14840,20 \\
\hline 6 & 14423,00 & 14525,90 & 14617,80 & 14790,30 \\
\hline 7 & 14153,20 & 14415,00 & 14631,90 & 14770,90 \\
\hline 8 & 13783,40 & 14088,80 & 14293,70 & 14453,20 \\
\hline 9 & 14076,00 & 14420,70 & 14588,40 & 14737,90 \\
\hline 10 & 13824,60 & 14073,50 & 14320,20 & 14400,60 \\
\hline
\end{tabular}

A. Sistema de inferência fuzzy

Um sistema de inferência deve receber as variáveis de entrada e 'fuzzyficar', ou seja, calcular o grau de pertinência da variável $j$ a regra $i\left(A_{j}^{i}\right)$ (Figura 7-1).

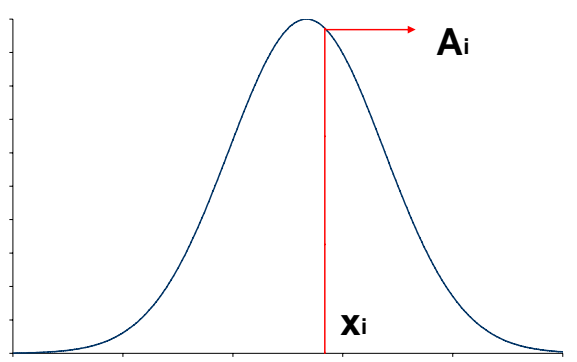

Figura 7-1 - ‘Fuzzyficação’ de variável 
Cada variável de entrada possui uma função de pertinência própria.

O Truth value $(T v)$ da regra é definido como a operação lógica AND Fuzzy entre as pertinências $A_{j}^{i}$ calculadas. O AND Fuzzy, representado por ^, corresponde a determinação do valor mínimo.

$$
T v^{i}=A_{1}^{i \wedge} A_{2}^{i} \cdots \wedge A_{j}^{i}=\min \left\{A_{1}^{i}, A_{2}^{i} \cdots A_{j}^{i}\right\}
$$

A regra ainda possui uma 'conseqüência' definida como uma função $y=f\left(x_{1}, x_{2}, \ldots x_{n}\right)$ que relaciona as variáveis de entrada com a saída. Pode-se adotar a função conseqüência como um polinômio do tipo:

$$
\begin{array}{ccc}
y=p_{0}+p_{1} x_{1}+p_{2} x_{2} \cdots+p_{k} x_{k} \\
\text { onde } & x_{i} & \text { variáveis de entrada } \\
& p_{i} & \text { parâmetros do polinômio } \\
k & \text { número de variáveis de entrada }
\end{array}
$$

De posse da conseqüência e do $T v$ de cada regra do sistema, a saída do sistema de inferência é a 'defuzzyficação' desses valores, que pode ser definida como a média ponderada das conseqüências pelos Tvs:

$$
Y=\frac{\sum_{i=1}^{n} T v^{i} \times y_{i}}{\sum_{i=1}^{n} T v^{i}}
$$

Onde $i$ é o número da regra.

Portanto, para o desenvolvimento do sistema de inferência, é preciso definir:

- o número de regras;

- o tipo da curva das funções de pertinência;

- os parâmetros do polinômio da função conseqüência. 
B. Determinação dos parâmetros do sistema de inferência

O número de regras a ser usado pode ser determinado ao se clusterizar os dados de entrada. A clusterização dos dados será definida através do cálculo do potencial de cada ponto através de:

$$
\begin{aligned}
& P_{i}=\sum_{j=1}^{n} e^{-\alpha\left\|x_{i}-x_{j}\right\|^{2}} \\
& \text { onde } \quad x_{i}, x_{j} \quad \text { conjunto de dados; } \\
& \alpha \quad \text { constante definida como } \alpha=\frac{4}{\gamma_{a}^{2}} \text {, onde } \gamma_{a} \text { é uma } \\
& \text { constante positiva a ser escolhida; } \\
& \left\|x_{i}-x_{j}\right\|^{2} \quad \text { Distância euclidiana entre os conjuntos de dados. }
\end{aligned}
$$

O conjunto com maior potencial será o primeiro centro de cluster.

Adotando-se $\gamma_{a}=10000$, para os dados fornecidos, tem-se os potenciais:

$$
\begin{aligned}
P_{1}= & e^{-4 \times 10^{-8}\left[(12838,80-12838,80)^{2}+(13136,80-13136,80)^{2}+(13349,70-13349,70)^{2}\right]}+\cdots \\
& +\cdots e^{-4 \times 10^{-8}\left[(14076,00-12838,80)^{2}+(14420,70-13136,80)^{2}+(14588,40-13349,70)^{2}\right]}=8,80667 \\
& \vdots \\
P_{10}= & e^{-4 \times 10^{-8}\left[(12838,80-13824,60)^{2}+(13136,80-14073,50)^{2}+(13349,70-14320,20)^{2}\right]}+\cdots \\
& +\cdots e^{-4 \times 10^{-8}\left[(13824,60-13824,60)^{2}+(14073,50-14073,50)^{2}+(14320,20-14320,20)^{2}\right]}=9,81964
\end{aligned}
$$

Os potenciais de todos os pontos estão na Tabela 7-2.

Tabela 7-2 - Potenciais dos dados de entrada

\begin{tabular}{|c|c|c|c|c|c|c|c|c|c|c|}
\hline conjunto & 1 & 2 & 3 & 4 & 5 & 6 & 7 & 8 & 9 & 10 \\
\hline potenciais & 8,80667 & 9,80341 & 9,73652 & 9,80982 & 9,68442 & 9,58333 & 9,70333 & 9,81930 & 9,72866 & 9,81964 \\
\hline
\end{tabular}

O conjunto 10 apresenta o maior potencial e é, portanto o centro do primeiro cluster $P_{1}^{*}=\{13824,60 ; 14073,50 ; 14320,20\}$. 
Para se determinar os demais clusters, deve-se subtrair dos potenciais calculados, o potencial do primeiro cluster $\left(P_{1}^{*}\right)$ através de:

$$
\begin{gathered}
P_{i}^{\prime}=P_{i}-P_{1}^{*} e^{-\beta\left\|x_{i}-x_{1}^{*}\right\|^{2}} \\
\text { onde } \beta \quad \begin{array}{l}
\text { constante definida como } \beta=\frac{4}{\gamma_{b}^{2}}, \text { onde } \gamma_{b} \text { é uma } \\
\text { constante positiva a ser escolhida que na prática } \\
\text { corresponde ao raio do cluster. }
\end{array}
\end{gathered}
$$

Os novos potenciais calculados com $\gamma_{b}=5000$ são:

$$
\begin{aligned}
& P_{1}^{\prime}=8,80667-9,81964 \times e^{-1,6 \times 10^{-7}\left[(12838,80-13824,60)^{2}+(13136,80-14073,50)^{2}+(13349,70-14320,20)^{2}\right]} \\
& \quad \vdots \\
& P_{10}^{\prime}=9,81964-9,81964 \times e^{-1,6 \times 10^{-7}\left[(13824,60-13824,60)^{2}+(14073,50-14073,50)^{2}+(14320,20-14320,20)^{2}\right]}
\end{aligned}
$$

Os novos potenciais estão na Tabela 7-3.

Tabela 7-3 - Novos potenciais dos dados de entrada

\begin{tabular}{|c|c|c|c|c|c|c|c|c|c|c|}
\hline conjunto & 1 & 2 & 3 & 4 & 5 & 6 & 7 & 8 & 9 & 10 \\
\hline potenciais & 2,52390 & 0,04596 & 0,25020 & 0,02464 & 0,43631 & 0,73548 & 0,37642 & 0,00380 & 0,30263 & 0,00000 \\
\hline
\end{tabular}

O segundo centro de cluster será o conjunto 1 .

Limitando o sistema a apenas dois clusters, têm-se os centros de cluster na Tabela 7-4.

Tabela 7-4 - Centros dos clusters obtidos

\begin{tabular}{|c|c|c|c|}
\hline regra & \multicolumn{2}{|c|}{ Centros dos clusters } & Conjunto de dados \\
\hline 1 & 12838,80 & 13136,80 & 1 \\
\hline 2 & 13824,60 & 14073,50 & 10 \\
\hline
\end{tabular}

Podem-se definir as funções de pertinência de cada regra do sistema de inferência como sendo gaussianas com o seguinte equacionamento: 
$A_{j}^{i}=e^{-\frac{\left(x_{j}-x_{i j}^{*}\right)^{2}}{2 \sigma_{j}^{2}}}$

onde $A_{j}^{i} \quad$ é a j-ésima função de pertinência da regra $i$

$\sigma_{j} \quad$ é o desvio padrão da variável de entrada $j$, adotado como sendo $\sigma=\frac{\gamma_{a}}{\sqrt{8}}$

$x_{i} \quad$ entrada $i$ do conjunto de entrada

$x_{i j}{ }^{*} \quad$ posição $i$ do centro de cluster $j$

Para os dados utilizados, tem-se $\sigma=\frac{1}{\sqrt{2 \alpha}}=3535,53$.

Na Figura 7-2 observa-se as funções de pertinência de cada entrada e regra.

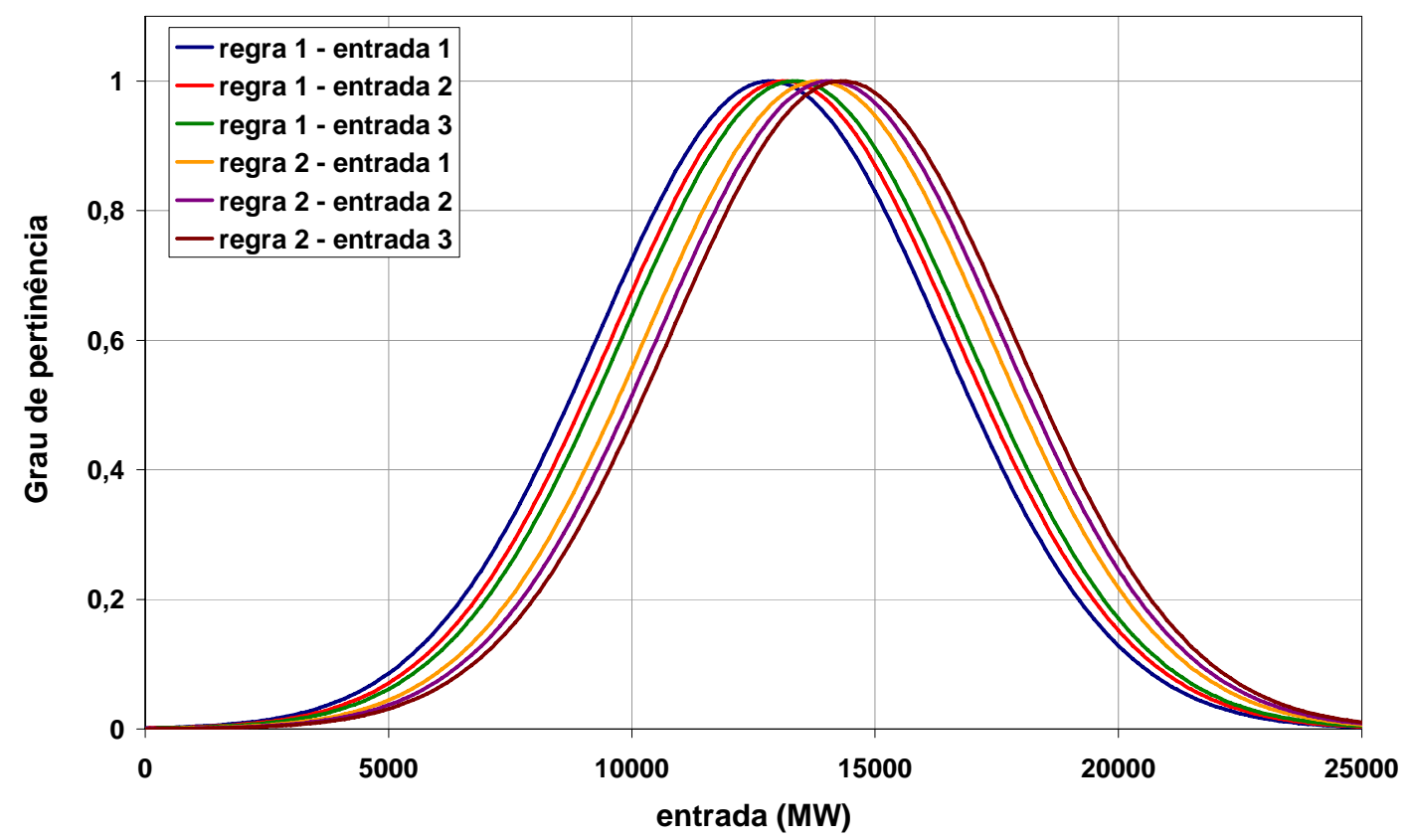

Figura 7-2 - Funções de pertinência obtidas

Aplicando cada conjunto de dados de entrada as funções de pertinência e aplicando-se o operador lógico AND FUZZY obtém-se os Tvs de cada regra. Exemplificando, para o conjunto 2 de dados (Tabela 7-1), aplicado à regra 1 , obtém-se a Figura 7-3. 


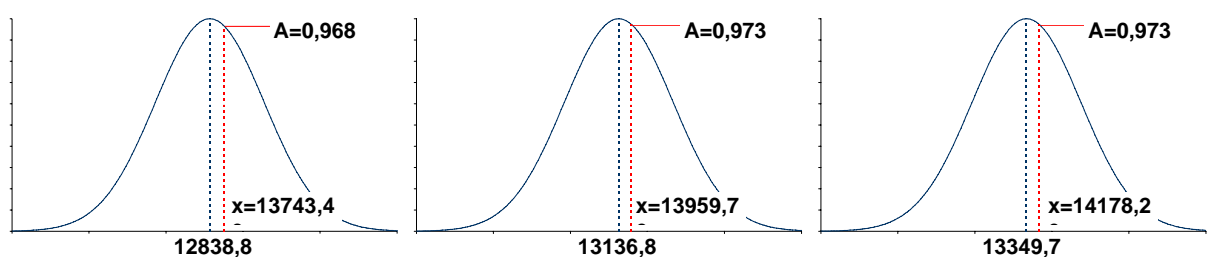

Figura 7-3 - Fuzzyficação do conjunto de dados 2

Para todos os conjuntos de dados de entrada e para as duas regras, tem-se os Tvs da Tabela 7-5 e Tabela 7-6.

Tabela 7-5 - Fuzzyficação na regra 1

\begin{tabular}{|c|c|c|c|c|}
\hline conjunto & $A_{1}^{1}$ & $A_{2}^{1}$ & $A_{3}^{1}$ & $T v_{1}$ \\
\hline 1 & 1,000 & 1,000 & 1,000 & 1,000 \\
\hline 2 & 0,968 & 0,973 & 0,973 & 0,968 \\
\hline 3 & 0,982 & 0,978 & 0,981 & 0,978 \\
\hline 4 & 0,970 & 0,971 & 0,967 & 0,967 \\
\hline 5 & 0,937 & 0,930 & 0,932 & 0,930 \\
\hline 6 & 0,904 & 0,926 & 0,938 & 0,904 \\
\hline 7 & 0,933 & 0,937 & 0,936 & 0,933 \\
\hline 8 & 0,965 & 0,964 & 0,965 & 0,964 \\
\hline 9 & 0,941 & 0,936 & 0,940 & 0,936 \\
\hline 10 & 0,962 & 0,966 & 0,963 & 0,962 \\
\hline
\end{tabular}

Tabela 7-6 - Fuzzyficação na regra 2

\begin{tabular}{|c|c|c|c|c|}
\hline conjunto & $A_{1}^{2}$ & $A_{2}^{2}$ & $A_{3}^{2}$ & $T v_{2}$ \\
\hline 1 & 0,962 & 0,966 & 0,963 & 0,962 \\
\hline 2 & 1,000 & 0,999 & 0,999 & 0,999 \\
\hline 3 & 0,996 & 0,999 & 0,997 & 0,996 \\
\hline 4 & 1,000 & 1,000 & 1,000 & 1,000 \\
\hline 5 & 0,997 & 0,993 & 0,995 & 0,993 \\
\hline 6 & 0,986 & 0,992 & 0,996 & 0,986 \\
\hline 7 & 0,996 & 0,995 & 0,996 & 0,995 \\
\hline 8 & 1,000 & 1,000 & 1,000 & 1,000 \\
\hline 9 & 0,997 & 0,995 & 0,997 & 0,995 \\
\hline 10 & 1,000 & 1,000 & 1,000 & 1,000 \\
\hline
\end{tabular}


Resta ainda a determinação dos parâmetros dos polinômios das funções conseqüência.

A resposta do sistema de inferência a um conjunto de dados $m$ é dada por:

$$
Y_{m}=\frac{\sum_{i=1}^{n} T v_{i m} \times\left(p_{0}^{i}+p_{1}^{i} x_{1 m}+\cdots+p_{k}^{i} x_{k m}\right)}{\sum_{i=1}^{n} T v_{i m}}
$$

Onde $\mathrm{n} \quad$ número de regas

$\mathrm{m} \quad$ número de conjuntos de dados

$\mathrm{k} \quad$ número de variáveis de entrada

Definindo-se:

$$
\beta_{i m}=\frac{T v_{i m}}{\sum_{i=1}^{n} T v_{i m}}
$$

E assim tem-se:

$$
Y_{m}=\sum_{i=1}^{n}\left(\beta_{i m} p_{0}^{i}+\beta_{i m} p_{1}^{i} x_{1 m}+\cdots+\beta_{\text {im }} p_{k}^{i} x_{k m}\right)
$$

Definindo-se as matrizes:

$$
\begin{gathered}
X_{m \times n(k+1)}=\left|\begin{array}{ccccccccc}
\beta_{11} & \beta_{11} x_{11} & \cdots & \beta_{11} x_{k 1} & \cdots & \beta_{n 1} & \beta_{n 1} x_{11} & \cdots & \beta_{n 1} x_{k 1} \\
\beta_{1 m} & \beta_{1 m} x_{1 m} & \cdots & \beta_{1 m} x_{k m} & \cdots & \beta_{n m} & \beta_{n m} x_{1 m} & \cdots & \beta_{n m} x_{k m}
\end{array}\right| \\
P_{n(k+1) \times 1}=\left[\begin{array}{c}
p_{0}^{1} \\
\vdots \\
p_{0}^{n} \\
\vdots \\
p_{k}^{1} \\
\vdots \\
p_{k}^{n}
\end{array}\right]
\end{gathered}
$$


Obtém-se:

$$
Y=X P
$$

Cuja solução que fornece os parâmetros $p$ das funções de conseqüência, pode ser determinada pela equação matricial:

$$
P=\left(X^{T} X\right)^{-1} X^{T} Y
$$

Onde -1 indica a inversa da matriz e $\mathrm{T}$ a sua transposta.

Para os dados utilizados, tem-se a Tabela 7-7.

Tabela 7-7 - Parâmetro $\beta$ para os dados de entrada

\begin{tabular}{|c|c|c|c|c|}
\hline conjunto & $T v_{1}$ & $T v_{2}$ & $\beta_{1}$ & $\beta_{2}$ \\
\hline 1 & 1,000 & 0,962 & 0,510 & 0,490 \\
\hline 2 & 0,968 & 0,999 & 0,492 & 0,508 \\
\hline 3 & 0,978 & 0,996 & 0,495 & 0,505 \\
\hline 4 & 0,967 & 1,000 & 0,492 & 0,508 \\
\hline 5 & 0,930 & 0,993 & 0,484 & 0,516 \\
\hline 6 & 0,904 & 0,986 & 0,478 & 0,522 \\
\hline 7 & 0,933 & 0,995 & 0,484 & 0,516 \\
\hline 8 & 0,964 & 1,000 & 0,491 & 0,509 \\
\hline 9 & 0,936 & 0,995 & 0,485 & 0,515 \\
\hline 10 & 0,962 & 1,000 & 0,490 & 0,510 \\
\hline
\end{tabular}

A matrizes $X, P$ e $Y$ serão:

$$
P=\left[\begin{array}{c}
p_{0}^{1} \\
p_{1}^{1} \\
p_{2}^{1} \\
p_{3}^{1} \\
p_{0}^{2} \\
p_{1}^{2} \\
p_{2}^{2} \\
p_{3}^{2}
\end{array}\right] \quad Y=\left[\begin{array}{l}
\mathrm{y}_{1} \\
\mathrm{y}_{2} \\
\mathrm{y}_{3} \\
\mathrm{y}_{4} \\
\mathrm{y}_{5} \\
\mathrm{y}_{6} \\
\mathrm{y}_{7} \\
\mathrm{y}_{8} \\
\mathrm{y}_{9} \\
\mathrm{y}_{10}
\end{array}\right]
$$




$X=\left[\begin{array}{cccccccc}\beta_{11} & x_{11} \beta_{11} & x_{21} \beta_{11} & x_{31} \beta_{11} & \beta_{21} & x_{11} \beta_{21} & x_{21} \beta_{21} & x_{31} \beta_{21} \\ \beta_{12} & x_{12} \beta_{12} & x_{22} \beta_{12} & x_{32} \beta_{12} & \beta_{22} & x_{12} \beta_{22} & x_{22} \beta_{22} & x_{32} \beta_{22} \\ \beta_{13} & x_{13} \beta_{13} & x_{23} \beta_{13} & x_{33} \beta_{13} & \beta_{23} & x_{13} \beta_{23} & x_{23} \beta_{23} & x_{33} \beta_{23} \\ \beta_{14} & x_{14} \beta_{14} & x_{24} \beta_{14} & x_{34} \beta_{14} & \beta_{24} & x_{14} \beta_{24} & x_{24} \beta_{24} & x_{34} \beta_{24} \\ \beta_{15} & x_{15} \beta_{15} & x_{25} \beta_{15} & x_{35} \beta_{15} & \beta_{25} & x_{15} \beta_{25} & x_{25} \beta_{25} & x_{35} \beta_{25} \\ \beta_{16} & x_{16} \beta_{16} & x_{26} \beta_{16} & x_{36} \beta_{16} & \beta_{26} & x_{16} \beta_{26} & x_{26} \beta_{26} & x_{36} \beta_{26} \\ \beta_{17} & x_{17} \beta_{17} & x_{27} \beta_{17} & x_{37} \beta_{17} & \beta_{27} & x_{17} \beta_{27} & x_{27} \beta_{27} & x_{37} \beta_{27} \\ \beta_{18} & x_{18} \beta_{18} & x_{28} \beta_{18} & x_{38} \beta_{18} & \beta_{28} & x_{18} \beta_{28} & x_{28} \beta_{28} & x_{38} \beta_{28} \\ \beta_{19} & x_{19} \beta_{19} & x_{29} \beta_{19} & x_{39} \beta_{19} & \beta_{29} & x_{19} \beta_{29} & x_{29} \beta_{29} & x_{39} \beta_{29} \\ \beta_{110} & x_{110} \beta_{110} & x_{210} \beta_{110} & x_{310} \beta_{110} & \beta_{210} & x_{110} \beta_{210} & x_{210} \beta_{210} & x_{310} \beta_{210}\end{array}\right]$

Substituindo os valores:

$X=\left|\begin{array}{llllllll}0,510 & 6544,152 & 6696,048 & 6804,566 & 0,490 & 6294,648 & 6440,752 & 6545,134 \\ 0,492 & 6762,018 & 6868,442 & 6975,948 & 0,508 & 6981,382 & 7091,258 & 7202,252 \\ 0,495 & 6690,939 & 6878,757 & 6956,192 & 0,505 & 6814,361 & 7005,643 & 7084,508 \\ 0,492 & 6744,629 & 6880,357 & 7014,412 & 0,508 & 6970,471 & 7110,743 & 7249,288 \\ 0,484 & 6826,435 & 7002,808 & 7096,242 & 0,516 & 7289,065 & 7477,392 & 7577,158 \\ 0,478 & 6901,365 & 6950,602 & 6994,576 & 0,522 & 7521,635 & 7575,298 & 7623,224 \\ 0,484 & 6848,667 & 6975,351 & 7080,308 & 0,516 & 7304,533 & 7439,649 & 7551,592 \\ 0,491 & 6767,028 & 6916,966 & 7017,562 & 0,509 & 7016,372 & 7171,834 & 7276,138 \\ 0,485 & 6823,007 & 6990,092 & 7071,380 & 0,515 & 7252,993 & 7430,608 & 7517,020 \\ 0,490 & 6777,969 & 6900,001 & 7020,954 & 0,510 & 7046,631 & 7173,499 & 7299,246\end{array}\right|$

$Y=\left|\begin{array}{l}13481,80 \\ 14390,50 \\ 14150,90 \\ 14380,80 \\ 14840,20 \\ 14790,30 \\ 14770,90 \\ 14453,20 \\ 14737,90 \\ 14400,60\end{array}\right|$

E obtem-se os parâmetros: 


$P=\left|\begin{array}{c}26152,891 \\ 42,214 \\ -5,394 \\ -37,447 \\ -5974,891 \\ -39,935 \\ 5,492 \\ 35,715\end{array}\right|$

As funções conseqüência serão:

$$
\begin{aligned}
& y_{1}=26152,891+42,214 \times x_{1}-5,394 \times x_{2}-37,447 \times x_{3} \\
& y_{2}=-5974,891-39,935 \times x_{1}+5,492 \times x_{2}+35,715 \times x_{3}
\end{aligned}
$$

C. Uso do sistema de inferência

Adotado um conjunto de dados não pertencente ao conjunto de treino:

$$
x=\{13700 ; 14300 ; 14200\}
$$

Calcula-se a pertinência:

\section{REGRA 1}
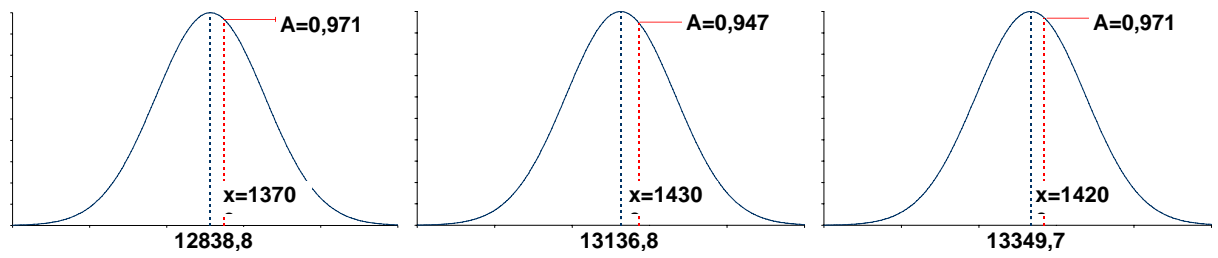

\section{REGRA 2}

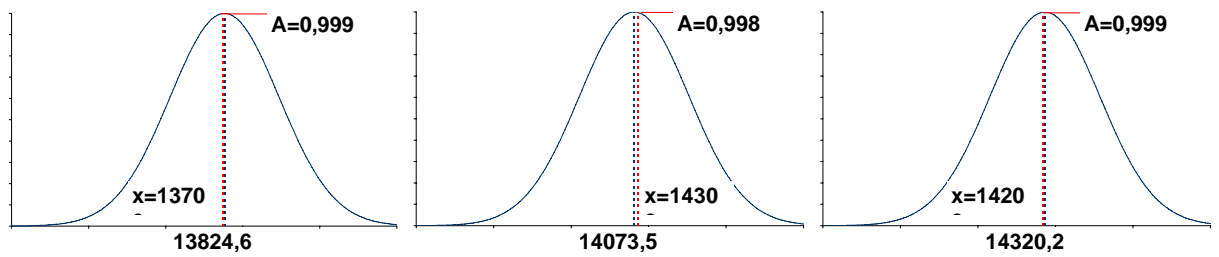

Figura 7-4 - Cálculo das pertinências no exemplo de sistema de inferência fuzzy 
Calculando os Tvs:

Tabela 7-8 - Tvs calculados

\begin{tabular}{|c|c|}
\hline$T v_{1}$ & $T v_{2}$ \\
\hline 0,947 & 0,998 \\
\hline
\end{tabular}

E as conseqüências:

Tabela 7-9 - Conseqüências calculadas

\begin{tabular}{|l|l|}
\hline$y_{1}$ & $-4399,891$ \\
\hline$y_{2}$ & 32603,372 \\
\hline
\end{tabular}

A previsão do sistema de inferência será:

$$
Y=\frac{-4399,891 \times 0,947+32603,372 \times 0,998}{0,947+0,998}=14583,315
$$

